WSRC-RP--91-1209

DE93 004586

\title{
A COMPARISON OF THE WIND SYSTEM ATMOSPHERIC MODELS AND MATS DATA (U)
}

J. D. FAST, S. BERMAN, and R. P. ADDIS

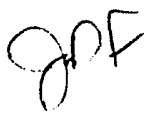

Publication Date: November 25, 1991

Westinghouse Srvannah River Company Savannah River site Aiken, SC 29808 


\section{CONTENTS}

ABSTRACT

1.0 INTRODUCTION

2.0 DESCRIPTION OF THE MATS EXPERIMENTS 2

3.0 DESCRIPTION OF THE MODELS

3.1 PUFF/PLUME Code 3

3.2 2DPUF Code 3

4.0 PROCEDURE 4

5.0 NUMERICAL RESULTS 4

5.1 Comparison with Sampler Measurements 5

5.1.1 Integrated concentration 5

5.1.2 Plume direction and width 6

5.1.3 Peak concentration 7

5.1.4 Timing of transport $\quad 7$

5.1.5 Ratio method 8

5.2 Comparison with TRAC Measurements 9

6.0 DISCUSSION 10

7.0 CONCLUSION 11

REFERENCES 13

APPENDIX 14 
Figure 1. Locations of the onsite meteorological towers and roads where sampling was done (hatched) for the MATS experiments

Figure 2. Sum of the $\mathrm{SF}_{6}$ concentration that was observed along the sampler arc and predicted by PUFF/PLUME for MATS experiment 8

Figure 3. Same as Fig. 2, except for MATS experiment 12

Figure 4. Same as Fig. 2, except for MATS experiment 14

Figure 5. Same as Fig. 2, except for MATS experiment 24

Figure 6. Same as Fig. 2, except for MATS experiment 31

Figure 7. Sum of the $\mathrm{SF}_{6}$ concentration that was observed along the sampler arc and predicted by 2DPUF for MATS experiment 8

Figure 8. Same as Fig. 7, except for MATS experiment 12

Figure 9. Same as Fig. 7, except for MATS experiment 14

Figure 10. Same as Fig. 7, except for MATS experiment 24

Figure 11. Same as Fig. 7, except for MATS experiment 31

Figure 12. Trajectories of the plume predicted by PUFF/PLUME and 2DPUF for various meteorological conditions for MATS experiment 14

Figure 13. Same as Fig. 12, except for MATS experiment 31

Figure 14. Sum of the $\mathrm{SF}_{6}$ concentration that was observed and width of the plume predicted by PUFF/PLUME and 2DPUF for MATS experiment 8

Figure 15. Same as Fig. 14, except for MATS experiment 12

Figure 16. Same as Fig. 14, except for MATS experiment 14

Figure 17. Same as Fig. 14, except for MATS experiment 24

Figure 18. Same as Fig. 14, except for MATS experiment 31

Figure 19. Maximum $\mathrm{SF}_{6}$ concentration that was observed at each of the time intervals and predicted by PUFF/PLUME and 2DPUF for MATS experiment 8 
Figare 20. Same as Fig. 19, except for MATS experiment 12

Figure 21. Same as Fig. 19, except for MATS experiment 14

Figure 22. Same as Fig. 19, except for MATS experiment 24

Figure 23. Same as Fig. 19, except for MATS experiment 31

Figure 24. Sum of the $\mathrm{SF}_{6}$ concentration that was observed and predicted by PUFF/PLUME, paired in space, for five MATS experiments

Figure 25. Same as Fig. 24, except for wind direction errors removed

Figure 26. Same as Fig. 24, except for maximum total $\mathrm{SF}_{6}$ concentrations

Figure 27. Percent of the sum of the $\mathrm{SF}_{6}$ concentrations predicted by PUFF/ PLUME within a factor $R$ of the observed values

Figure 28. Sum of the $\mathrm{SF}_{6}$ concentration that was observed and predicted by 2DPUF, paired in space, for five MATS experiments

Figure 29. Same as Fig. 28, except for wind direction errors removed

Figure 30. Same as Fig. 28, except for maximum sum of the $\mathrm{SF}_{6}$ concentrations

Figure 31. Percent of the sum of the $\mathrm{SF}_{6}$ concentrations predicted by 2DPUF within a factor $R$ of the observed values

Figure 32. $\mathrm{SF}_{6}$ concentration that was observed by the TRAC vehicle for traverse AA and predicted by PUFF/PLUME and 2DPUF for MATS experiment 27

Figure 33. Trajectory of the plume predicted by 2DPUF and the path of the TRAC vehicle for MATS experiment 32

Figure 34. Trajectory of the plume predicted by 2DPUF and the path of the TRAC vehicle for MATS experiment 37 
Table 1. A brief summary of the sampler, release, and meteorological data for each of the MATS experiments used in this study

Table 2. A summary of the meteorological data for each of the MATS experiments used in this study

Table 3. Maximum concentration of the total $\mathrm{SF}_{6}$ that was observed along the sampler arc and predicted by PUFF/PLUME

Table 4. Plume width of the total $\mathrm{SF}_{6}$ distribution that was observed along the sampler arc and predicted by PUFF/PLUME

Table 5. Location of the maximum concentration of the total $\mathrm{SF}_{6}$ that was observed and predicted by PUFF/PLUME

Table 6. Maximum concentration of the total $\mathrm{SF}_{6}$ that was observed along the sampler arc and predicted by 2 DPUF

Table 7. Plume width of the total $\mathrm{SF}_{6}$ distribution that was observed along the sampler arc and predicted by 2DPUF

Table 8. Location of the maximum concentration of the total $\mathrm{SF}_{6}$ that was observed and predicted by $2 \mathrm{DPUF}$

Table 9. Maximum concentration of $\mathrm{SF}_{6}$ that was observed along the sampler arc and predicted by PUFF/PLUME

Table 10. Plume width of the $\mathrm{SF}_{6}$ distribution that was observed along the sampler arc and predicted by PUFF/PLUME at the time the maximum concentration of $\mathrm{SF}_{6}$ occurred

Table 11. Maximum concentration of $\mathrm{SF}_{6}$ that was observed along the sampler arc and predicted by 2DPUF

Table 12. Plume width of the $\mathrm{SF}_{6}$ distribution that was observed along the sampler arc and predicted by 2DPUF at the time the maximum concentration of $\mathrm{SF}_{6}$ occurred

Table 13. Elapsed time at which the maximum concentration of $\mathrm{SF}_{6}$ occurred that was observed along the sampler arc and predicted by PUFF/PLUME

Table 14. Elapsed time at which the maximum concentration of $\mathrm{SF}_{6}$ oc urred that was observed along the sampler arc and predicted by 2DPUF

Table 15. Integrated $\mathrm{SF}_{6}$ that was observed at all of the samplers and predicted by PUFF/PLUME, 2DPUF, and MATHEW/ADPIC 
LIST OF TABLES (cont'd)

Table 16. Concentration and plume width that was observed and predicted by PUFF/PLUME and 2DPUF for MATS experiment 27

Table 17. Same as Table 16, except for MATS experiment 32

46

Table 18. Same as Table 16, except for MATS experiment 37 


\title{
A COMPARISON OF THE WIND SYSTEM ATMOSPHERIC MODELS AND MATS DATA
}

\author{
By J. D. Fast, S. Berman, and R. P. Addis \\ Westinghouse Savannah River Company \\ Savannah River Site \\ Aiken, SC 29808
}

\begin{abstract}
The results produced by two of the WIND System atmospheric models, PUFF/PLUME and 2DPUF, were compared with a select group of eight MATS experiments to determine the performance of the models. Three of the MATS experiments employed TRAC vehicle sampling and the remaining five used a line of fixed samplers. The performance of the models was based on certain dispersion characteristics that are important in emergency response situations. Both PUFF/PLUME and 2DPUF were executed with the same source term and meteorological data. When the numerical results from the models were compared to the observed values from the MATS experiments, it was found that 2DPUF produced concentrations and plume widths that were closer to the observed values than PUFF/PLUME. Both models did not produce any bias in the values of the concentration when individual data points were examined; however, PUFF/PLUME consistently overpredicted the peak and total concentrations. 2DPUF did not exibit any bias in the peak and total concentrations. When wind direction errors were removed, 80 - 84\% of the concentrations from PUFF/PLUME and $88 \%$ of the concentrations from 2DPUF where within a factor of 10 of the observed values. In some instances, both models were able to predict concentration values that were comparible to a more complex, three-dimensional model called MATHEW-ADPIC. Considering all of the possible uncertainties associated with dispersion modeling, PUFF/PLUME and 2DPUF performed reasonably well. The differences between the dispersion forecasts made by PUFF/PLUME and 2DPUF and the observed surface tracer concentration are very similar to many other emergency response models based on the Gaussian assumption.
\end{abstract}

\subsection{INTRODUCTION}

Atmospheric transport and diffusion models have been developed by the Environmental Technology Section (ETS) of the Savannah River Laboratory to calcuiate the location and concentration of toxic or radioactive materials during an accidental release at the Savannah River Site (SRS). The output from these models have been used to support initial onsite and offsite emergency response activities such as protective action decision making and field monitoring coordination. These atmospheric transport and diffusion models have been incorporated into an automated computer based system called the WIND (Weather INformation and Display) System and linked to real-time meteorological and radiological monitoring instruments to provide timely information for these emergency response activities ${ }^{1}$.

In an effort to establish more formal quality assurance procedures for the WIND System atmospheric codes, a software evaluation is being conducied by the ETS ${ }^{2}$. The evaluation will determine the effectiveness of these models in emergency response situations for the SRS. One of the objectives of the software evaluation is to compare the results produced by the WIND System atmospheric models with observational data. The Mesoscale Atmospheric Transport Studies (MATS) tracer experiments were performed at SRS from $1981-1985^{3}$ to 
provide a database for model validation studies. Data from the MATS experiments have already been employed to evaluate a variety of dispersion models ${ }^{4,5}$ that range in complexity from simple straight-line Gaussian to three-dimensional, mass-consistent models. The performance of some of the WIND System atmospheric models in predicting the observed tracer distribution in the MATS experiments also has been examined in some detail ${ }^{6}$.

This study will compare two of the WIND System atmospheric models, PUFF/PLUME and 2DPUF, with a select group of MATS experiments and examine the results in detail to determine the performance of the models. The performance of the models will be based on certain dispersion characteristics that are important in emergency response situations. Some of these characteristics include:

(1) Centerline location of plume or puff,

(2) Centerline concentration (peak and average),

(3) Width of plume or puff (peak and average),

(4). Overall integrated concentration in time at a particular location,

(5) Peak concentration estimates (uncorrelated spatially or temporally),

(6) Peak concentration estimates (correlated spatially or temporally),

(7) Concentration estimates (correlated spatially or temporally)

This report consists of the following four parts:

(1) Description of the MATS experiments: The meteorological and tracer data from a subset of the MATS experiments used in this study is presented.

(2) Description of the Models: A brief description of the WIND System atmospheric models including the source term, atmospheric transport and diffusion, and dose and consequence characteristics is made.

(3) Procedure: The method in which meteorological and tracer data is incorporated into the WIND System atmospheric models is presented.

(4) Numerical Results: PUFF/PLUME and 2DPUF were executed with the same source strength and meteorological data. The concentration estimates are compared with the observations to evaluate the performance of the models.

In addition, the applicability of the WIND System atmospheric models to the prediction of accidental radiological releases at the SRS will be discussed.

\subsection{DESCRIPTION OF THE MATS EXPERIMENTS}

The MATS program consisted of 37 experimental studies over a three year period to investigate the atmospheric dispers on over the gentle rolling terrain in and around the SRS ${ }^{3}$. The location of the sampling instruments were located at various distances surrounding the SRS as indicated in Fig. 1. Most of the experiments were performed during the day using $15 \mathrm{~min}$ releases of sulfur hexaflouride $\left(\mathrm{SF}_{6}\right)$. Of the $37 \mathrm{MATS}$ experiments, eight were selected for evaluating ETS's PUFF/PLUME and 2DPUFF dispersion models, namely experiment numbers 8,12 , $14,24,27,31,32$, and 37 . Three of the experiments (numbers 27, 32, and 37) employed TRAC vehicle sampling and the remaining five used a line of fixed samplers. A brief summary of conditions for each experiment is found in in Table 1.

In choosing the subset of eight MATS experiments, the main criteria used were that they have relatively complete and reliable data sets. The meteorological data were examined to make sure they included upper-air soundings and near-surface observations from the towers throughout the sampling periods. From this group, a subset of cases was selected in which the plume's centerline intersected the sampling arc with a reasonably complete distribution of tracer material 
on either side. For TRAC experiments, only those which provided accurate geographical coordinates for the vehicle's sampling traverses and reliable $\mathrm{SF}_{6}$ concentrations were used. Finally, an effort was made to include experiments representing a wide variety of wind and stability conditions.

\subsection{DESCRIPTION OF THE MODELS}

The WIND System atmospheric models that are used in the evaluation include PUFF/PLUME and 2DPUF. These codes currently run on a VAX 8550 mainframe computer so that they can be easily linked to real-time meteorological and radiological monitoring instruments across the SRS. A number of remote terminals at various sites at the SRS can access these codes from the WIND System menu. PUFF/PLUME and 2DPUF differ in complexity because each was designed for a different emergency response application; therefore, significantly different dose or concentration estimates may be obtained.

\subsection{PUFF/PLUME Code}

The PUFF/PLUME code ${ }^{1.7}$ (version 2.5) is a sequential Gaussian model designed to predict plume or puff characteristics and perform dosimetry calculations for the site boundary and beyond due to a release at the site. PUFF/PLUME is appropriate for relatively short-range forecasts because of the meteorological data that is employed. The code has four options for selecting a wind field based on observations from SRS meteorological towers and forecasts from the NWS; however, in each case the wind field does not vary in space but may vary in time. For instance, one option uses the most recent wind data at the release site and allows it to vary in time according to a Model Output Statistics (MOS) forecast. MOS forecasts employ regression equations to link the observed tower data with predictions from the National Weather Service (NWS) Limited Fine Mesh (LFM) model. A single 15 min release duration is used for "puff" calculations, or the user may specify the release duration for "plume" predictions. Dose or concentration estimates are determined for onsite and offsite locations. The dose or concentration estimates are automatically printed out in tabular form and graphically depicted as contours overlaid on SRS background maps.

\subsection{DPUF Code}

The 2DPUF code 1,8 (version 3.1) is a sequential Gaussian model designed to predict more complex concentration distributions on and off-site to obtain accurate dosimetry calculations. 2DPUF can produce both short-range and long-range forecasts because of the meteorological data that are employed. The code has three options for the wind field based on observations from SRS meteorological towers and observations and forecasts from the NWS. The wind field may either vary in time but not in space for a "local" calculation, or may vary in space and in time for "regional" calculation. For instance, NWS hourly surface observations and available upper-air observations throughout the southeast can be used to generate a regional wind field that varies horizontally. NWS prediction models and MOS can also be used to calculate a time-dependent wind field that does not vary in space. The total duration of the release is specified by the user. Then, the emission is simulated as a series of "puffs", each with a 15 min duration. As in PUFF/PLUME dose or concentration estimates are determined for onsite and offsite locations. Dose estimates are automatically printed out in tabular form and graphically depicted as contours overlaid on a SRS background maps.

Since 2DPUF does not normally compute the transport of tracer material, it had to be modified slightly to output values of $\mathrm{SF}_{6}$ concentration for this study. 


\subsection{PROCEDURE}

Both PUFF/PLUME and 2DPUF were executed with the source term and meteorological data described in Tables 1 and 2. The models were executed with three different meteorological data sets to determine the model performance. The first data set, $\mathrm{M}_{\mathrm{C}}$, assumed constant meteorological conditions based on an hourly averaged data from the time of the release and a site area mean (SAM) of the site wind field. The second data set, $\mathrm{M}_{\mathrm{H}}$, consisted of timedependent meteorological conditions based on hourly averaged data taken from the $\mathrm{H}$-area tower near the release location. The last data set, Ms, also consisted of time-dependent meteorological conditions; however, the hourly averaged data was taken from the SAM wind field.

The model results that incorporated the $\mathrm{M}_{C}$ data set were evaluated to test the validity of constant meteorological conditions near the site. A comparison of the model results for $\mathrm{M}_{\mathrm{H}}$ and MS was made to determine if a site area wind field would characterize transport near the site better. In addition, data from $\mathrm{M}_{\mathrm{H}}$ and $\mathrm{M}_{\mathrm{S}}$ can be viewed as a "perfect" forecast, since both PUFF/PLUME and 2DPUF can incorporate time-dependent meteorological conditions h:lsed on data from NWS forecasts models in emergency response situations. The NWS for:ast data was not available during the MATS experiments; therefore, this capability cannot be evaluated fully.

The depth of the mixed-layer, $\mathrm{H}$, throughout the release period in each of the meteorological data sets was computed by a simple model. The mixed-layer depth in this model was based on the most recent upper-air sounding and hourly values of the surface temperature. Mixed-layer depths were determined at each hour by extrapolating the surface temperature adiabatically upward until it intersected the sounding.

After PUFF/PLUME and 2DPUF was executed with source term data from Table 1 and meteorological data from Table 2 , the centerline ground concentration, in parts per trillion (ppt) $\left(10^{-12}\right)$, was extrapolated to the sampler or TRAC locations using the particular Gaussian method employed by either of the models. In this way, the numerical results could be directly compared to the observed values.

A second moment fit technique 9 was used to calculate the half width of the plume (Sigma-y) perpendicular to the sampler network or a particular TRAC traverse for both the numerical results and the observed values. In this method, the concentration values are weighted by the square of their distances from the center of mass. The method also assumes that the sampling traverse lies along a straight line perpendicular to the centerline. This is only an approximation, since $\cdots$ sampler network and TRAC traverses in the MATS experiments were not exactly perper.jicular to the centerline as seen in some of the figures in the next section. Sigma-y should not be significantly affected by this approximation for the cases examined in this study.

\subsection{NUMERICAL RESULTS}

The numerical results from the models for MATS experiments 8, 12, 14, 24, 27, 31, 32, and 37 were compared to the observed concentrations. Because the observed concentrations were measured by either fixed samplers or the mobile TRAC vehicle, the techniques used to compare the numerical results with the observation depended upon the particular MATS experiment. The numerical results from MATS experiments 27, 32, and 37 had to be modified somewhat so that a direct comparison could be made with the data taken from the TRAC vehicle. This data was available on a much finer horizontal and temporal scale than the sampler method. 
The predictions made by the models are subject to errors in (1) source term, (2) transport and diffusion, and (3) dosimetry. In this study, the source term is known with a high degree of accuracy; therefore, all of the differences between the model results and the observations are associated with the transport and diffusion portions of the codes. It is important to remember that the source term is rarely known with such accuracy in emergency response situations, and it is usually the major contribution to model uncertainty. Since sulfur hexaflouride was used for the release, potential errors in the dosimetry portions of the code were not evaluated.

\subsection{Comparison with Sampler Measurements}

\subsubsection{Integrated concentration}

Statistics are necessary to quantitatively evaluate the important characteristics of dispersion for emergency response including the centerline location, centerline concentration, width of a plume, overall integrated concentration, and peak concentration estimates. A number of methods for comparing observations to predicted concentrations have been proposed by experts in the field of atmospheric dispersion modeling 10.11.12. In this study, the ratio method was the predominate statistic used to evaluate PUFF/PLUME and 2DPUF. Graphical display of data was also used to qualitatively evaluate the performance of the models and to determine whether the numerical results contained any bias.

The sum of the $\mathrm{SF}_{6}$ concentration in time, $\mathrm{C}_{\mathrm{t}}$, also referred to as the total $\mathrm{SF}_{6}$ concentration is given by:

$$
\mathrm{C}_{\mathrm{t}} \text { (sampler) }=\sum_{\mathrm{i}=1}^{\mathrm{n}} \mathrm{C}_{\mathrm{i}} \text { (sampler) }
$$

where $\mathrm{n}$ is the total number of sampling periods for a particular MATS experiment. $C_{t}$ is a useful quantity because it is more comparable to a dose that would be received from a radionuclide release. The width of $C_{t}$ will give a measure of the horizontal extent of the plume during the entire passage of the plume at the sampler arc. The location of the maximum value of $\mathrm{C}_{\mathrm{t}}$ indicates that the centerline of the plume passed over it for a relatively long period of time.

The values of $C_{t}$ that were observed and computed by PUFF/PLUME at each of the sampler locations with various meteorological conditions is depicted Figs. 2 - 6. It is clear from these figures that PUFF/PLUME tended to overpredict the total $\mathrm{SF}_{6}$ concentration. The ratios of the predicted $C_{t}$ to the observed $C_{t}$ listed in Table 3 indicated the magnitude of this overprediction was up to a factor of 8.3. PUFF/PLUME underpredicted the value of $C_{t}$ by no more that a factor of 1.4. The half width of the plume, Sigma-y, seemed to be in good agreement with the observations as shown by the ratios of the predicted Sigma-y to the observed Sigma-y listed in Table 4; however, the model was consistently narrower. The locations of the maximum value of $\mathrm{C}_{\mathrm{t}}$ computed by PUFF/PLUME were of ten different from the observed locations because of wind direction errors. The actual distance between the measured and calculated locations of the maximum value of $\mathrm{C}_{\mathrm{t}}$ is listed in Table 5 . Considering that the average distance from $\mathrm{H}$-area to the samplers was approximately $30 \mathrm{~km}$ in most cases, most of the spatial differences were relatively modest.

Note that in Fig. 2, the predicted plume using the $\mathrm{M}_{\mathrm{H}}$ data set missed the sampler network entirely so that all of the $C_{t}$ values were zero. This was the only simulation in which the predicted plume missed the sampler network. 
The location and magnitude of the maximum value of $C_{t}$ was highly dependent upon the meteorological conditions used by PUFF/PLUME. The model results from the $\mathrm{M}_{\mathrm{S}}$ data set should have produced the best results because the time-dependent SAM wind field is more representative of the meteorological conditions in and around the site than those obtained from $\mathrm{H}$-area. The results from the model from the $\mathrm{M}_{S}$ data set were indeed better than those from the $M_{H}$ data set for MATS experiments 8 and 31; however, the $M_{H}$ data set produced better results for MATS experiment 12. PUFF/PLUME produced nearly identical results using the $M_{S}$ and $M_{H}$ data sets for MATS experiments 14 and 24 since the wind field did not differ substantially over the site during those periods. The model results from the $\mathrm{M}_{\mathrm{C}}$ data set, which employed constant meteorological conditions, also produced relatively good results when compared to the observations. In MATS 24 the model results were nearly identical to the observations because the meteorological conditions were nearly constant in time and space so that the Gaussian assumptions employed by the model were appropriate.

The values of $C_{t}$ that were observed and computed by 2DPUF at each of the sampler locations with various meteorological conditions is depicted Figs. $7-11$. These figures show that 2DPUF produced values of $C_{t}$ that were closer to the observations than those computed by PUFF/PLUME. The ratios of the predicted $C_{t}$ to the cbserved $C_{t}$ listed in Table 6 indicated the magnitude of the overprediction was less than a factor of 6.0 and the magnitude of the underprediction was less than a factor of 2.8. The half width of the plume, Sigma-y, seemed to be in good agreement with the observations as indicated by the ratios of the predicted Sigma$y$ to the observed Sigma-y listed in Table 7; however, 2DPUF did not predict plume widths that were consistently narrower than the observations as did PUFF/PLUME. Since 2DPUF employed the same meteorological conditions as PUFF/PLUME, the locations of the maximum value of $C_{t}$ were often different from the observed locations because of wind direction errors. The actual distance between the measured and calculated locations of the maximum value of $C_{t}$ is listed in Table 8. As with PUFF/PLUME, most of the spatial differences were relatively modest.

\subsubsection{Plume direction and width}

It is important to note that the location of the maximum value of $\mathrm{C}_{\mathrm{t}}$ can be slightly different for PUFF/PLUME and 2DPUF even though the same meteorological conditions are employed. This discrepancy arises because the models employ different methods for the plume transport. In PUFF/PLUME, observed or forecasted meteorological conditions are specified at one hour intervals. The meteorological conditions are held constant during this one hour interval so that transport occurs in a straight line during this time. In 2DPUF, meteorological conditions are interpolated in time between the observed or forecasted hourly values so that transport can curve horizontally. This effect is demonstrated by the trajectory of the plume computed by the models for MATS experiments 14 (Fig. 12) and 31 (Fig. 13) for the MS data set. The paths of the trajectories for PUFF/PLUME and 2DPUF diverge by $2-3 \mathrm{~km}$ by the time they reach the sampler network. PUFF/PLUME's trajectory was closer to the observed one for MATS experiment 31 when the values of $C_{t}$ are examined (Figs. 6 and 11); however, 2DPUF's trajectory was closer to the observed one in MATS experiment 14 (Figs. 4 and 9) so it is not clear which method produces superior results in general. MATS experiments 14 and 31 had wind direction shifts that were greater than any of the other experiments examined in this study.

While the locations of the maximum values of $\mathrm{C}_{\mathrm{t}}$ are a measure of the performance of the models in predicting the location of the plume, it is not the only one. For instance, the emergency response organization at SRS often makes a more conservative estimate of the location of a plume. Once the plume centerline has been determined by PUFF/PLUME or 2DPUF, the total plume width is set equal to $4 *$ Sigma-y. In addition, protection action 
guidelines are applied to an area on either side of the predicted centerline that subtends an angle of $22.5^{\circ}$.

To demonstrate how the models would have performed in an emergency-response application, the results from the models with the $M_{C}$ data set were compared to the observat:uns in Figs. 14 - 18. It is clear that a value of 4*Sigma-y from PUFF/PLUME was much narrower than the observed total width of the plume in most of the experiments examined in this study. 2DPUF more accurately represented the total width of the plume that was measured at the samplers and would have provided a relatively good estimate of the centerline location and total plume width for MATS experiments 12, 24, and 31. The width of the plume was also well predicted for MATS experiments 8 and 14, but wind direction errors would have placed the centerline location a distance of more than 4*Sigma-y from the observed location. Nevertheless, the more conservative estimate of the total plume width used by the emergency response organization would have covered the observed plume location for MATS experiments 8 and 14 as well. This envelope was not plotted in Figs. $14-18$ because it usually fell outside the bounds of the plot. A conservative estimate for the total plume width should be used for protective action guidelines, especially for PUFF/PLUME, because of the potential wind direction errors that can occur.

\section{!.1.3 Peak concentration}

Ar. in measure of the performance of the models is to compare the observed with the prec d maximum concentrations (unpaired in time or space). The ratios of the maximum concentration predicted by PUFF/PLUME to the observed values are listed in Table 9 indicared the magnitude of the overprediction was less than a factor of 13.9 and the magnitude of the underprediction was less than a factor of 1.2. The plume width at the time the maximum concentration occurred that was observed and predicted by PUFF/PLUME is presented in Table 10. The ratios of the maximum concentration predicted vy 2DPUF to the observed values listed in Table 11 indicated the magnitude of the overprediction was less than a factor of 13.3 and the magnitude of the underprediction was less than a factor of 2.3. The plume width at the time of the maximum concentration was also well predicted by 2DPUF as indicated by Table 12. The results from the maximum concentrations draw nearly the same conclusions as was determined by the sum of the $\mathrm{SF}_{6}$ concentrations. Individual concentrations are relatively lower in 2.DPUF compared to PUFF/PLUME and are closer to the observations. Both models produce the cross-wind widths of the plume quite well although PUFF/PLUME again underpredicts the plume width.

\subsubsection{Timing of transport}

The particular time in which the maximum concentration occurs can be used as another measure of the performance of the models to determine the transport errors in the model results. Figs. 19 - 23 depict the maximum concentrations observed and predicted by PUFF/PLUME and 2DPUF along the sampler arc using the meteorological data set $M_{S}$. In these figures, the maximum concentrations at a particular time are cot necessarily located at the same sampler locations. Tables 13 and 14 is a summary of the elapsed time at which the maximum concentration occurred that was observed and predicted by the models for all three meteorological data sets. For three MATS experiments (12, 24, and 31), both models predicted the transport speed quite well; however 2DPUF performed better with the Ms data set. In the other MATS experiments ( 8 and 14) the models underpredicted the transport speed; in those cases the observed plume arrived before the model predicted it to by as much as an hour. 
Differences between the observed transport of the plume and predictions by the models may be due to three factors including (1) wind speed errors, (2) errors in determining the along-wind dispersion parameter, $\sigma_{\mathrm{x}}$, or (3) a combination of $(1$; and (2). Table 2 shows that there was only a minor increase in the wind speed for MATS experiment 8 and the wind speed did not increase at all in MATS experiment 14; thus, the transport errors associated with these experiments could be the result of an increased wind speed downwind of the site since the models did account for the horizontal variability in the wind field in this study. The models also do not account for the change of wind speed with height. If there was a significant increase of wind speed with height, it is possible that the plume may have been transported in that layer of the atmosphere. There is also some indication that the transport errors may be due to the fact that the horizontal dispersion parameters, $\sigma_{x}$ and $\sigma_{y}$, are assumed to be equal in both the along-wind and cross-wind directions of the plume for both models 7,8 . This feature was most pronounced for MATS experiments 12, 14, and 31 (Figs. 20, 21, and 23) since the samplers observed $\mathrm{SF}_{6}$ concentrations for a longer period of time than predicted by the models. Near-surface effects tend to slow down the tansport of the plume and widen it so that the puff ultimately takes on an elliptical shape. If $\sigma_{x}$ were larger than $\sigma_{y}$, the maximum concentrations in Figs. 19 - 23 would be :educed and probably be closer to the observed values as well.

\subsubsection{Ratio method}

The ratio method was $t^{2}$ iployed to graphically depict the total $\mathrm{SF}_{6}$ concentration that was observed predicted by PLFF/PLUME at the sampler locations for all of the MATS experiments examined in this study as shown in Fig. 24. All of the sampler measurements were $25-35 \mathrm{~km}$ downwind of the source. Data points where no concentration was measured or the predicted by the model at the samplers were not plotted. A $R$ value of 1 indicates that the model results are in perfect agreement with the observations. There is considerable spread about $R=1$, but there is no tendency for PUFF/PLUME to overpredict or underpredict when individual data points are examined; however there are many cases where the predicted and observed total concentrations differ by more than a factor of 10 .

Figure 25 is very similar to Fig. 24, except that the comparison was made after the wind direction errors were removed from the oredictions of PUFF/PLUME. When the wind direction rrrors are ramoved, most of the predicted concentrations are within a factor of 4 of the observed values. i. FF/PLUME shows a tendency to overpredict the peak values of the total concentrations as seen in Table 3.

The results from Figs. 24 and 25 are summarized in Fig. 27 to show e percentage of the predicted concent:-tions that are within a factor $\mathrm{R}$ of the observations. $4-50 \%$ of the results from PUFF/PLUK values. When the wind direction errors are removed, nearly $80-84 \%$ of the results from PUFF/PLUME are within a factor of 10 of the observed values. Meteorological conditions from $\mathrm{H}$-area nearly always produced results that were poorer than those obtained from a siteaveraged wind field. The local wind behavior at the site did not adequately describe the downwind transport at the sampler network.

Figures 28 and 29 are similar to Figs. 24 and 25, except that the results from 2DPUF are presented. These figures also indicate that 2DPUF is not producing an $\%$ bias in the values of the concentration when individual data points are examined. When the $F: a k$ values of the sum of the concentrations are examined, one finds that 2DPUF does nc end to consistently overpredict the values like PUFF/PLUME as seem in F : $: 30$. All of ie peak values of the total concentration were within a factor of 6 of the observed values for the MATS experiments examined in this study as shown in Table $F$ The results from Figs. 28 and 29 are summarized in Fig. 31 which shows the percentage of th. predicted concentrations that were within a factor 
of $R$ of the observations. $59-61 \%$ is the results from 2DPUF using the $M_{C}$ and $M_{S}$ data sets were within a factor of 10 of the observed values; when the wind direction errors are removed, this percentage increased to $88 \%$. As with PUFF/PLUME, the $\mathrm{M}_{\mathrm{C}}$ and $\mathrm{M}_{\mathrm{S}}$ data sets were consistently better that the $\mathrm{M}_{\mathrm{H}}$ data set, but a greater percentage of the results from 2DPUF are within a factor of 10 of the observations.

The total concentrations were summed over all of the samplers and the results are presented in Table 15. This table again addresses the issue of bias and it is clear that 2DPUF produces a result that is nearly always closer to the observed value than PUFF/PLUME. The results from the MATHEW/ADPIC model ${ }^{12}$ are also presented to demonstrate how the WIND System models perform with other dispersion models. MATHEW/ADPIC is more complex than either PUFF/PLUME or 2DPUF because it can represent a three-dimensional wind field and it uses a particle method to determine pollutant transport. However, the wind field in MATHEW/ ADPIC cannot change in time. For MATS experiment 8 , all of the models produced results that were very similar to the observed values. PUFF/PLUME and 2DPUF did a much better job in predicting the total concentrations for MATS experiment 12 than did MATHEW/ADPIC; nevertheless, MATHEW/ADPIC produced superior results for MATS experiment 14. The MATHEW/ADPIC model was not applied to other MATS experiments $(24,27,31,32,37)$ examined in this report.

\subsection{TRAC Measurements}

The models were also run with data taken from MATS experiments 27, 32, and 37 that employed the Tracking Radioactive Atmospheric Contaminants (TRAC) vehicle ${ }^{13}$ to measure the $\mathrm{SF}_{6}$ concentration. PUFF/PLUME and 2DPUF were executed with only the $\mathrm{M}_{\mathrm{S}}$ data set for these experiments. A direct comparison of the model results with the observations from the TRAC measurements could not easily be made; however, some valuable information about how the models performed was obtained from examining these MATS experiments.

There were a total of 5 traverses made by the TRAC vehicle at various downwind distances for MATS experiment 27. A direct comparison of the observed concentrations from the first traverse and the concentrations predicted by PUFF/PLUME and 2DPUF at the same times and locations as the observations is shown in Fig. 32. PUFF/PLUME produced a peak concentration that is nearly equal to the observed peak, but it is $2 \mathrm{~km}$ too far south. In this case, the predicted width of the plure is slightl: larger that the observed one. 2DPUF seems to predict the correct width and location of the plume, but the concentration is too low. The results of 2DPUF and PUFF/PLUME differ significantly because of the time-interpolation scheme that is used by each of the models as described in section 3 and demonstrated in Figs. 12 and 13. In this experiment, the center of the puff predicted by PUFF/PLUME is approximately the same distance downwind as the TRAC vehicle so that the concentrations are roughly the same order of magnitude. The puff predicted by 2DPUF at this time has already gone further downwind so that the concentration at the TRAC location is significantly less.

A direct comparison of the results with the other traverses could not be made because the predicted puffs were either behind or ahead of the TRAC path even though the spatial differences were relatively small considering the distances from the source. Table 16 is included to provide some additional information obtained from this experiment. However, the observed and predicted maximum concentrations cannot be compared directly because the path of the TRAC was different for each traverse and the observed maximum may not be the true center of mass of the puff.

For MATS experiment 32, a direction comparison of the model results and the observed concentrations could not be made as well because the predicted plumes were just south of the 
path of the TRAC vehicle. The trajectory of the puff predicted by 2DPUF and the path of the TRAC vehicle is shown in Fig. 33. The times and locations in which maximum concentration values were observed along the TRAC path are also indicated. 2DPUF did a relatively good job in this case because the plume centerline was only about $5 \mathrm{~km}$ from the center of the TRAC path. Since the TRAC path was approximately $28 \mathrm{~km}$ downwind of $\mathrm{H}$-area, this is only a $10^{\circ}$ error in the wind direction. The predicted puff passed by the TRAC path at the time the first couple of maximum values were measured; therefore, the transport was well predicted. The TRAC continued to record maximum values after $0200 \mathrm{GMT}$, but they were significantly less than before and it is clear that the center of the puff passed downwind of the TRAC path. As in Figs. $19-23$, this figure also indicated that the model assumption that the dispersion is the same in both horizontal directions may not be correct. It is clear that the observed along-wind width of the plume was larger than the predicted width as shown in Table 17 upon comparison of the observed Sigma-y and the predicted dispersion parameter $\sigma_{y}$. The path of PUFF/ PLUME was not plotted, but it is $0.5-1.0 \mathrm{~km}$ further southwest of the location of 2DPUF in Fig. 33.

Since the TRAC vehicle took measurements over the same road in MATS experiment 32 , the observed maximum concentration for various traverses and the predicted centerline concentration can be qualitacively compared (Table 17). The center of mass of the observed puff was measured at about 0207 GMT. At this time PUFF/PLUME and 2DPUF were overpredicting the maximum concentration by a factor of $3-5$.

The trajectory of the puff predicted by 2DPUF for MATS experiment 37 and the path of the TRAC vehicle is shown in Fig. 34. This MATS experiment was the only one with very stable atmospheric conditions as indicated from Table 1 . In this case, the centerline of 2DPUF passed almost directly over the same location as the observed peak concentrations values; however the predicted puff arrived about $20 \mathrm{~min}$ after the first peak value was recorded. The TRAC path was about $34 \mathrm{~km}$ downwind of $\mathrm{H}$-area and the centerline of 2DPUF was within 1 $\mathrm{km}$ of the observed peak concentrations. In order for this to occur, the wind field must have been nearly constant horizontally. The width of the plume was approximately equal to the observed width as well. Thus, 2DPUF did remarkably well for a stable case, the only drawback was again the elliptical nature of the observed plume that 2DPUF cannot simulate. The path of PUFF/PLUME was not plotted, but it is $3.0 \mathrm{~km}$ further to the west of the location of the TRAC path.

As in MATS experiment 32, the TRAC vehicie took measurements over the same road in this case and the observed maximum concentration for various traverses and the predicted centerline concentration can be qualitatively compared (Table 18). The center of mass of the observed puff was measured at about 00901 GMT. At this time PUFF/PLUME and 2DPUF were overpredicting the maximum concentration by a factor of $3-9$.

\subsection{DISCUSSION}

The statistics associated with the ratio method indicated that 2DPUF produced concentrations and plume widths that were closer to the observed values than PUFF/PLUME. PUFF/PLUME consistently overpredicted the peak and total concentrations from the MATS experiments. 2DPUF was closer to the observed concentrations in most of the experiments examined in this study. While both models predicted the plume width reasonably well, PUFF/PLUME slightly underpredicted the plume width. It is not clear which model performed better in locating the path of the plume downwind of the source. Additional MATS experiments would need to be examined to determine whether the segmented approach to the meteorological conditions employed by PUFF/PLUME and the continuous method used by 
2DPUF produce significantly different results. Both models may need to incorporate better representations of the horizontal, vertical, and temporal variability of the wind field.

The statistics in this study indicated that when the models employed meteorological conditions from the $M_{C}$ and the $M_{S}$ data sets, the results were nearly always better than those that incorporated the wind field from the $\mathrm{H}$-area tower. As expected, a site-averaged wind field was a better approximation for transport offsite. During emergency response sicuations, a meteoroiogical data set like Ms would not be available; however, both PUFF/PLUME and 2DPUF have the ability to incorporate forecast data from NWS models so that a timedependent wind field can be used. The transport may be affected by the errors in the NWS models; however, they have been proven to be fairly accurate for relatively short forecast periods that are normally used by the emergency response models. Like the site-averaged wind field, the NWS forecasts are only valid for the SRS. 2DPUF can also incorporate a wind field that varies horizontally if meteorological data is available from synoptic stations surrounding the SRS. In this way, horizontal variability in the wind may be accounted for during plume transport over relatively large distances.

The model results that employed the $\mathrm{M}_{\mathrm{C}}$ data set were nearly as good as those produced by the Ms data set. However, there may be many instances in which transport may be poorly predicted when constant meteorological conditions are used. For instance, significant horizontal variations in the wind field can occur over a relatively short period of time during morning/evening transition periods, passage of a synoptic fronts, or severe weather episodes.

As expected, both models predicted the concentration distribution and location of the plume for MATS experiment 24 particularly well. During the period of the release, the wind speed and direction measured at the SRS meteorological towers was very constant. The wind direction and speed also must have been spatially invariant; otherwise, the location of the predicted predicted peak concentration would not have agreed so well with the observed one. The meteorological conditions in this case suggest that the Gaussian assumptions employed by the models were satisfied so that excellent forecasts were made. In the cases where the meteorological conditions changed significantly in time (MATS experiments 14 and 31) the models produced results that did not agree as well with the observations. Even though the simulations that incorporated the $\mathrm{M}_{\mathrm{S}}$ data set contained the observed time-dependent wind field from the site, changes in the meteorological conditions downwind probably caused the predicted plume path to be slightly different than the observed one. For MATS experiment 31 , the predicted plume path was as much as $15 \mathrm{~km}$ from the observed path about $36 \mathrm{~km}$ downwind of $\mathrm{H}$-area. Nevertheless, the predicted path for most of the MATS experiments was within $5 \mathrm{~km}$ of the observed path at the MATS sampler arc or the TRAC traverses.

\subsection{CONCLUSION}

Most of the dispersion characteristics listed in Section 1 that are important in emergency response applications were examined in this study. Considering all of the possible uncertainties associated with dispersion modeling, both PUFF/PLUME and 2DPUF performed reasonably well. The errors in the dispersion forecasts made by PUFF/PLUME and 2DPUF are probably very similar to many other emergency response models based on the Gaussian assumption. PUFF/PLUME and 2DPUF also performed as well or better than the more complex, three-dimensional model MATHEW/ADPIC in certain MATS experiments. It is important to note that the source term was known with a high degree of accuracy in the MATS experiments. In emergency response situations, the source term estimate may be in error by a factor of 10 or more; therefore, the true forecast error produced by these models would be much larger than indicated by this study. 
If the quality source term and meteorological data is high, relatively accurate and timely forecasts for emergency response situations can be made by the WIND System atmospheric models. ETS personnel must also be aware of the potential errors associated with dispersion modeling so that the results of the WIND System atmospheric models can be interpreted correctly.

The results of this study indicate that further research may lead to improvements in the predictions of concentration, plume width, and plume location made by PUFF/PLIJME and 2DPUF. For instance, dispersion characteristics in the along wind direction that are different than the cross wind direction may be more realistic and may improve the results of the models when compared to data from the MATS experiments. The effort required to investigate the improvement of Gaussian-based models such as PUFF/PLUME and 2DPUF must be evaluated against the application of more complex dispersion models at the SRS. Threedimensional prognostic models should be examined to test their accuracy and their potential application to emergency response purposes. 


\section{REFERENCES}

1. Hunter, C. H. Weather Information and Display (WIND) System User's Manual. WSRC-TM-90-14, Savannah River Site, Aiken, SC (1990).

2. Fast, J. D., and R. P. Addis. Evaluation Protocol for the WIND System Atmospheric Models. WSRC-RP-91-426, Savannah River Site, Aiken, SC (1991).

3. Weber, A. H., S. Berman, R. J. Kurzeja, and R. P. Addis. "The MATS Experiments Mesoscale Atmospheric Transport Studies at the Savannah River Site", submitted to Nuclear Safety. (1991).

4. Weber, A. H. "The MATS (Mesoscale Atmospheric Transport Studies) Experiments". Proceedings of the DOE/AMS air pollution model evaluation workshop, Kiawah Island, SC, October 23-26, 1984, pp 1-24, Vol. 1. DP-1701-1. DuPont de Nemours and Company, Savannah River Laboratory, Aiken, SC (1984).

5. Weber, A. H., and R. J. Kurzeja. Proceedings of the DOE/AMS Air Pollution Model Evaluation Workshop, Kiawah Island, SC, Vol. 2. DP-1201-2, DuPont de Nemours and Company, Savannah River Laboratory, Aiken, SC (1984)

6. Addis, R. P. An Evaluation of SRL Emergency Response Codes using MATS Data. DPST-850715, DuPont de Nemours and Company, Savannah River Laboratory, Aiken, SC (1985).

7. Garrett, A. J., and C. E. Murphy Jr. A Puff-Plume Atmospheric Deposition Model for use at SRP in Emergency Response Situations. DP-1595, DuPont de Nemours and Company, Savannah River Laboratory, Aiken, SC (1981).

8. Addis, R. P and L. O'Steen. 2DPUF, A Sequential Gaussian Puff Model. WSRCRP-90-1208, Savannah River Site, Aiken, SC (1991).

9. Liu, M. K., and G.E. Moore. Final Report. Validation of Plume Models at a Plains Site. EPRI. (1983).

10. Fox, D. G. "Judging Air Quality Model Performance", Bulliten of the American Meteorological. Society 62, pp 599-609 (1980).

11. Hanna, S. R. "A Simple Method of Evaluating Air Quality Models", Proceedings of the DOE/AMS air pollution model evaluation workshop. Kiawah Island, SC, October 2326, 1984, Vol. 1. DP-1701-1. DuPont de Nemours and Company, Savannah River Laboratory, Aiken, SC (1984).

12. Dickerson, M. H., and D. L. Ermak. The Evaluation of Emergency Response Trace Gas and Dense Gas Dispersion Models, Lawrence Livermore National Laboratory, UCRL-99348, Livermore, CA (1988).

13. Sigg, R. A. "A Mobile Laboratory for Near Real-Time Measurements of Very LowLevel Radioactivity ", Proceedings of the Fifth DOE Environmental Protection Information Meeting. November 6-8, pp 629-636, Albuquerque, NM (1984). 


\section{APPENDIX}

List of Symbols and Abbreviations:

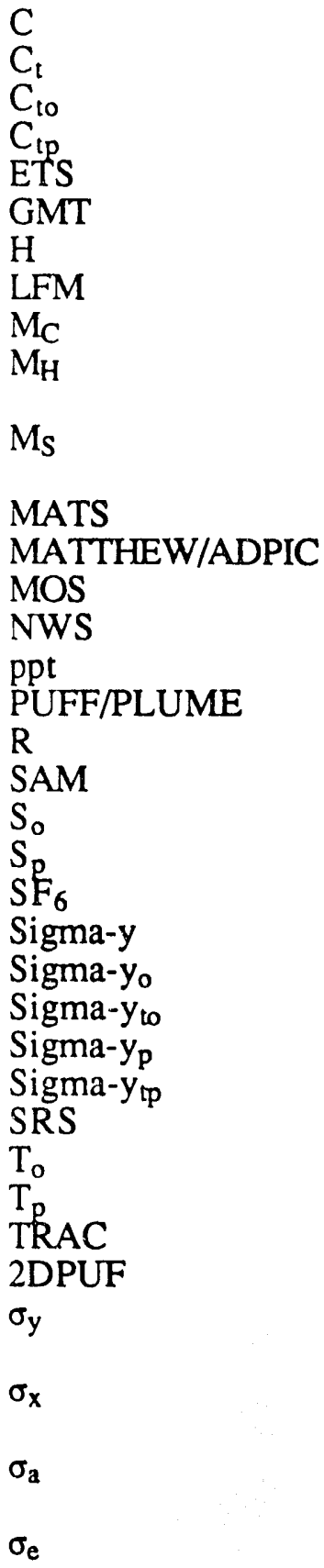

$\mathrm{SF}_{6}$ concentration

sum of the $\mathrm{SF}_{6}$ concentration in time, total $\mathrm{SF}_{6}$ concentration

observed total $\mathrm{SF}_{6}$ concentration

predicted total $\mathrm{SF}_{6}$ concentration

Environment Technology Section

Greenwich Mean Time

mixed layer depth

Limited Fine Mesh model of the NWS

data set consisting of constant meteorology based on SAM data

data set consisting of time-dependent meteorology based on $\mathrm{H}$-area

data

data set consisting of time-dependent meteorology based on SAM

data

Mesoscale Atmospheric Transport Studies

Lawrence Livermore National Laboratory dispersion model

Model Output Statistics from NWS forecast model

Nationa Weather Service

parts per trillion

WIND System atmospheric model

ratio of predicted quancity divided by observed quantity

site-averaged wind field based on SRS meteorological towers

sampler number of location of observed maximum concentration

sampler number of location of predicted maximum concentration

sulfur hexaflouride

plume width

observed plume width

observed plume width of the total $\mathrm{SF}_{6}$ distribution

predicted plume width

predicted plume width of the total $\mathrm{SF}_{6}$ distribution

Savannah River Site

observed time that the maximum concentration of $\mathrm{SF}_{6}$ occurred

predicted time that the maximum concentration of $\mathrm{SF}_{6}$ occurred

mobile sampling facility

WIND System atmospheric model

cross-wind dispersion parameter used in PUFF/PLUME and 2DPUF

along-wind dispersion parameter used in PUFF/PLUME and 2DPUF

horizontal fluctuation of the wind direction measured at the SRS meteorological towers

vertical fluctuation of the wind direction measured at the SRS

meteorological towers 


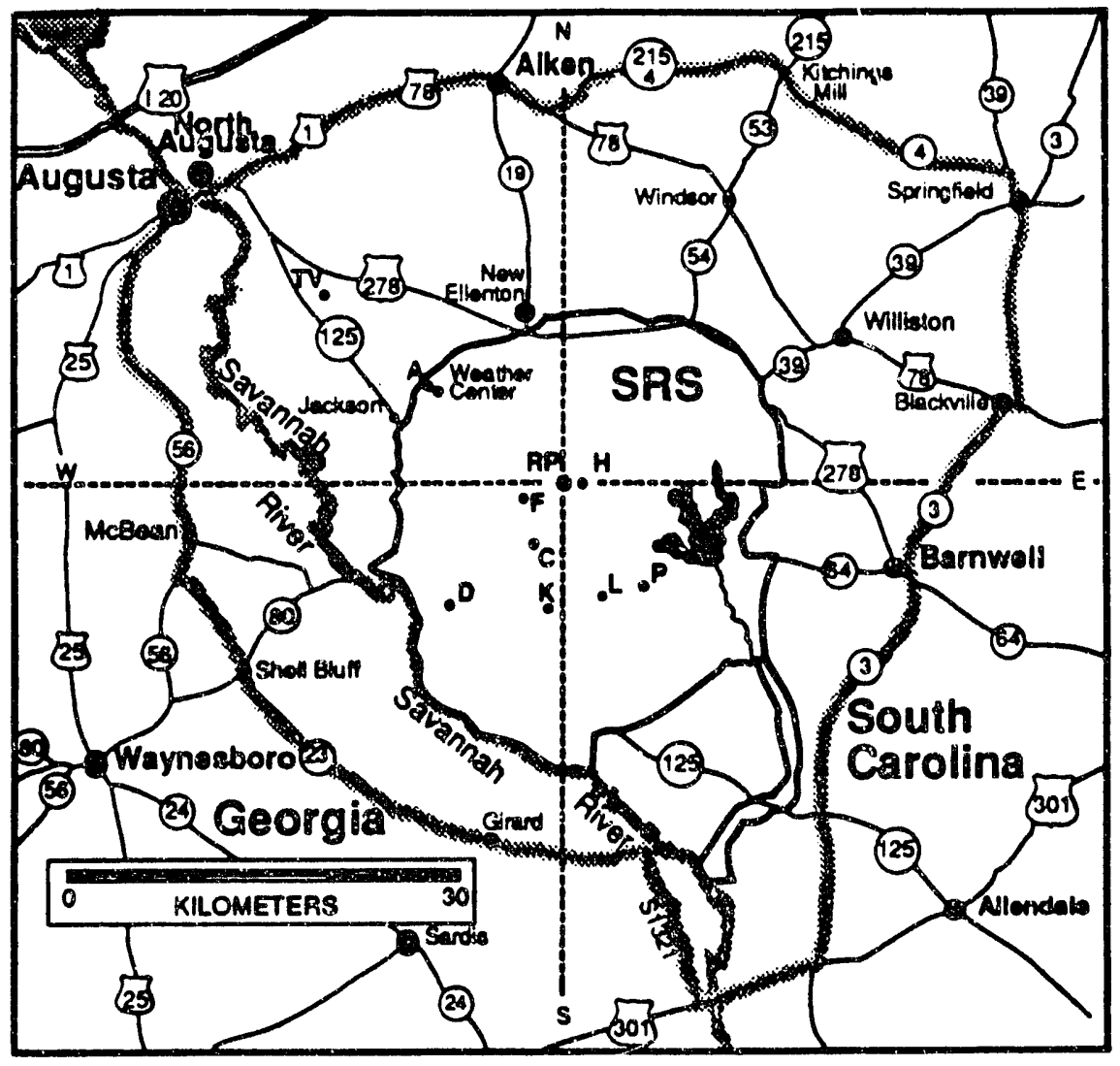

Figure 1. Locations of the onsite meteorological towers and roads where sampling was done (hatched) for the MATS experiments 


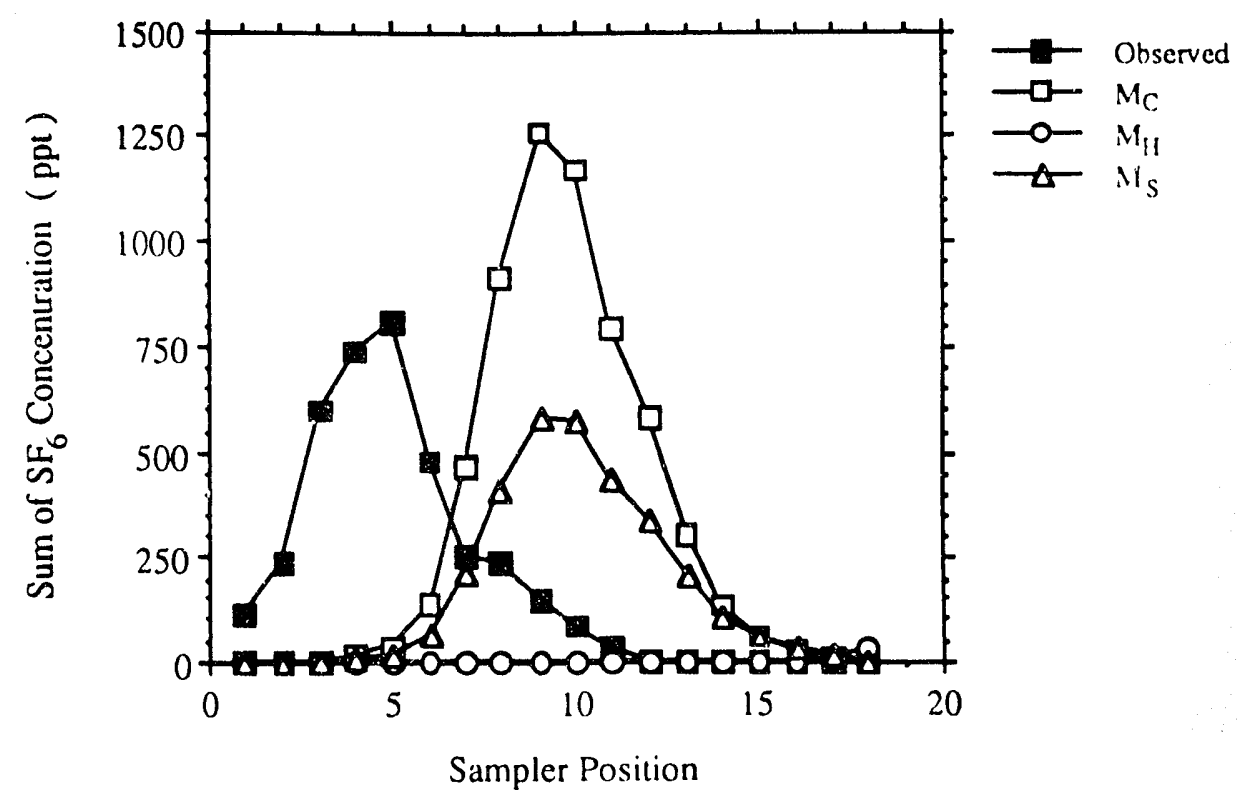

Figure 2. Sum of the $\mathrm{SF}_{6}$ concentration that was observed along the sampler arc and predicted by PUFF/PLUME for MATS experiment 8

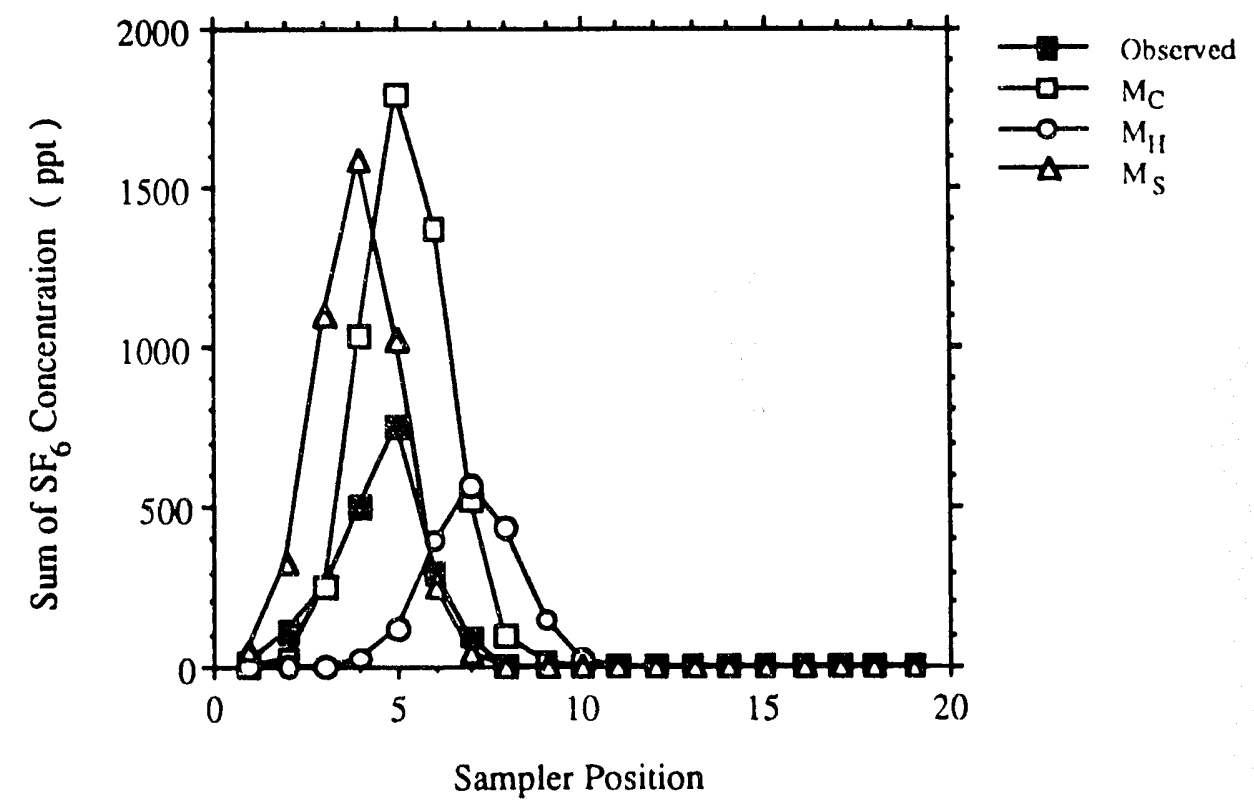

Figure 3. Same as Fig. 2, except for MATS experiment 12 


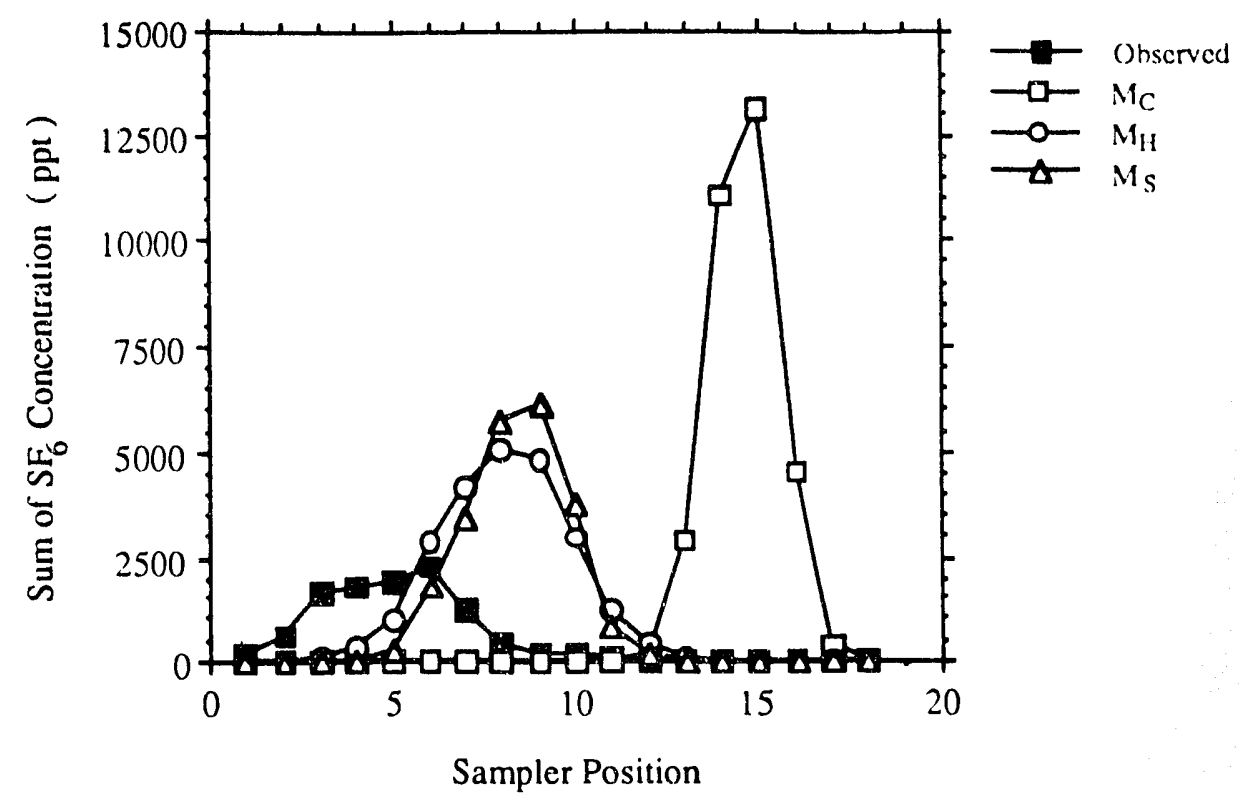

Figure 4. Same as Fig. 2, except for MATS experiment 14

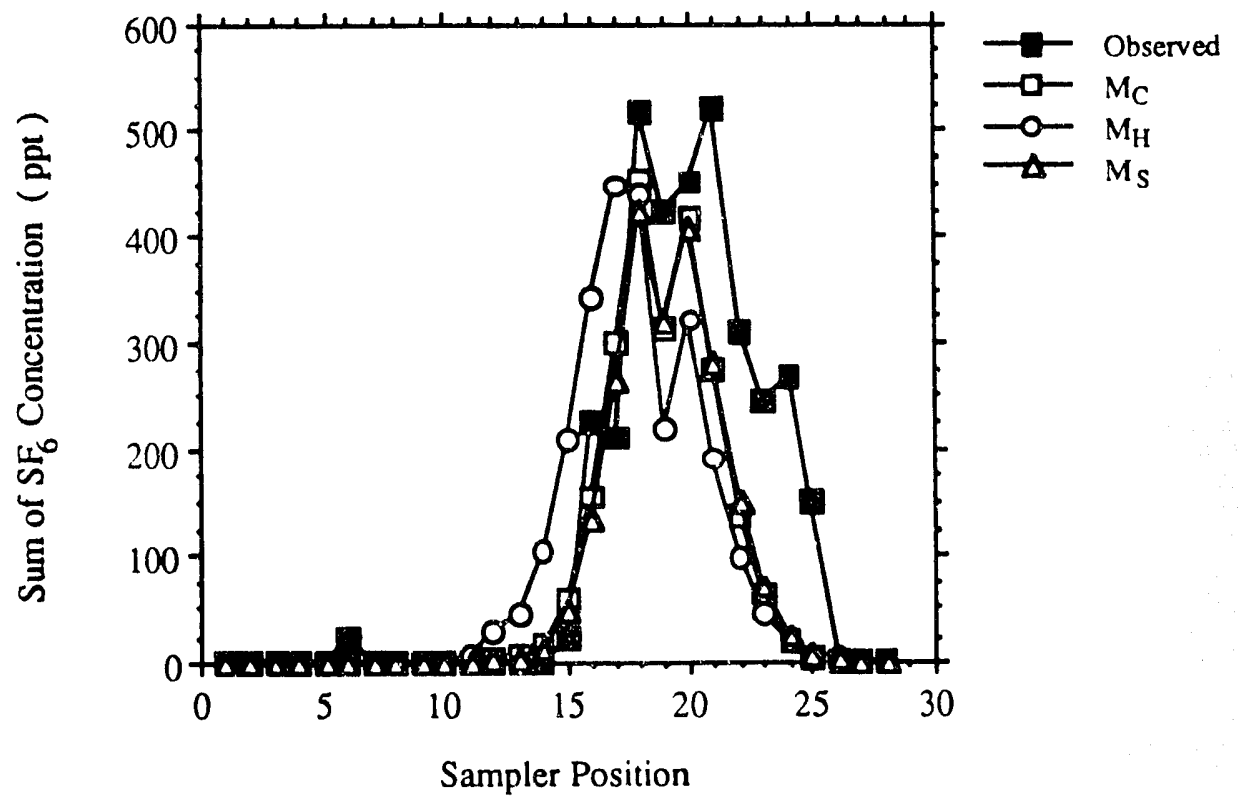

Figure 5. Same as Fig. 2, except for MATS experiment 24 


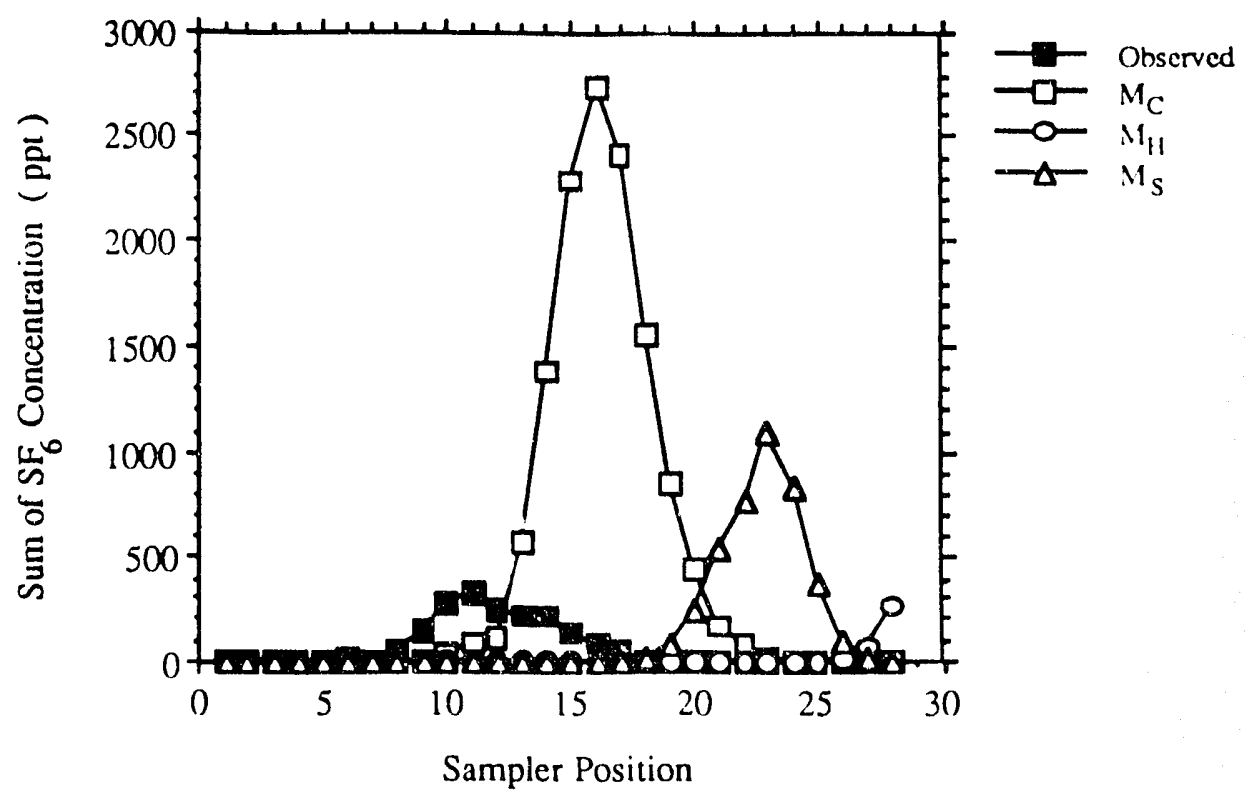

Figure 6. Same as Fig. 2, except for MATS experiment 31

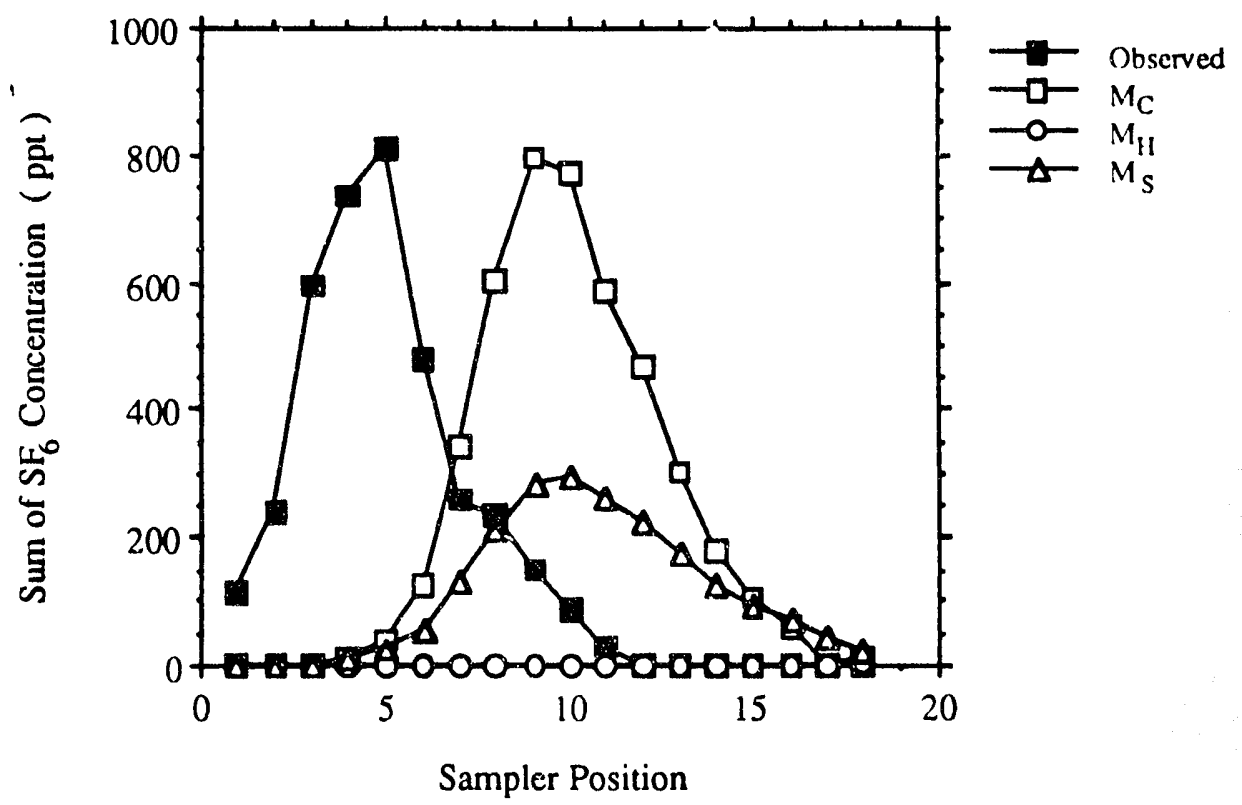

Figure 7. Sum of the $\mathrm{SF}_{6}$ concentration that was observed along the sampler arc and predicted by 2DPUF for MATS experiment 8 


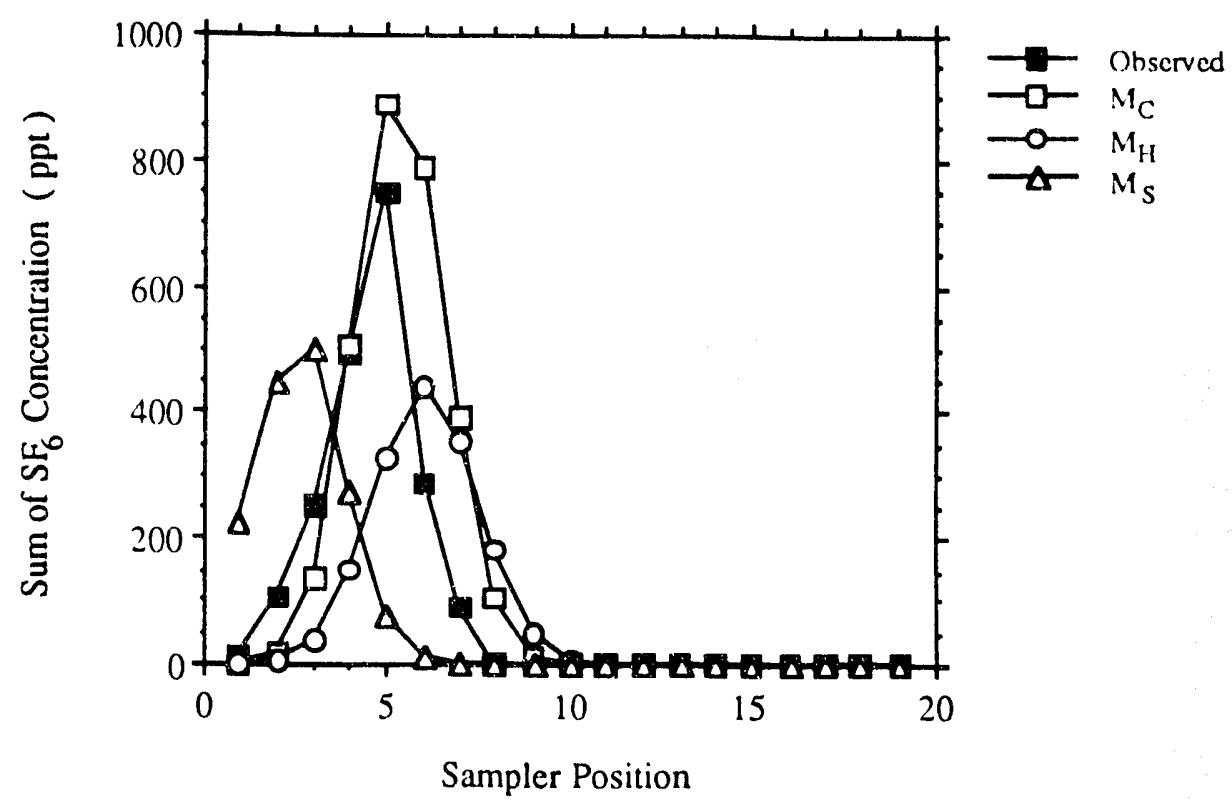

Figure 8. Same as Fig. 7, except for MATS experiment 12

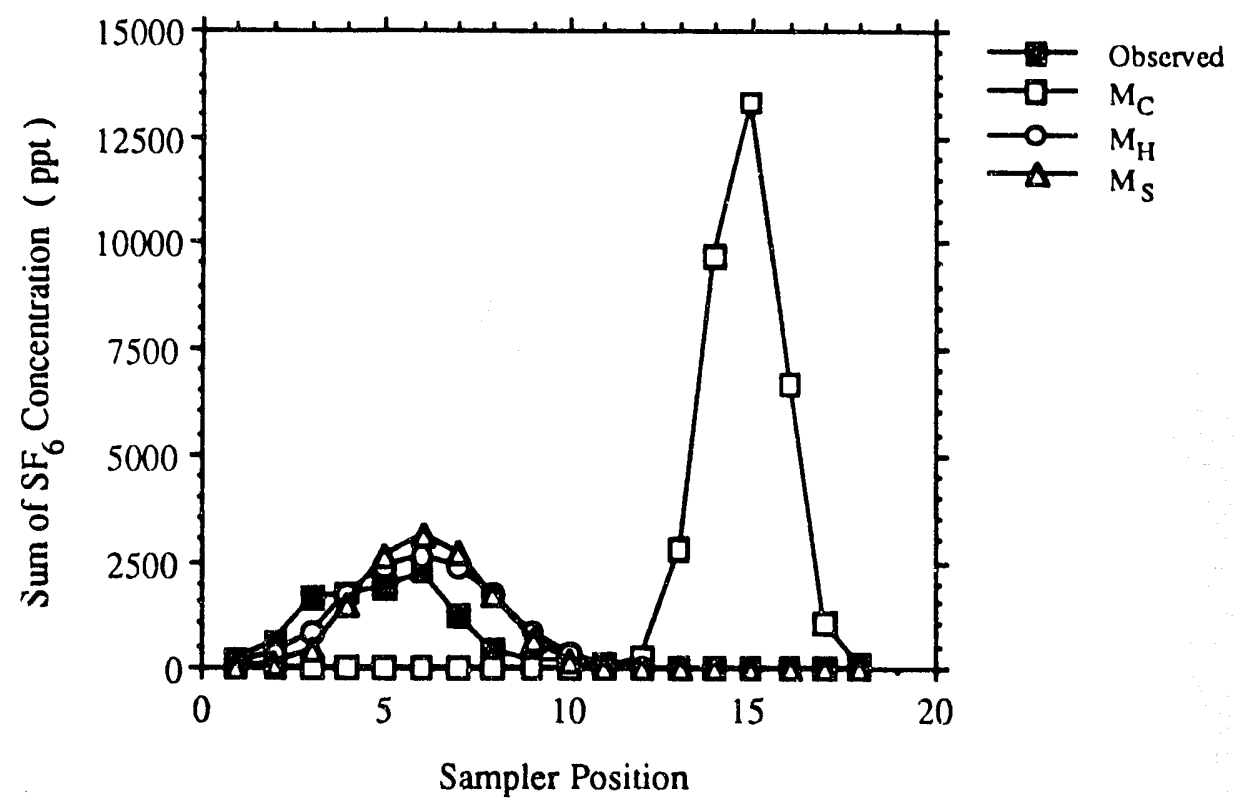

Figure 9. Same as Fig. 7, except for MATS experiment 14 


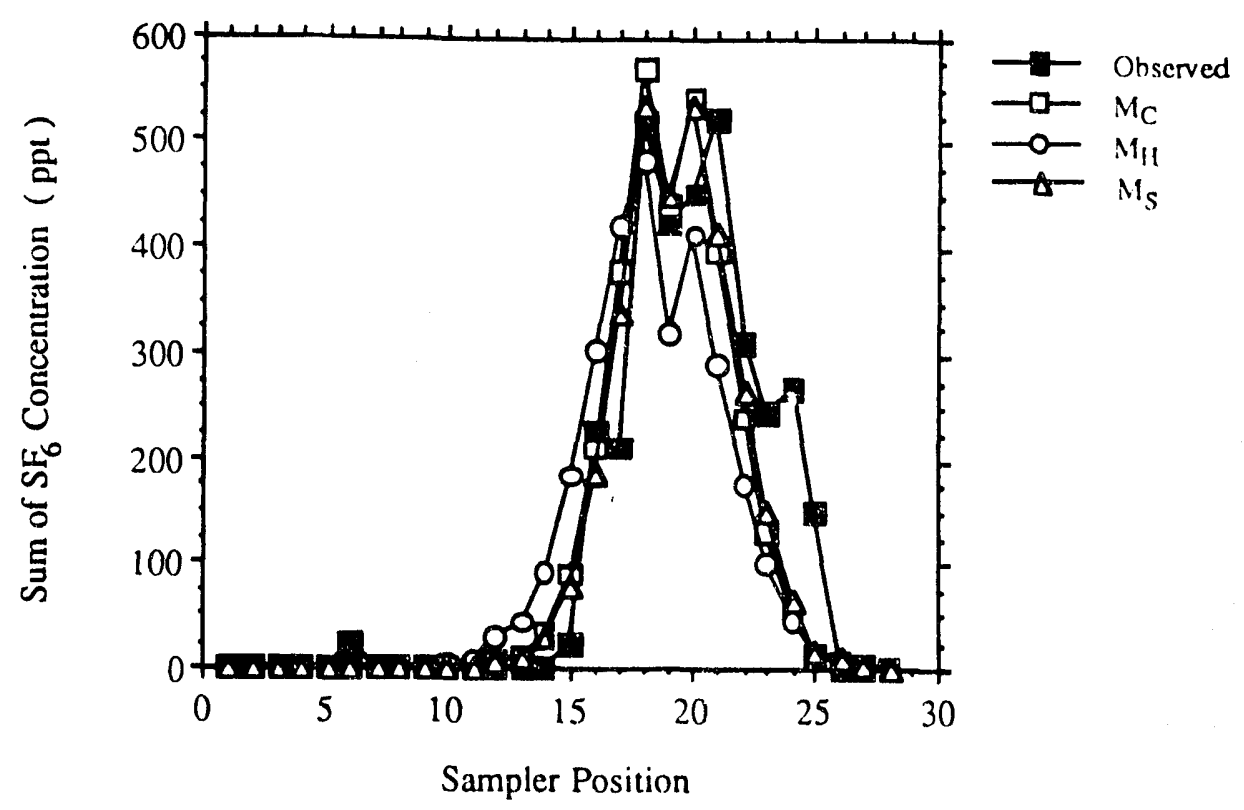

Figure 10. Same as Fig. 7, except for MATS experiment 24

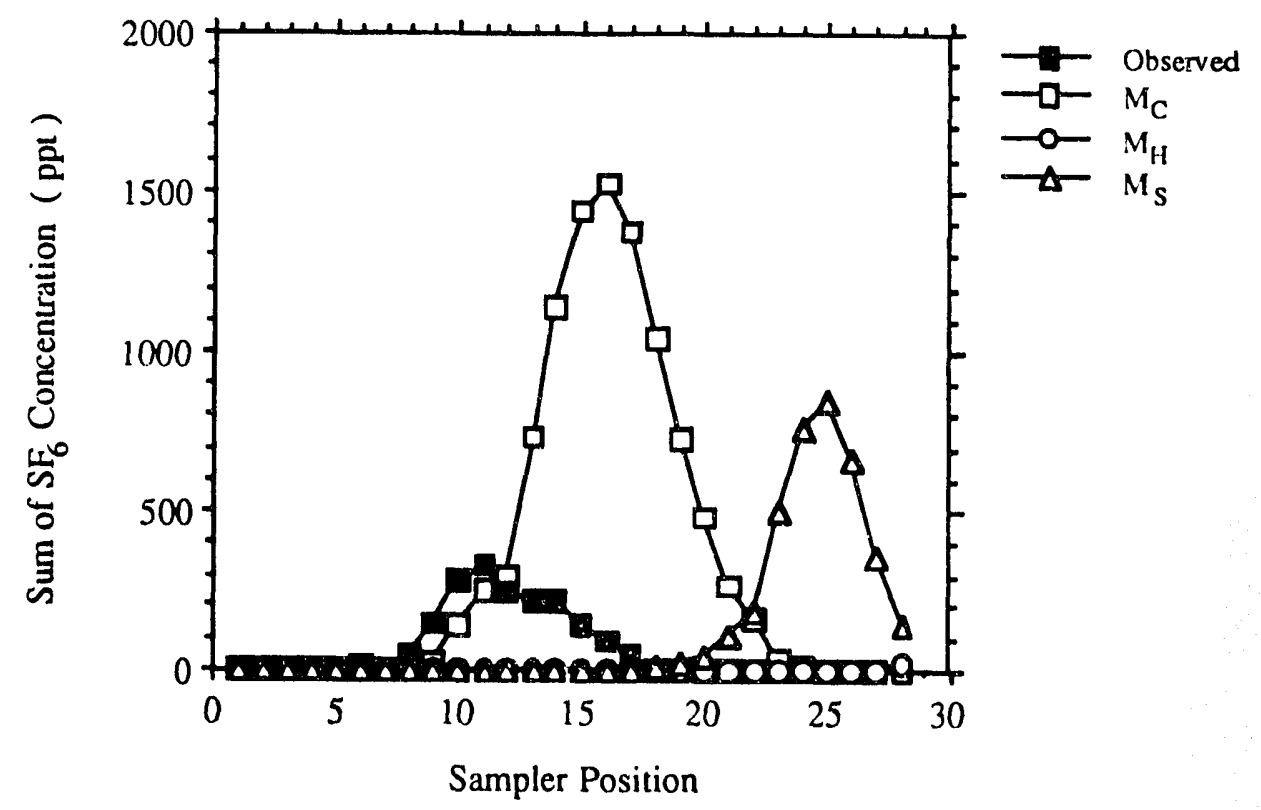

Figure 11. Same as Fig. 7, except for MATS experiment 31 


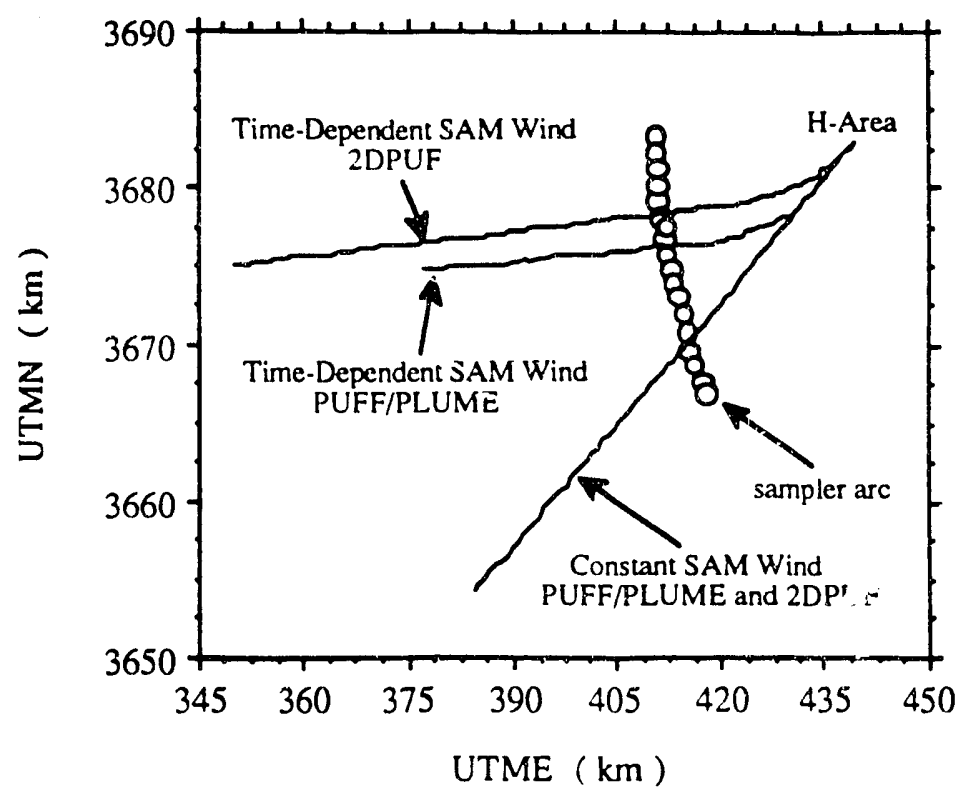

Figure 12. Trajectories of the plume predicted by PUFF/PLUME and 2DPUF for various meteorological conditions for MiATS experiment 14

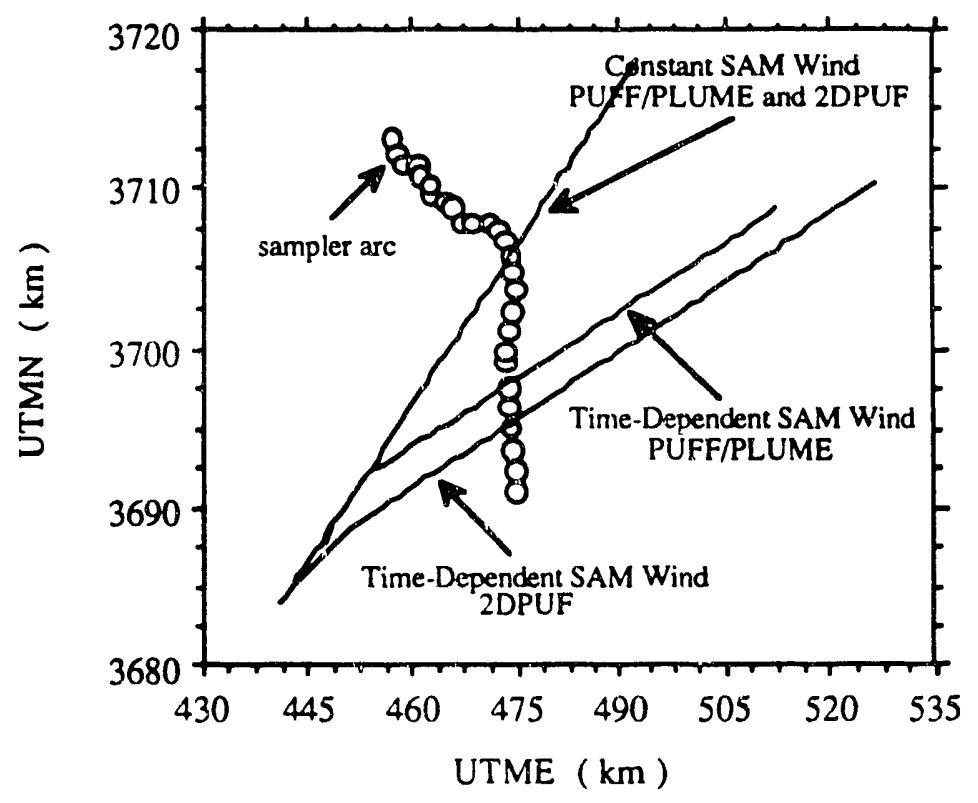

Figure 13. Same as Fig. 12, except for MATS experiment 31 


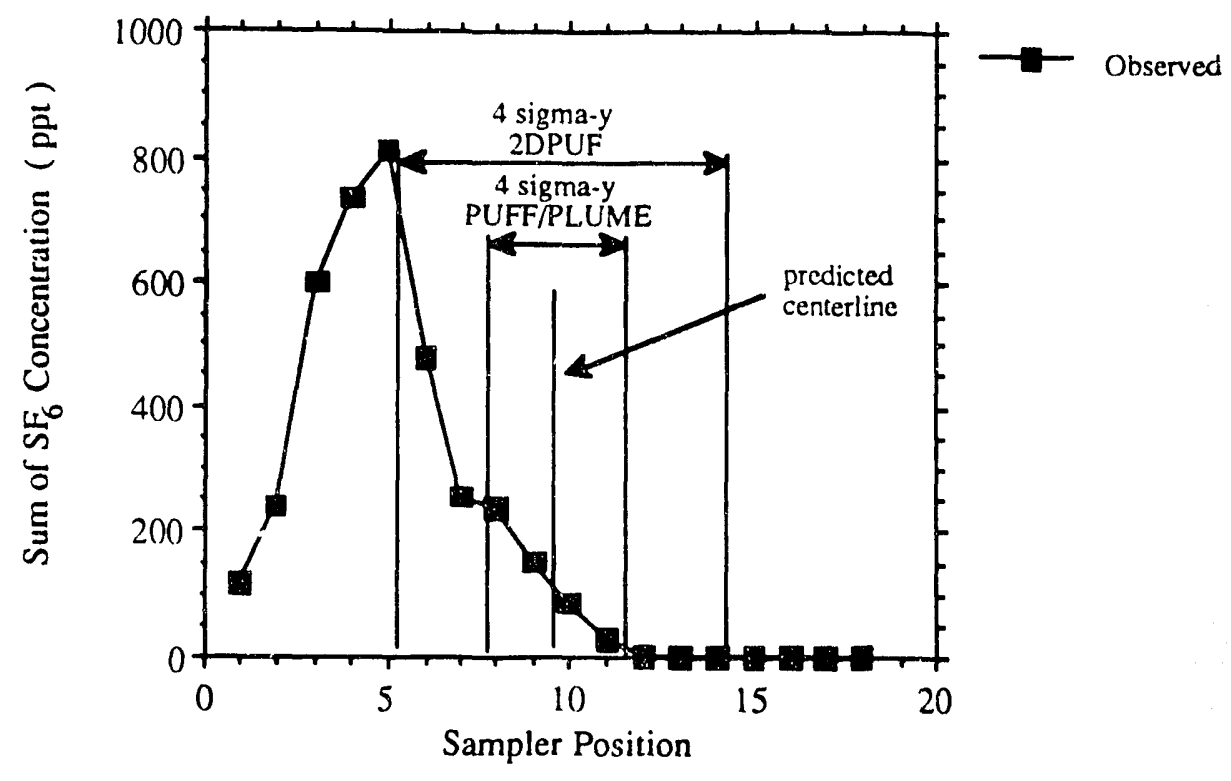

Figure 14. Sum of the $\mathrm{SF}_{6}$ concentration that was observed and width of the plume predicted by PUFF/PLUME and 2DPUF for MATS experiment 8

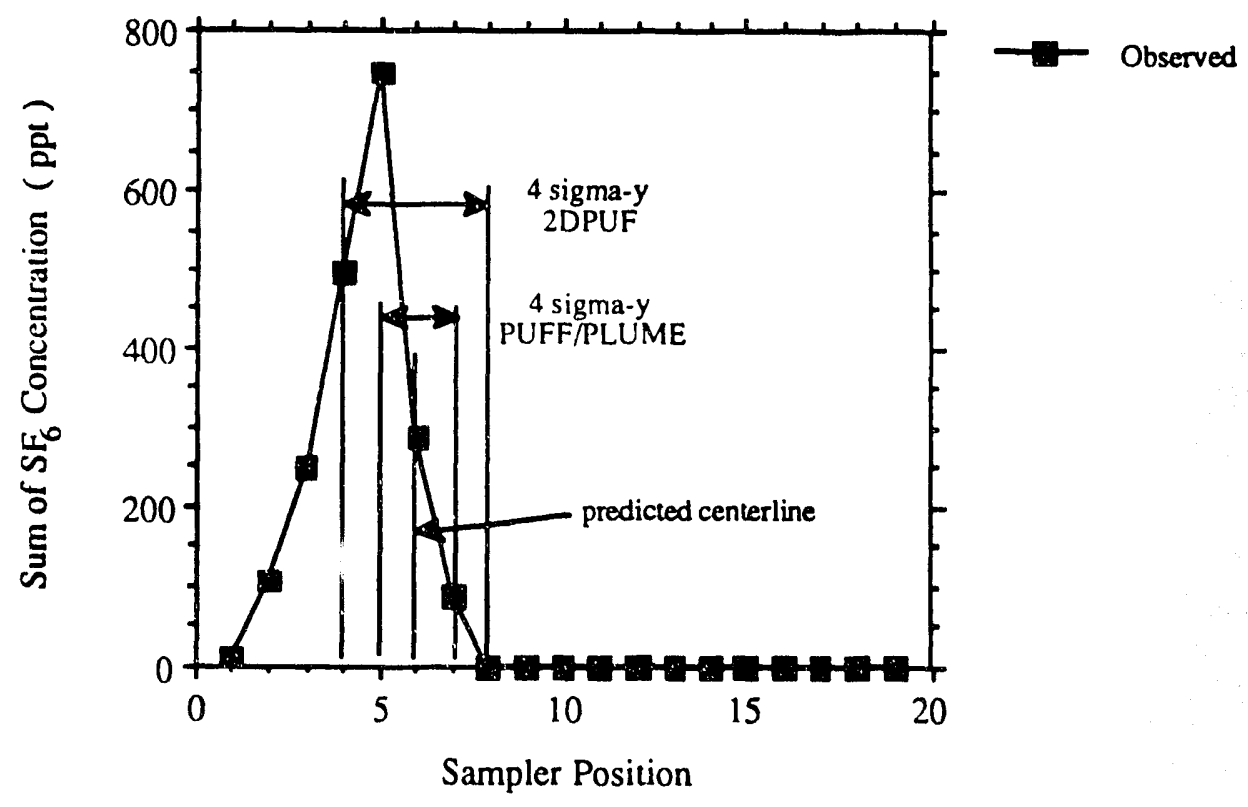

Figure 15. Same as Fig. 14, except for MATS experiment 12 


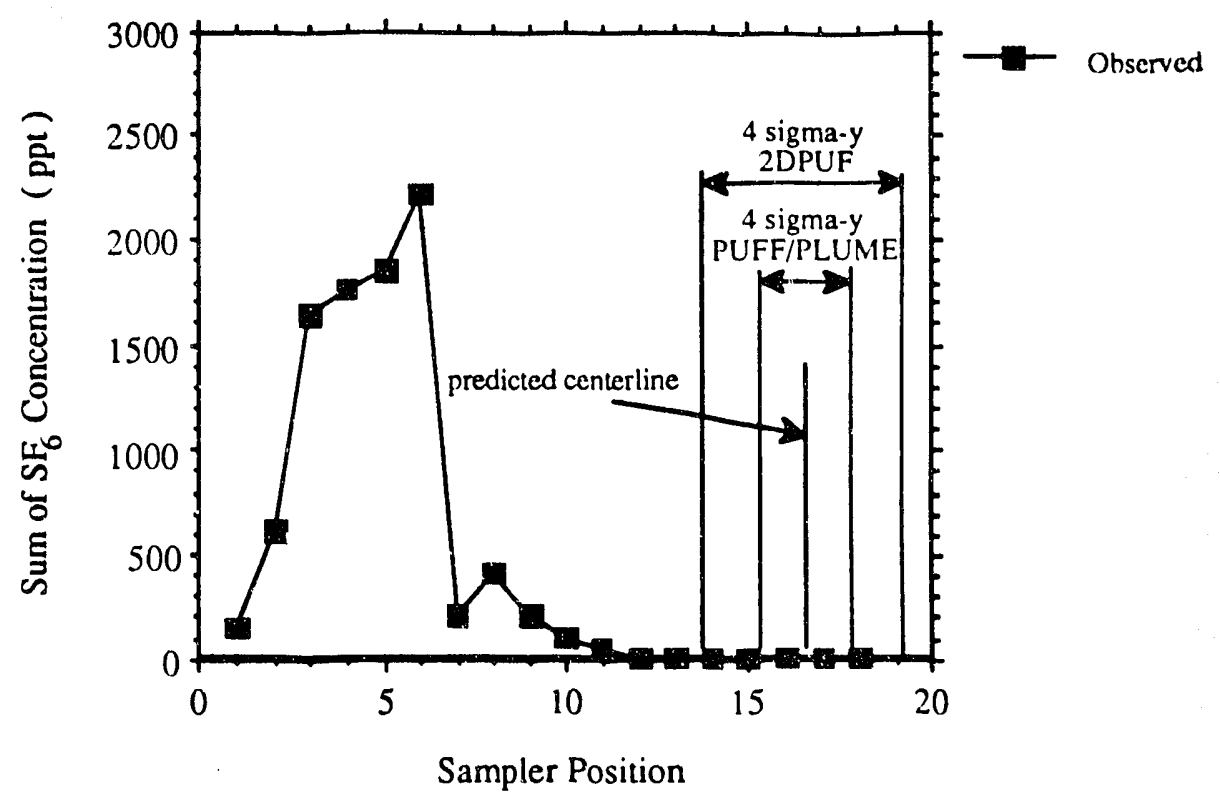

Figure 16. Same as Fig. 14, except for MATS experiment 14

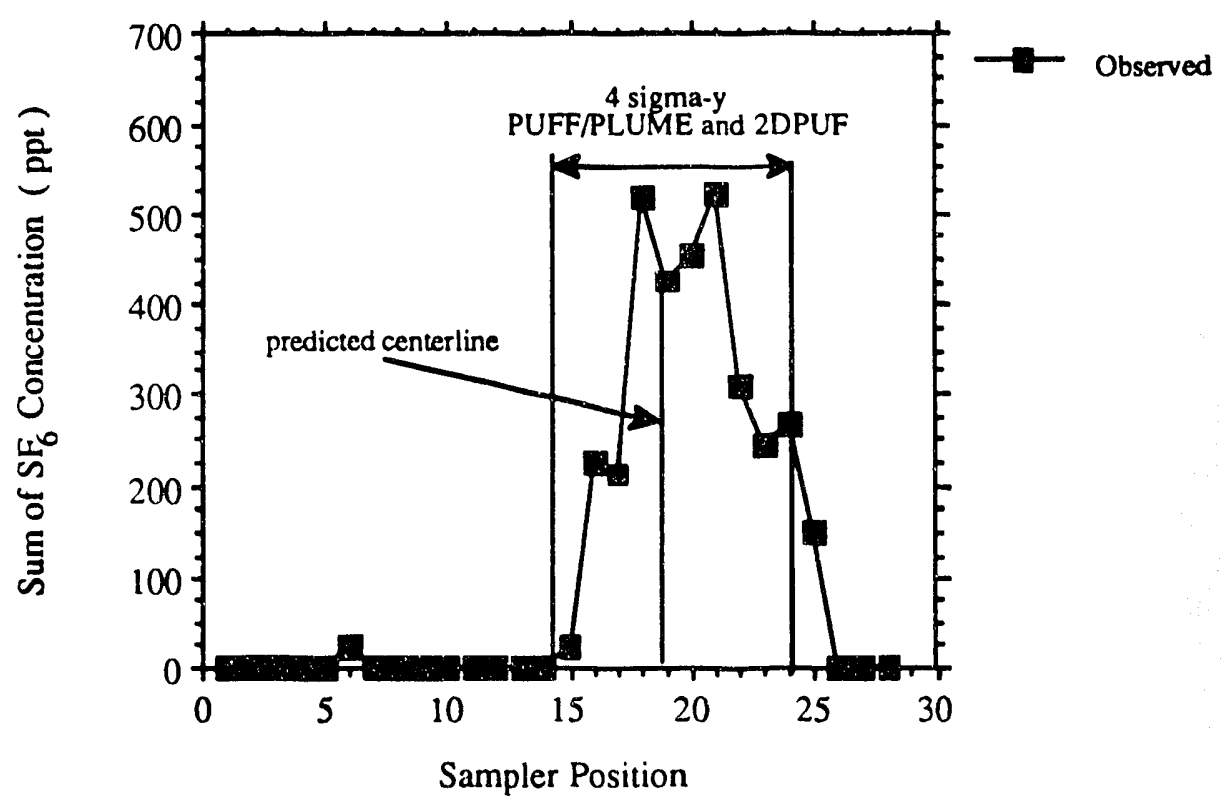

Figure 17. Same as Fig. 14, except for MATS experiment 24 


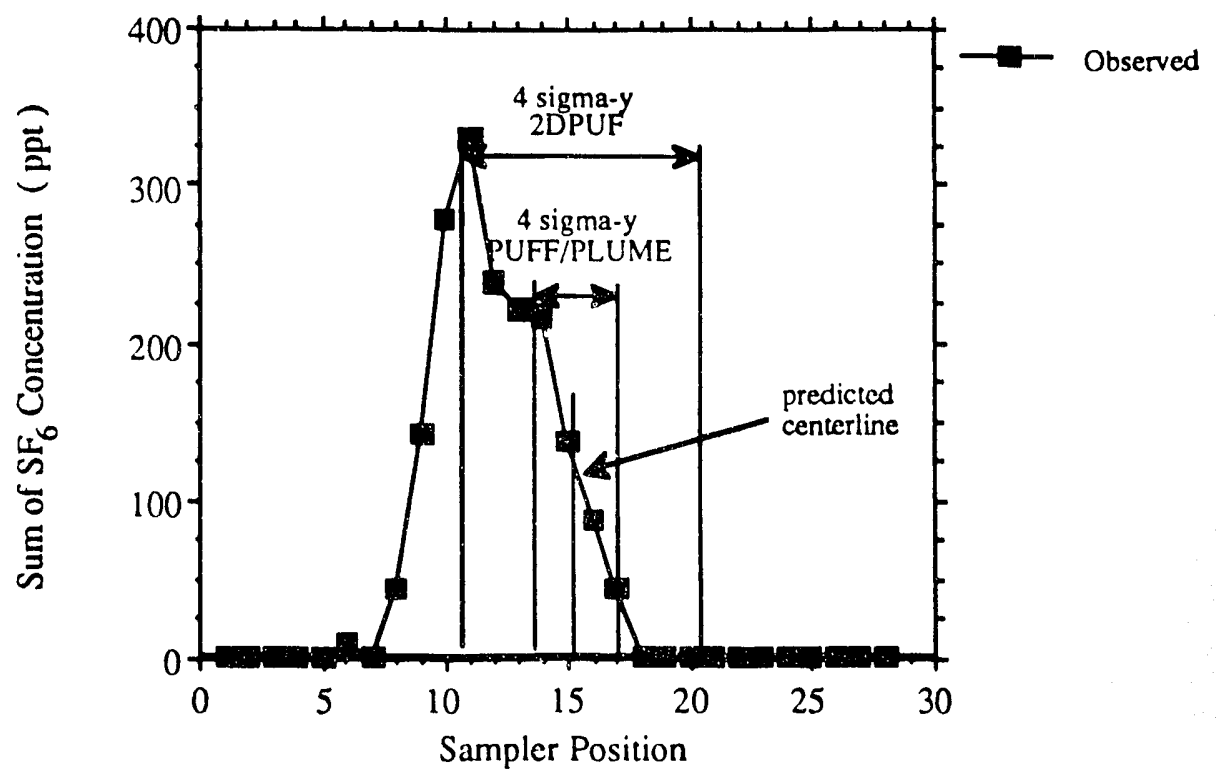

Figure 18. Same as Fig. 14, except for MATS experiment 31

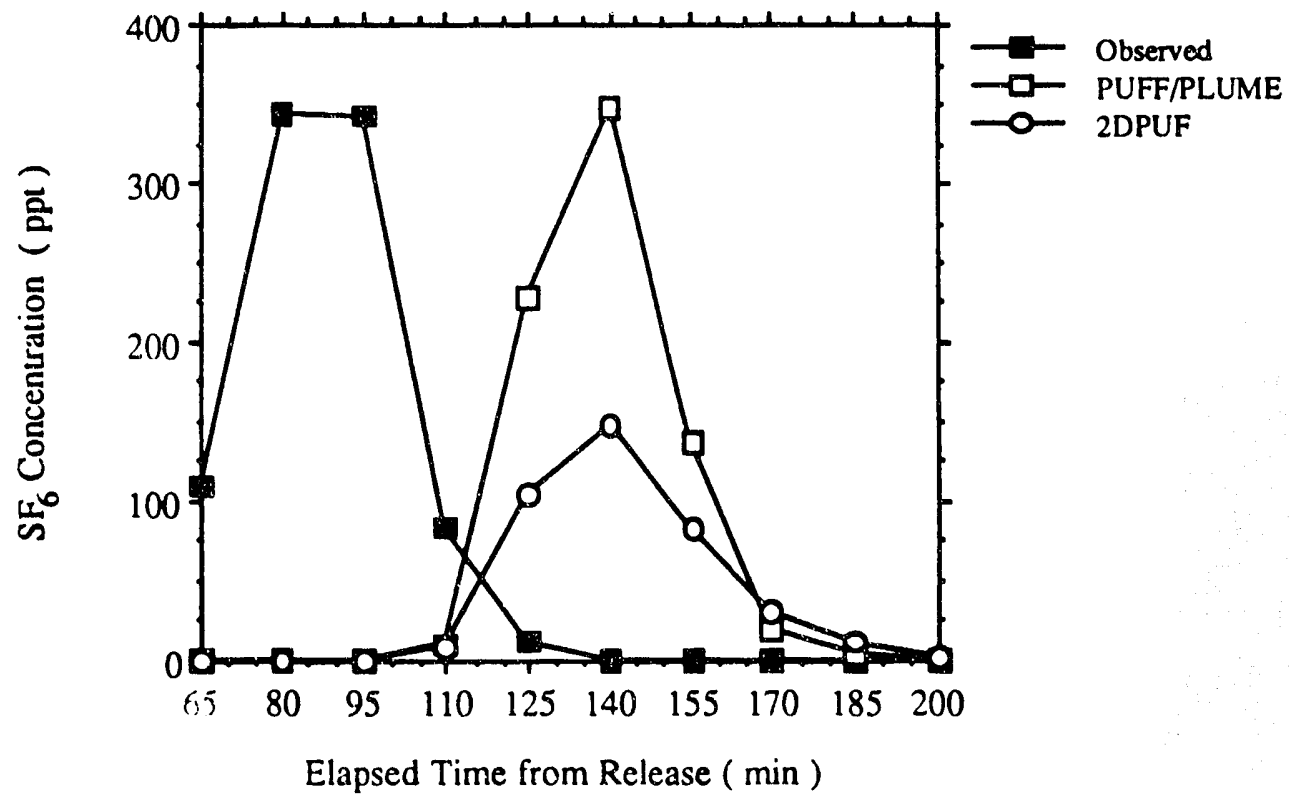

Figure 19. Maximum $\mathrm{SF}_{6}$ concentration that was observed at each of the time intervals and predicted by PUFF/PLUME and 2DPUF for MATS experiment 8 


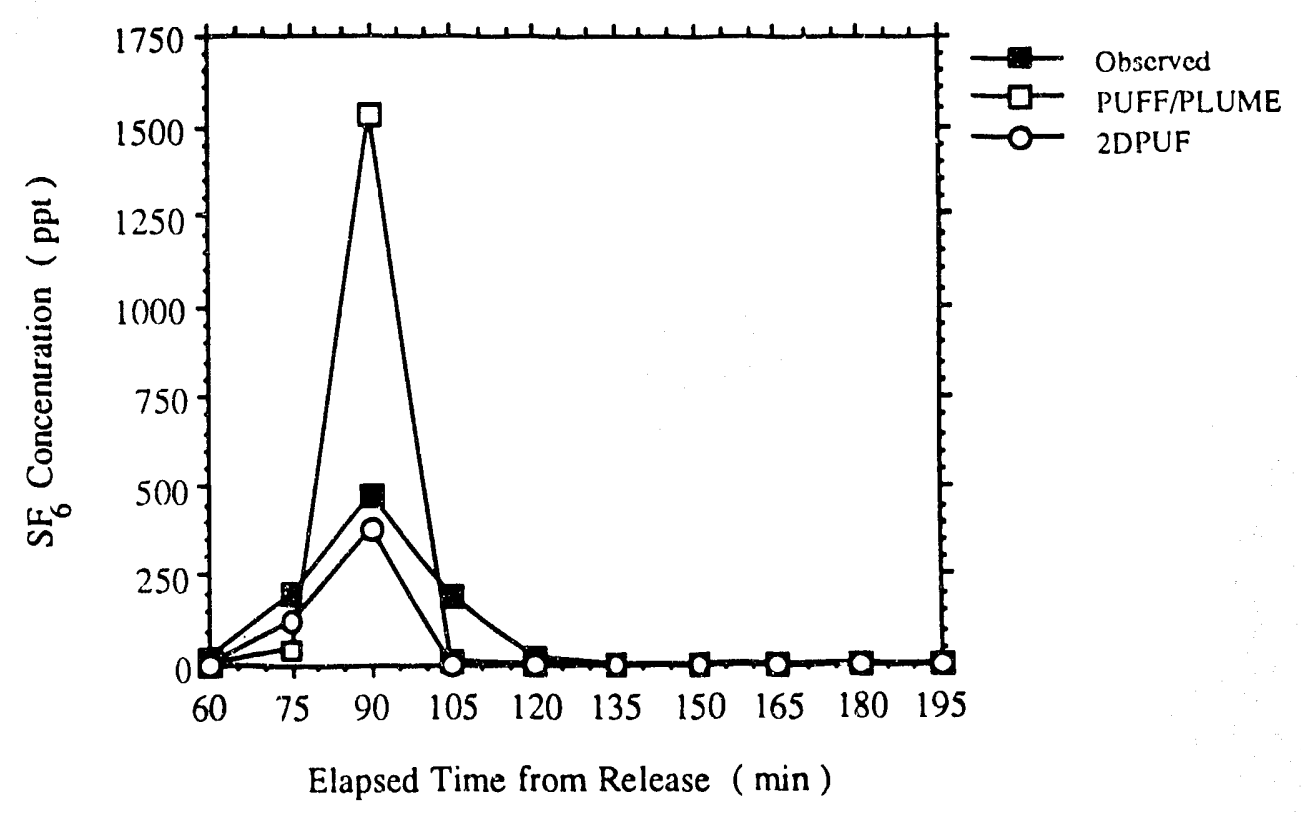

Figure 20. Same as Fig. 19, except for MATS experiment 12

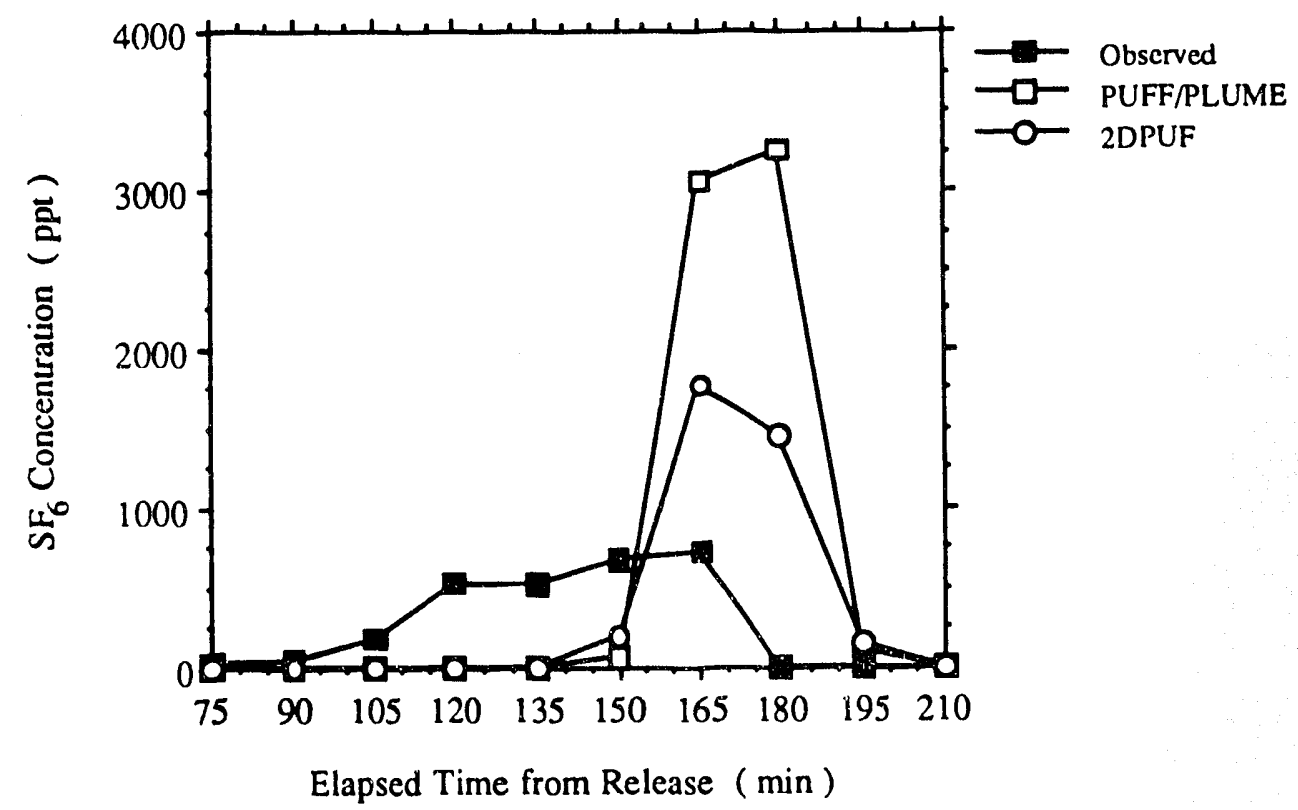

Figure 21. Same as Fig. 19, except for MATS experiment 14 


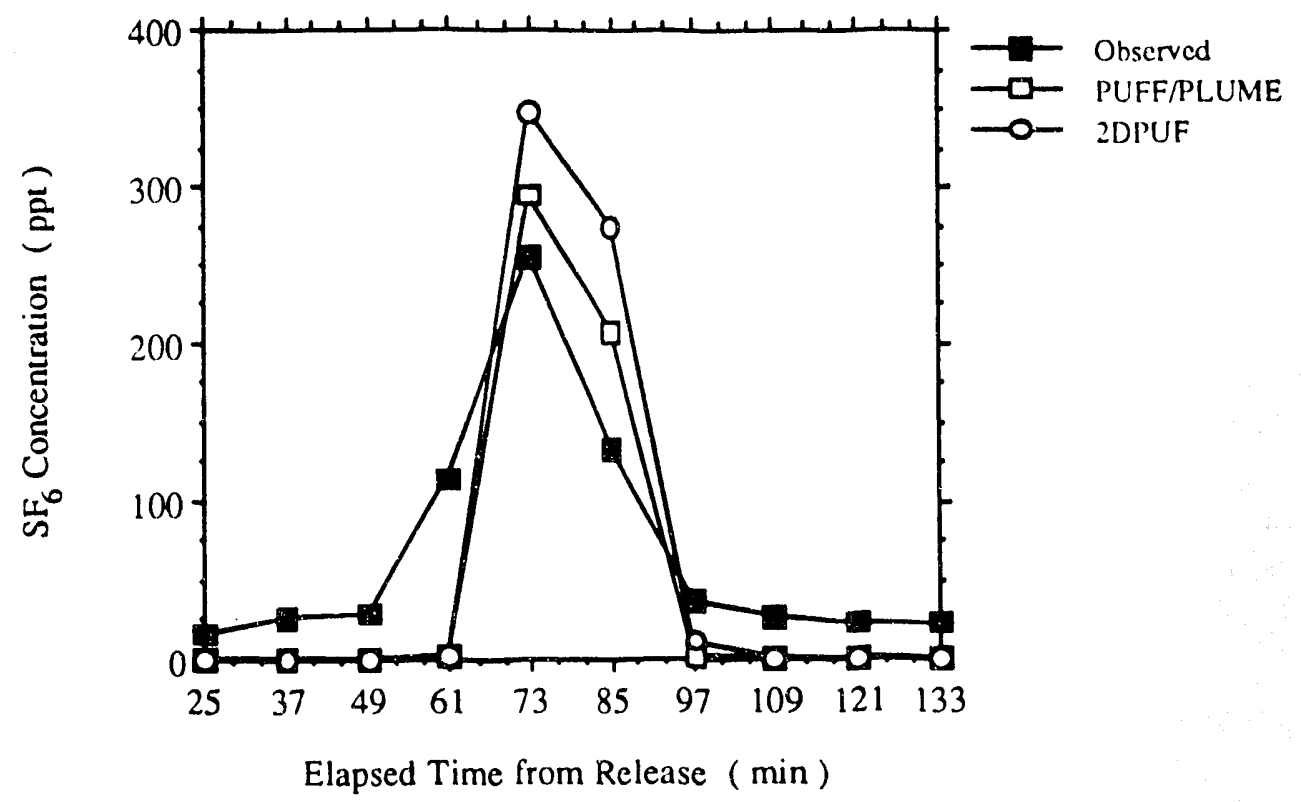

Figure 22. Same as Fig. 19, except for MATS experiment 24

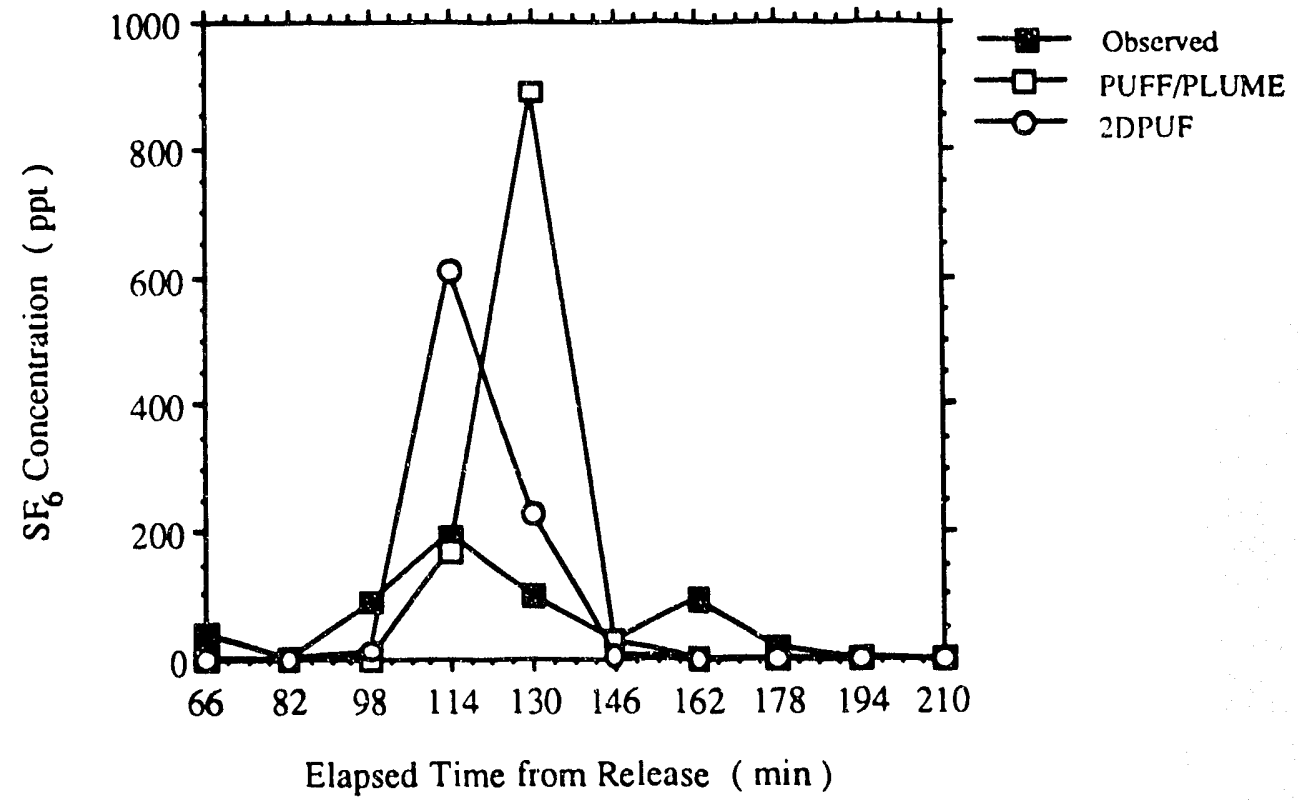

Figure 23. Same as Fig. 19, except for MATS experiment 31 


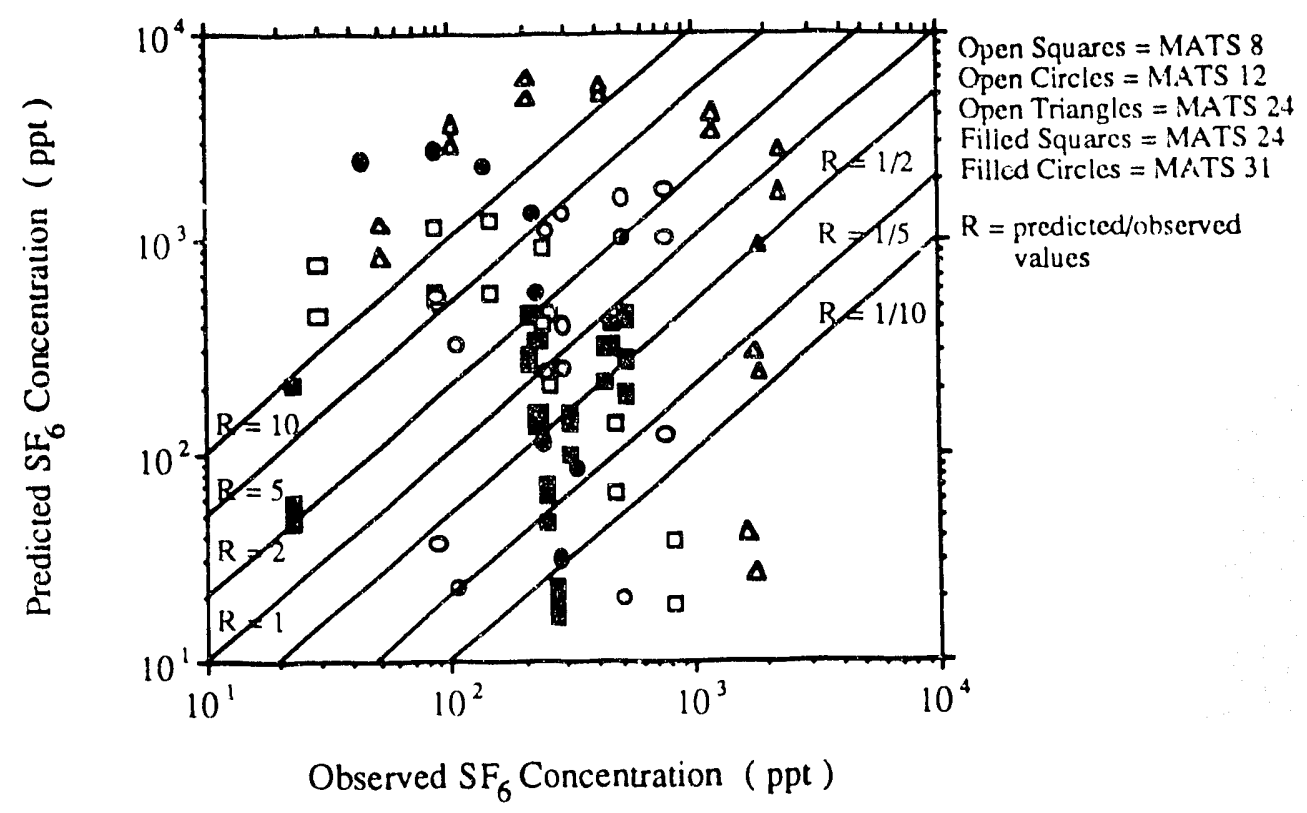

Figure 24. Sum of the $\mathrm{SF}_{6}$ concentration that was observed and predicted by PUFF/PLUME, paired in space, for five MATS experiments

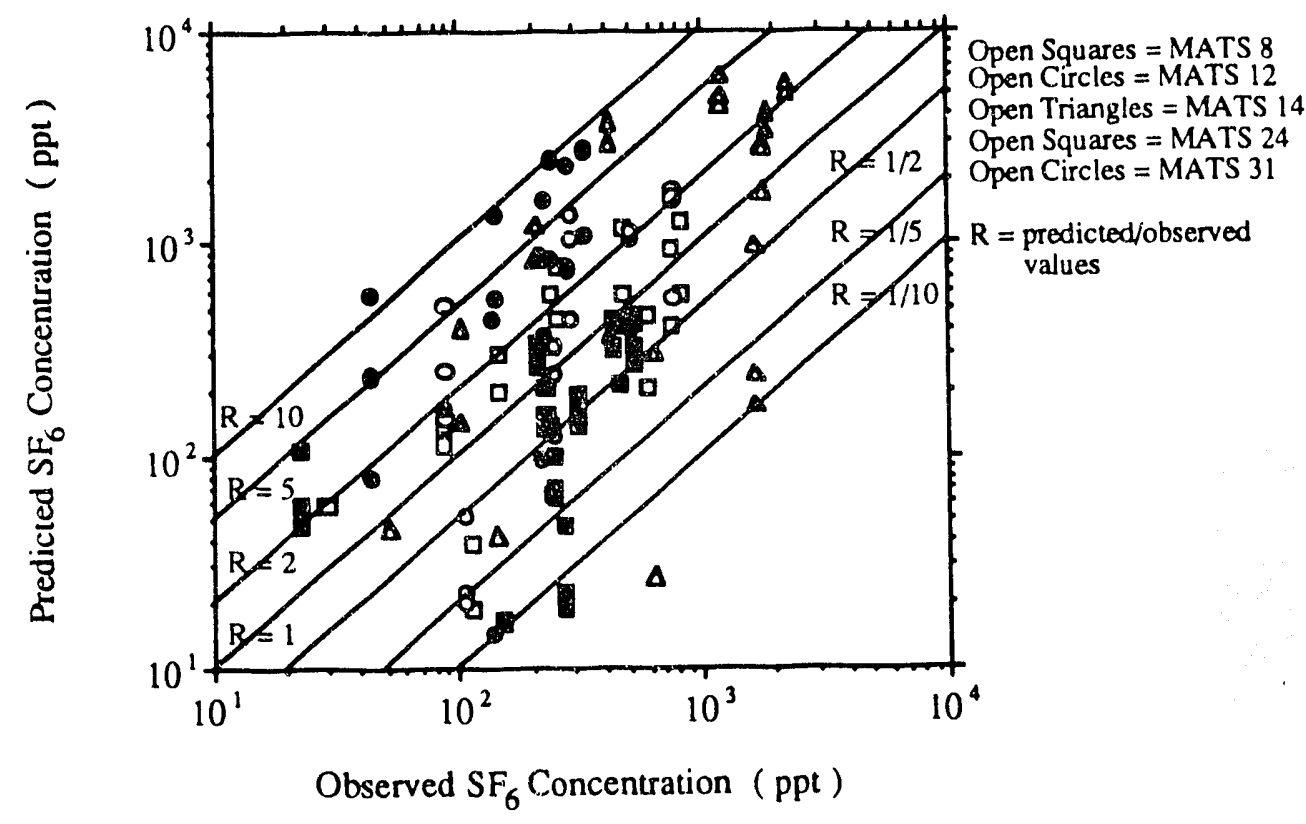

Figure 25. Same as Fig. 24, except for wind direction errors removed 


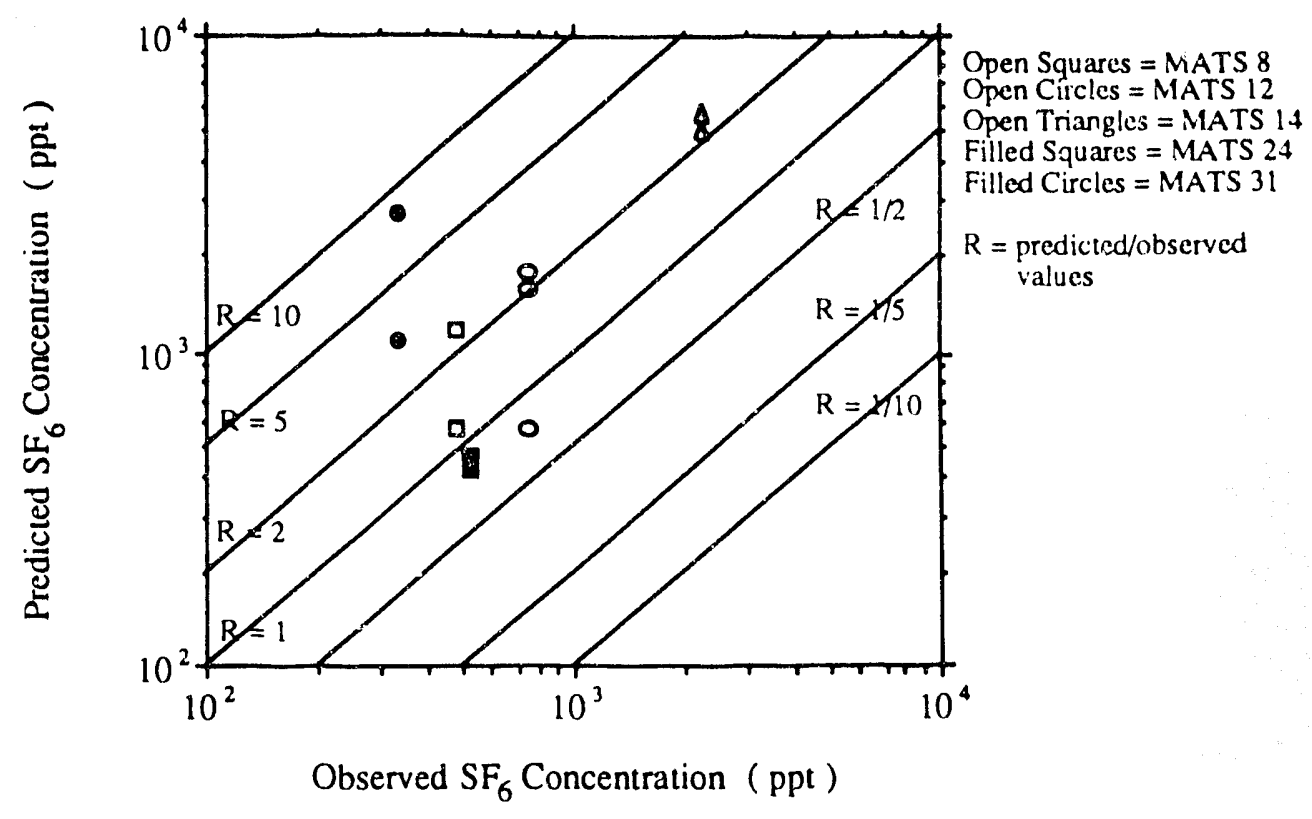

Figure 26. Same as Fig. 24, except for maximum sum of the $\mathbf{S F}_{6}$ concentrations

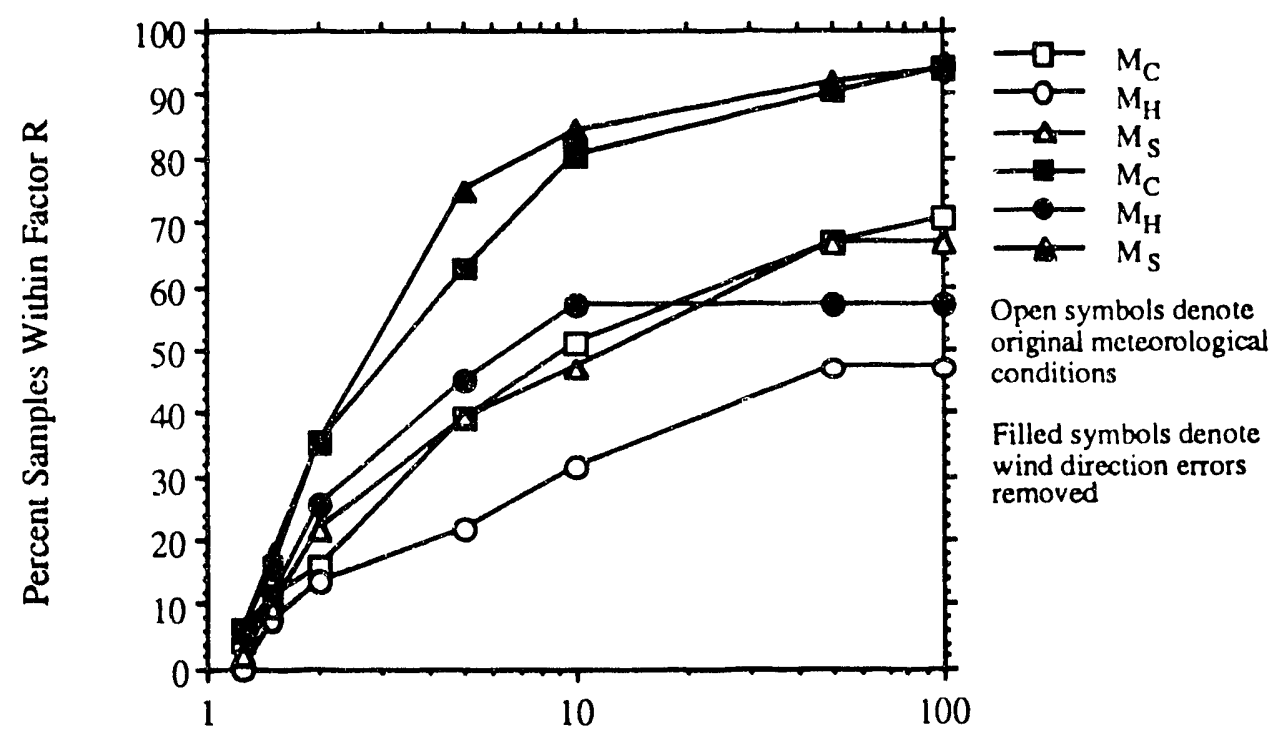

Factor $\mathbf{R}$

Figure 27. Percent of the sum of the $\mathrm{SF}_{6}$ concentrations predicted by PUFF/ PLUME within a factor $R$ of the observed values 


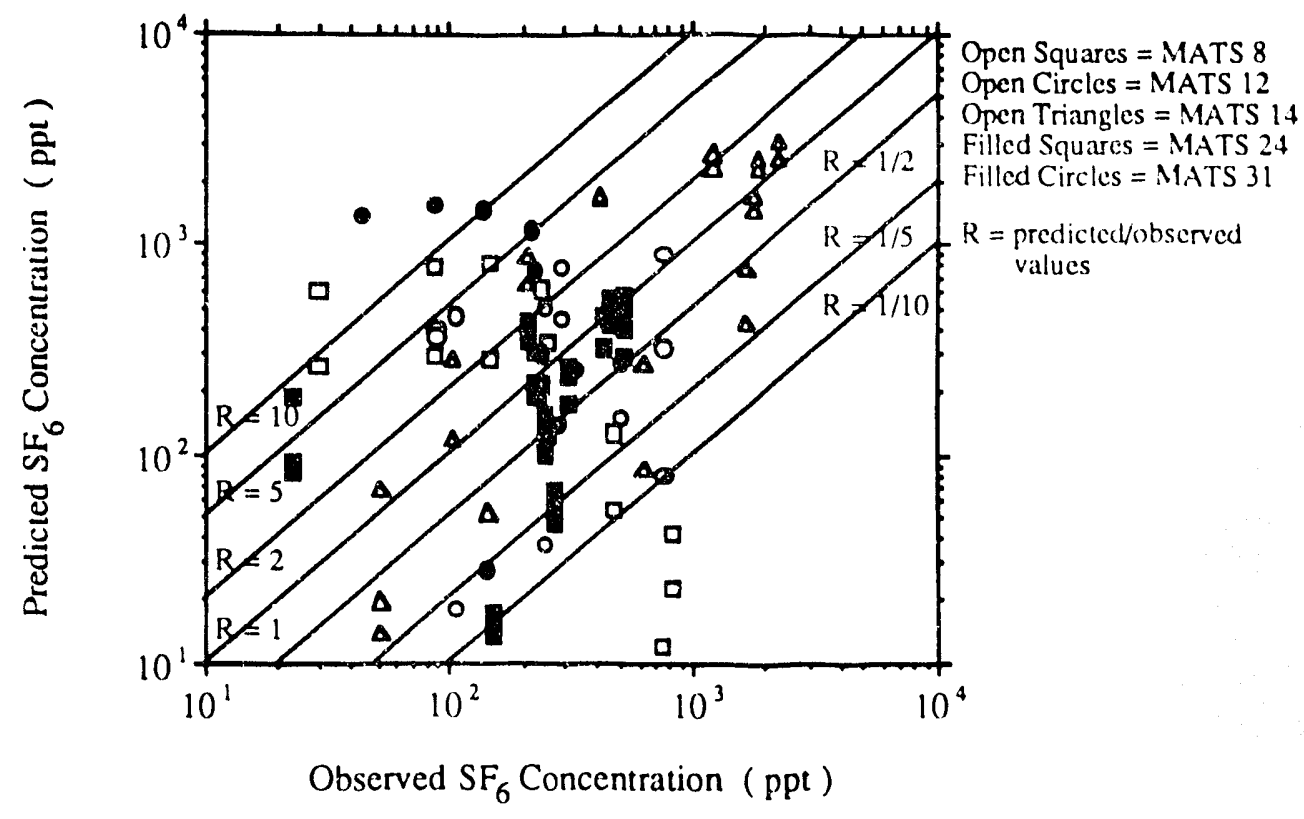

Figure 28. Sum of the $\mathrm{SF}_{6}$ concentration that was observed and predicted by 2DPUF, paired in space, for five MATS experiments

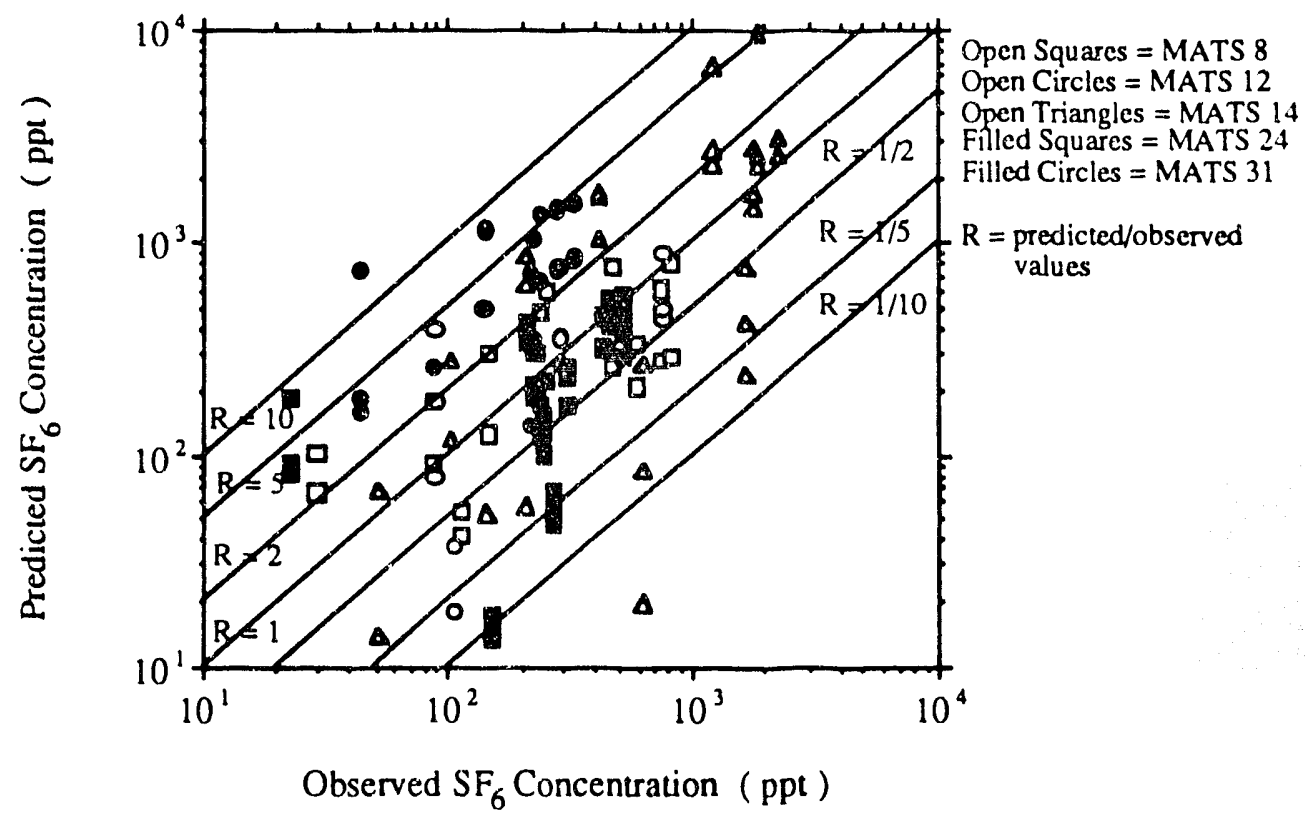

Figure 29. Same as Fig. 28, except for wind direction errors removed 


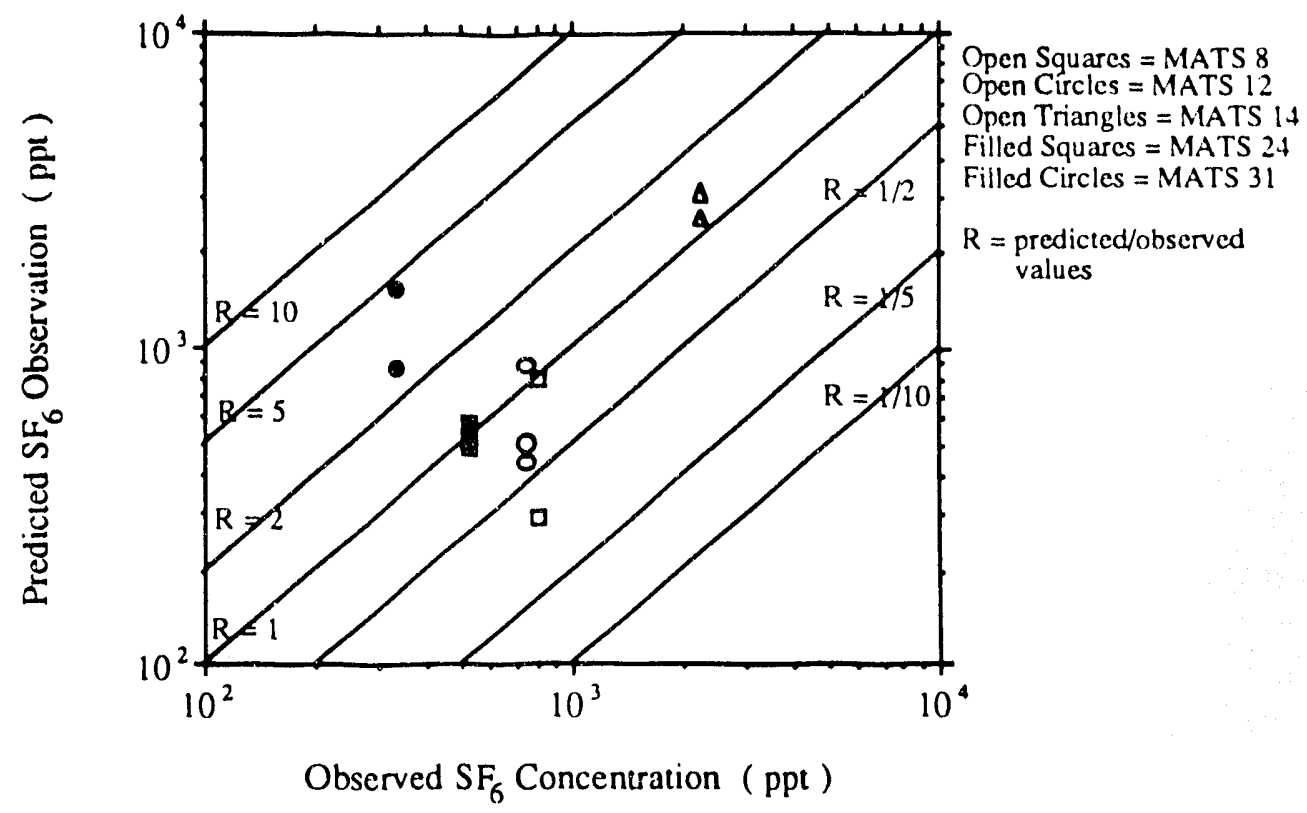

Figure 30. Same as Fig. 28, except for maximum sum of the $\mathrm{SF}_{6}$ concentrations

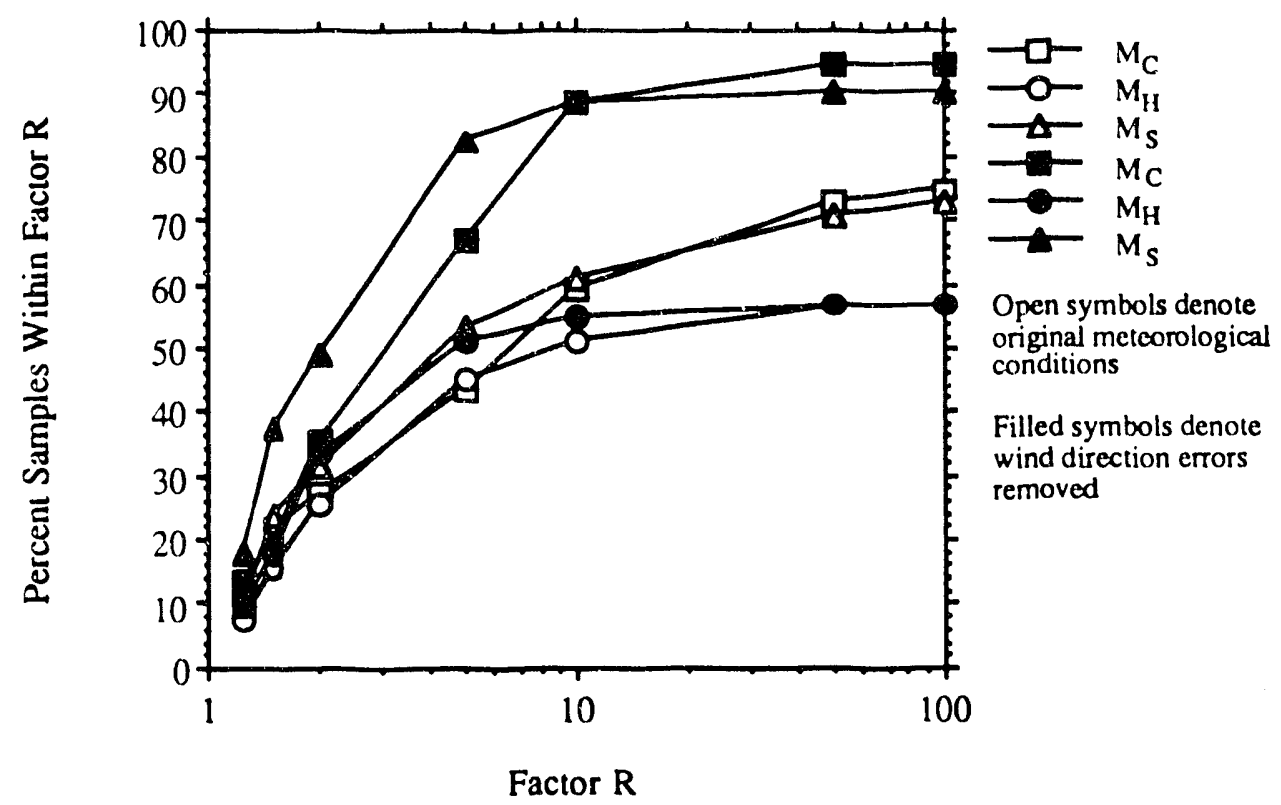

Figure 31. Percent of the sum of the $\mathrm{SF}_{6}$ concentrations predicted by $2 \mathrm{DPUF}$ within a factor $R$ of the observed values 


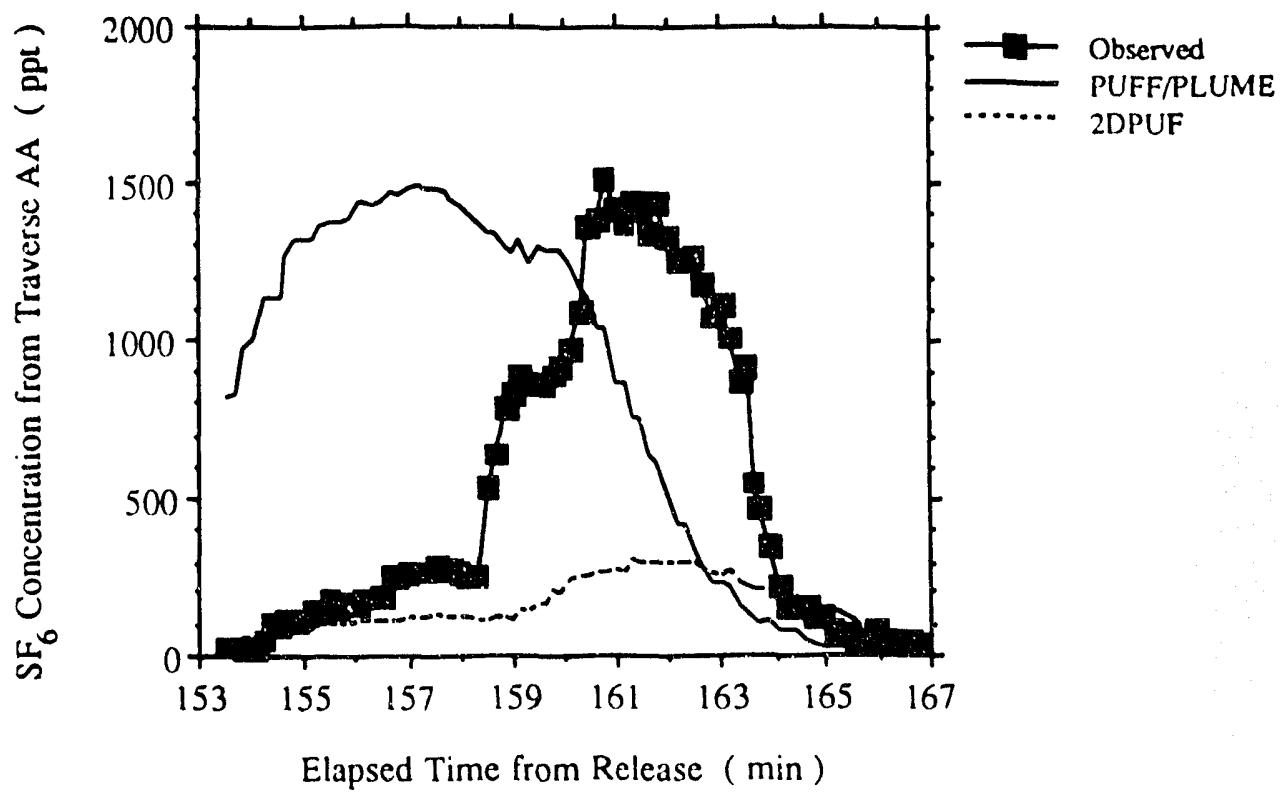

Figure 32. $\mathrm{SF}_{6}$ concentration that was observed by the TRAC vehicle for traverse AA and predicted by PUFF/PLUME and 2DPUF for MATS experiment 27

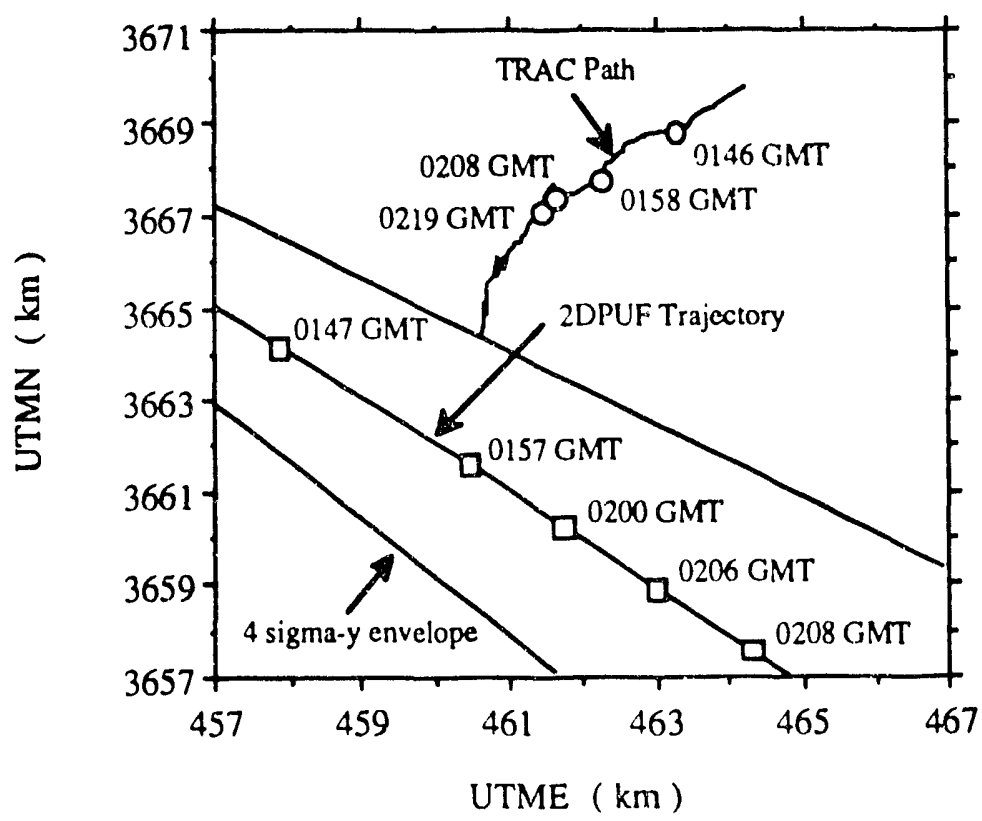

Figure 33. Trajectory of the plume predicted by 2DPUF and the path of the TRAC vehicle for MATS experiment 32 


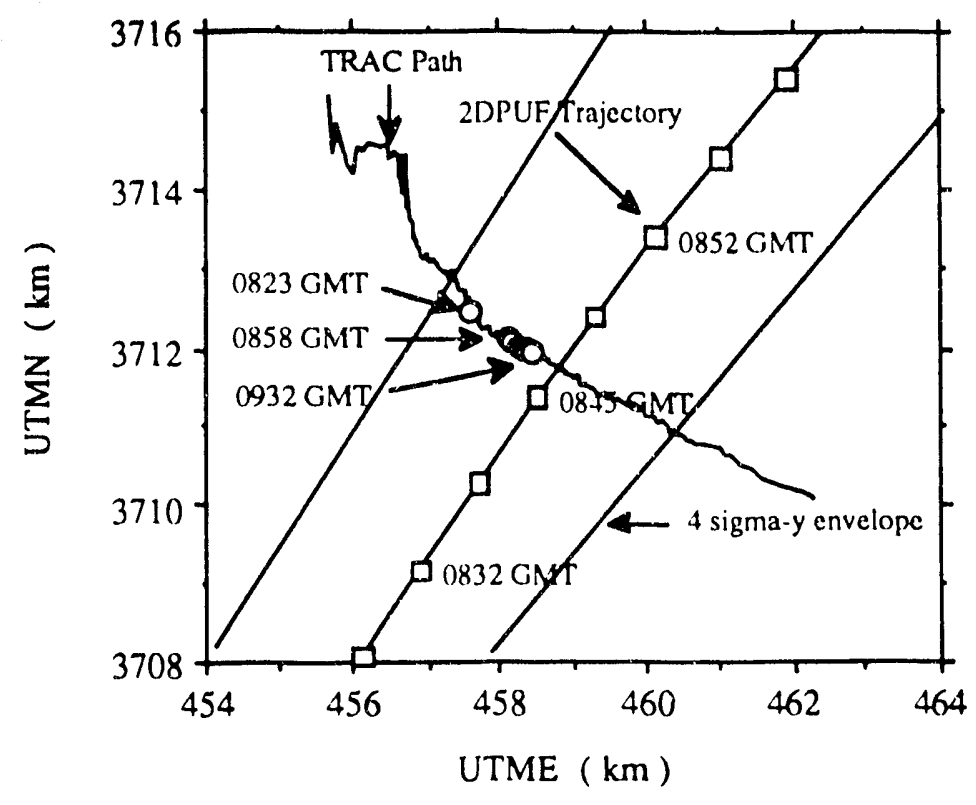

Figure 34. Trajectory of the plume predicted by 2DPUF and the path of the TRAC vehicle for MATS experiment 37 
Table 1. A brief summary of the sampler, release, and meteorological data for each of the MATS experiments used in this study

\begin{tabular}{|r|r|r|r|r|r|}
\hline \multicolumn{1}{|c|}{$\begin{array}{l}\text { MATS } \\
\text { Exp. \# }\end{array}$} & Date & $\begin{array}{c}\text { \# Samplers } \\
\text { and Type }\end{array}$ & $\begin{array}{r}\text { Release Time } \\
\text { (GMT) }\end{array}$ & $\begin{array}{r}\text { Sampler Start } \\
\text { Time (GMT) }\end{array}$ & $\begin{array}{c}\text { Release Rate } \\
\left(\mathrm{gm} \mathrm{s}^{-1}\right)\end{array}$ \\
\hline 8 & $07 / 22 / 83$ & 18 E sampler & 1530 & 1620 & 63.3 \\
12 & $09 / 28 / 83$ & 19 S sampler & 1430 & 1515 & 88.9 \\
14 & $10 / 17 / 83$ & 18 S sampler & 1400 & 1500 & 110.6 \\
24 & $11 / 05 / 85$ & 28 S sampler & 1600 & 1700 & 67.0 \\
27 & $12 / 18 / 85$ & TRAC & 1630 & - & 133.0 \\
31 & $02 / 19 / 86$ & 28 S sampler & 1600 & 1650 & 100.0 \\
32 & $03 / 04 / 86$ & TRAC & 0100 & - & 133.0 \\
37 & $08 / 08 / 86$ & TRAC & 0700 & - & 24.2 \\
\hline
\end{tabular}

\begin{tabular}{|r|r|r|r|r|r|}
\hline \multicolumn{1}{|c|}{$\begin{array}{l}\text { MATS } \\
\text { Exp. \# }\end{array}$} & $\begin{array}{c}\text { Duration of } \\
\text { Release (min) }\end{array}$ & Azimuth (deg) & $\begin{array}{c}\text { Wind Speed } \\
\left(\mathrm{m} \mathrm{s}^{-1}\right)\end{array}$ & $\begin{array}{c}\sigma_{\mathrm{a}} \text { (deg) and } \\
\text { stability class }\end{array}$ & $\begin{array}{c}\sigma_{\mathrm{c}} \text { (deg) and } \\
\text { stability class }\end{array}$ \\
\hline 8 & 15 & 254 & 4.2 & $17.4(\mathrm{C})$ & 11.5 (C) \\
12 & 15 & 028 & 5.7 & $13.3(\mathrm{D})$ & 10.8 (C) \\
14 & 15 & 085 & 2.8 & $14.1(\mathrm{D})$ & 9.8 (D) \\
24 & 15 & 277 & 6.2 & $16.5(\mathrm{C})$ & 12.1 (C) \\
27 & 15 & 291 & 2.2 & $28.4(\mathrm{~A})$ & 16.1 (B) \\
31 & 15 & 271 & 6.2 & $18.2(\mathrm{C})$ & 10.9 (C) \\
32 & 15 & 333 & 6.6 & 11.7 (D) & 9.3 (D) \\
37 & 15 & 202 & 5.8 & $6.2(\mathrm{E})$ & 2.1 (F) \\
\hline
\end{tabular}

Explanation of Symbols:

E sampler $=$ evacuation-type fixed samplers

$S$ sampler $=$ syringe-type fixed samplers

TRAC $=\quad$ TRAC vehicle sampling 
Table 2. A summary of the meteorological data for each of the MATS experiments used in this study

MATS Experiment 8:

\begin{tabular}{|c|c|c|c|c|c|}
\hline \multicolumn{6}{|c|}{$\mathrm{H}$-area Meteorological Conditions $\left(\mathrm{M}_{\mathrm{H}}\right)$} \\
\hline Time & $\begin{array}{l}\text { Azimuth } \\
\text { (deg) }\end{array}$ & $\begin{array}{l}\text { Wind Speed } \\
\left(\mathrm{m} \mathrm{s}^{-1}\right)\end{array}$ & $\sigma_{\mathrm{a}}(\mathrm{deg})$ & $\sigma_{\mathrm{e}}(\operatorname{deg})$ & $\begin{array}{l}\text { Mixed-Layer } \\
\text { Depth }(\mathrm{m})\end{array}$ \\
\hline $\begin{array}{l}\text { hour } 1 \\
\text { hour } 2 \\
\text { hour } 3\end{array}$ & $\begin{array}{l}249 \\
254 \\
240\end{array}$ & $\begin{array}{l}3.7 \\
4.2 \\
4.1\end{array}$ & $\begin{array}{r}16.6 \\
18.8 \\
7.5\end{array}$ & $\begin{array}{l}14.6 \\
12.0 \\
28.1\end{array}$ & $\begin{array}{r}668.7 \\
1260.1 \\
1767.5\end{array}$ \\
\hline \multicolumn{6}{|c|}{ SAM Meteorological Conditions $\left(\mathrm{M}_{\mathrm{S}}\right)$} \\
\hline Time & $\begin{array}{l}\text { Azimuth } \\
\text { (deg) }\end{array}$ & $\begin{array}{c}\text { Wind Speed } \\
\left(\mathrm{m} \mathrm{s}^{-1}\right)\end{array}$ & $\overline{\sigma_{\mathrm{a}}(\mathrm{deg})}$ & $\tau_{\mathrm{c}}(\mathrm{deg})$ & $\begin{array}{l}\text { Mixed-Layer } \\
\text { Depth (m) }\end{array}$ \\
\hline $\begin{array}{l}\text { hour } 1 \\
\text { hour } 2 \\
\text { hour } 3\end{array}$ & $\begin{array}{l}267 \\
266 \\
265\end{array}$ & $\begin{array}{r}3.7 \\
3.8 \\
3.6\end{array}$ & $\begin{array}{l}16.9 \\
19.6 \\
22.3\end{array}$ & $\begin{array}{l}1 \\
12.0 \\
14.1\end{array}$ & $\begin{array}{r}668.7 \\
1260.1 \\
1767.5\end{array}$ \\
\hline
\end{tabular}

MATS Experiment 12:

$\mathrm{H}$-area Meteorological Conditions $\left(\mathrm{M}_{\mathrm{H}}\right.$

\begin{tabular}{|r|r|r|r|r|r|}
\hline Time & $\begin{array}{c}\text { Azimuth } \\
(\mathrm{deg})\end{array}$ & $\begin{array}{c}\text { Wind Speed } \\
\left(\mathrm{m} \mathrm{s}^{-1}\right)\end{array}$ & $\sigma_{\mathrm{a}}(\mathrm{deg})$ & $\sigma_{\mathrm{e}}(\mathrm{deg})$ & $\begin{array}{c}\text { Mixed-Layer } \\
\text { Depth }(\mathrm{m})\end{array}$ \\
\hline hour 1 & 020 & 5.1 & 13.6 & 11.4 & 814.4 \\
hour 2 & 028 & 5.9 & 15.5 & 10.0 & 1584.8 \\
hour 3 & 025 & 5.0 & 17.2 & 12.5 & 1642.0 \\
\hline
\end{tabular}

SAM Meteorological Conditions $\left(\mathrm{M}_{\mathrm{S}}\right)$

\begin{tabular}{|r|r|r|r|r|r|}
\hline Time & $\begin{array}{c}\text { Azimuth } \\
(\mathrm{deg})\end{array}$ & $\begin{array}{c}\text { Wind Speed } \\
\left(\mathrm{m} \mathrm{s}^{-1}\right)\end{array}$ & $\sigma_{\mathrm{a}}(\mathrm{deg})$ & $\sigma_{\mathrm{e}}(\mathrm{deg})$ & $\begin{array}{c}\text { Mixed-Layer } \\
\text { Depth }(\mathrm{m})\end{array}$ \\
\hline hour 1 & 027 & 5.2 & 13.2 & 9.6 & 814.4 \\
hour 2 & 037 & 5.9 & 13.0 & 8.8 & 1584.8 \\
hour 3 & 034 & 5.2 & 15.3 & 9.8 & 16.12 .0 \\
\hline
\end{tabular}


Table 2. cont'd

MATS Experiment 14:

$\mathrm{H}$-area Meteorological Conditions $\left(\mathrm{M}_{\mathrm{H}}\right)$

\begin{tabular}{|c|c|c|c|c|c|}
\hline Time & $\begin{array}{l}\text { Azimuth } \\
\text { (deg) }\end{array}$ & $\begin{array}{l}\text { Wind Speed } \\
\left(\mathrm{m} \mathrm{s}^{-1}\right)\end{array}$ & $\sigma_{\mathrm{a}}(\mathrm{deg})$ & $\sigma_{\mathrm{e}}(\mathrm{deg})$ & $\begin{array}{l}\text { Mixed-Layer } \\
\text { Depth }(\mathrm{m})\end{array}$ \\
\hline hour 1 & 057 & 2.4 & 15.2 & 10.4 & 109.2 \\
\hline hour 2 & 081 & 2.4 & 15.6 & 10.6 & 249.7 \\
\hline hour 3 & 086 & 2.8 & 15.6 & 10.3 & 496.9 \\
\hline \multicolumn{6}{|c|}{ SAM Meteorological Conditions $\left(\mathrm{M}_{\mathrm{S}}\right)$} \\
\hline Time & $\begin{array}{l}\text { Azimuth } \\
\text { (deg) }\end{array}$ & $\begin{array}{c}\text { Wind Speed } \\
\left(\mathrm{m} \mathrm{s}^{-1}\right)\end{array}$ & $\sigma_{\mathrm{a}}(\mathrm{deg})$ & $\overline{\sigma_{\mathrm{c}}(\mathrm{deg})}$ & $\begin{array}{l}\text { Mixed-Layer } \\
\text { Depth (m) }\end{array}$ \\
\hline hour 1 & 062 & 2.9 & $1 \overline{1.3}$ & 7.7 & 109.2 \\
\hline hour 2 & 080 & 2.9 & 11.3 & 8.3 & 249.7 \\
\hline hour 3 & 087 & 3.0 & 13.9 & 10.1 & 496.9 \\
\hline
\end{tabular}

MATS Experiment 24:

$\mathrm{H}$-area Meteorological Conditions $\left(\mathrm{M}_{\mathrm{H}}\right)$

\begin{tabular}{|r|r|r|r|r|r|}
\hline Time & \multicolumn{1}{|c|}{$\begin{array}{c}\text { Azimuth } \\
(\mathrm{deg})\end{array}$} & $\begin{array}{c}\text { Wind Speed } \\
\left(\mathrm{m} \mathrm{s}^{-1}\right)\end{array}$ & $\sigma_{\mathrm{a}}(\mathrm{deg})$ & $\sigma_{\mathrm{c}}(\mathrm{deg})$ & $\begin{array}{c}\text { Mixed-Layer } \\
\text { Depth }(\mathrm{m})\end{array}$ \\
\hline hour 1 & 279 & 6.4 & 18.8 & 11.7 & 902.7 \\
hour 2 & 277 & 6.2 & 17.4 & 12.2 & 941.5 \\
hour 3 & 288 & 5.6 & 20.3 & 13.1 & 963.5 \\
\hline
\end{tabular}

SAM Muteorological Conditions ( $\mathrm{M}_{\mathrm{S}}$ )

\begin{tabular}{|r|r|r|r|r|r|}
\hline Time & \multicolumn{1}{|c|}{$\begin{array}{c}\text { Azimuth } \\
\text { (deg) }\end{array}$} & $\begin{array}{c}\text { Wind Speed } \\
\left(\mathrm{m} \mathrm{s}^{-1}\right)\end{array}$ & $\sigma_{\mathrm{z}}(\mathrm{deg})$ & \multicolumn{1}{|c|}{$\sigma_{\mathrm{e}}(\mathrm{deg})$} & $\begin{array}{c}\text { Mixed-Layer } \\
\text { Depth }(\mathrm{m})\end{array}$ \\
\hline hour 1 & 277 & 6.3 & 15.5 & 11.6 & 902.7 \\
hour 2 & 276 & 6.1 & 16.1 & 11.2 & 941.5 \\
hour 3 & 286 & 5.6 & 16.3 & 12.3 & 963.5 \\
\hline
\end{tabular}


Table 2. cont'd

MATS Experiment 27:

$\mathrm{H}$-area Meteorological Conditions $\left(\mathrm{M}_{\mathrm{H}}\right)$

\begin{tabular}{|r|r|r|r|r|r|}
\hline Time & \multicolumn{1}{|c|}{$\begin{array}{c}\text { Azimuth } \\
(\mathrm{deg})\end{array}$} & $\begin{array}{r}\text { Wind Speed } \\
\left(\mathrm{m} \mathrm{s}^{-1}\right)\end{array}$ & $\sigma_{\mathrm{a}}(\mathrm{deg})$ & $\sigma_{\mathrm{e}}(\mathrm{deg})$ & $\begin{array}{c}\text { Mixed-Layer } \\
\text { Depth }(\mathrm{m})\end{array}$ \\
\hline hour 1 & 290 & 1.9 & 25.8 & 16.7 & 535.8 \\
hour 2 & 264 & 3.2 & 20.2 & 10.8 & 774.9 \\
hour 3 & 269 & 3.6 & 19.0 & 11.8 & 959.0 \\
\hline
\end{tabular}

SAM Meteorological Conditions $\left(\mathrm{M}_{\mathrm{S}}\right)$

\begin{tabular}{|r|r|r|r|r|r|}
\hline Time & \multicolumn{1}{|c|}{$\begin{array}{c}\text { Azimuth } \\
(\mathrm{deg})\end{array}$} & $\begin{array}{c}\text { Wind Speed } \\
\left(\mathrm{m} \mathrm{s}^{-1}\right)\end{array}$ & $\sigma_{\mathrm{a}}(\mathrm{deg})$ & $\sigma_{\mathrm{e}}(\mathrm{deg})$ & $\begin{array}{c}\text { Mixed-Layer } \\
\text { Depth }(\mathrm{m})\end{array}$ \\
\hline hour 1 & 301 & 2.2 & 21.4 & 15.0 & 535.8 \\
hour 2 & 273 & 3.1 & 21.0 & 12.5 & 774.9 \\
hour 3 & 269 & 3.6 & 17.2 & 12.5 & 959.0 \\
\hline
\end{tabular}

MATS Experiment 31:

$\mathrm{H}$-area Meteorological Conditions $\left(\mathrm{M}_{\mathrm{H}}\right)$

\begin{tabular}{|r|r|r|r|r|r|}
\hline Time & $\begin{array}{c}\text { Azimuth } \\
(\mathrm{deg})\end{array}$ & $\begin{array}{c}\text { Wind Speed } \\
\left(\mathrm{m} \mathrm{s}^{-1}\right)\end{array}$ & $\sigma_{\mathrm{a}}(\mathrm{deg})$ & $\sigma_{\mathrm{e}}(\mathrm{deg})$ & $\begin{array}{c}\text { Mixed-Layer } \\
\text { Depth }(\mathrm{m})\end{array}$ \\
\hline hour 1 & 253 & 4.9 & 17.9 & 10.7 & 308.3 \\
hour 2 & 271 & 6.2 & 19.8 & 11.0 & 514.9 \\
hour 3 & 285 & 5.8 & 18.6 & 11.6 & 536.5 \\
\hline
\end{tabular}

SAM Meteorological Conditions $\left(\mathrm{M}_{\mathrm{S}}\right)$

\begin{tabular}{|r|r|r|r|r|r|}
\hline Time & \multicolumn{1}{|c|}{$\begin{array}{c}\text { Azimuth } \\
(\mathrm{deg})\end{array}$} & $\begin{array}{c}\text { Wind Speed } \\
\left(\mathrm{m} \mathrm{s}^{-1}\right)\end{array}$ & $\sigma_{\mathrm{a}}(\mathrm{deg})$ & $\sigma_{\mathrm{e}}(\mathrm{deg})$ & $\begin{array}{c}\text { Mixed-Layer } \\
\text { Depth (m) }\end{array}$ \\
\hline hour 1 & 236 & 4.4 & 17.1 & 10.6 & 308.3 \\
hour 2 & 254 & 5.7 & 15.9 & 10.1 & 514.9 \\
hour 3 & 254 & 5.7 & 15.7 & 10.3 & 536.5 \\
\hline
\end{tabular}


Table 2. cont'd

MATS Experiment 32:

$\mathrm{H}$-area Meteorological Conditions $\left(\mathrm{M}_{\mathrm{H}}\right)$

\begin{tabular}{|r|r|r|r|r|c|}
\hline Time & $\begin{array}{c}\text { Azimuth } \\
(\mathrm{deg})\end{array}$ & $\begin{array}{c}\text { Wind Speed } \\
\left(\mathrm{m} \mathrm{s}^{-1}\right)\end{array}$ & $\sigma_{\mathrm{a}}(\mathrm{deg})$ & $\sigma_{\mathrm{e}}(\mathrm{deg})$ & $\begin{array}{c}\text { Mixed-Layer } \\
\text { Depth }(\mathrm{m})\end{array}$ \\
\hline hour 1 & 331 & 6.6 & 11.1 & 8.6 & 1235.1 \\
hour 2 & 337 & 7.6 & 13.8 & 9.6 & 1134.4 \\
\hline
\end{tabular}

SAM Meteorological Conditions $\left(\mathrm{M}_{\mathrm{S}}\right)$

\begin{tabular}{|r|r|r|r|r|r|}
\hline Time & \multicolumn{1}{|c|}{$\begin{array}{c}\text { Azimuth } \\
(\mathrm{deg})\end{array}$} & $\begin{array}{c}\text { Wind Speed } \\
\left(\mathrm{m} \mathrm{s}^{-1}\right)\end{array}$ & $\sigma_{\mathrm{a}}(\mathrm{deg})$ & $\sigma_{\mathrm{e}}(\mathrm{deg})$ & $\begin{array}{c}\text { Mixed-Layer } \\
\text { Depth }(\mathrm{m})\end{array}$ \\
\hline hour 1 & 312 & 7.2 & 9.4 & 9.5 & 1235.1 \\
hour 2 & 316 & 7.7 & 12.5 & 11.0 & 1134.4 \\
\hline
\end{tabular}

MATS Experiment 37:

$\mathrm{H}$-area Meteorological Conditions $\left(\mathrm{M}_{\mathrm{H}}\right)$

\begin{tabular}{|r|r|r|r|r|r|}
\hline Time & \multicolumn{1}{|c|}{$\begin{array}{c}\text { Azimuth } \\
(\mathrm{deg})\end{array}$} & $\begin{array}{c}\text { Wind Speed } \\
\left(\mathrm{m} \mathrm{s}^{-1}\right)\end{array}$ & $\sigma_{\mathrm{a}}(\mathrm{deg})$ & $\sigma_{\mathrm{e}}(\mathrm{deg})$ & $\begin{array}{c}\text { Mixed-Layer } \\
\text { Depth }(\mathrm{m})\end{array}$ \\
\hline hour 1 & 202 & 5.7 & 6.9 & 2.1 & 100.0 \\
hour 2 & 204 & 6.0 & 6.9 & 1.9 & 100.0 \\
hour 3 & 222 & 5.5 & 12.6 & 3.0 & 150.0 \\
\hline
\end{tabular}

SAM Meteorological Conditions $\left(\mathrm{M}_{\mathrm{S}}\right)$

\begin{tabular}{|r|r|r|r|r|r|}
\hline Time & \multicolumn{1}{|c|}{$\begin{array}{c}\text { Azimuth } \\
(\mathrm{deg})\end{array}$} & $\begin{array}{c}\text { Wind Speed } \\
\left(\mathrm{m} \mathrm{s}^{-1}\right)\end{array}$ & $\sigma_{\mathrm{a}}(\mathrm{deg})$ & $\sigma_{\mathrm{e}}(\mathrm{deg})$ & $\begin{array}{c}\text { Mixed-Layer } \\
\text { Depth }(\mathrm{m})\end{array}$ \\
\hline hour 1 & 204 & 4.9 & 8.0 & 3.2 & 100.0 \\
hour 2 & 207 & 4.8 & 7.3 & 3.6 & 100.0 \\
hour 3 & 220 & 4.3 & 11.4 & 3.6 & 150.0 \\
\hline
\end{tabular}


Table 3. Maximum concentration of the total $\mathrm{SF}_{6}$ that was observed along the sampler arc and predicted by PUFF/PLUME

\begin{tabular}{|c|c|c|c|c|c|c|c|}
\hline \multirow[t]{2}{*}{ Exp. \# } & \multirow[t]{2}{*}{$\mathrm{C}_{\mathrm{to}}(\max )$} & \multicolumn{3}{|c|}{$C_{t p}(\max )$} & \multicolumn{3}{|c|}{ Ratio: $C_{t p}(\max ) / C_{t o}(\max )$} \\
\hline & & $\overline{M_{C}}$ & $\overline{M_{H}}$ & $\overline{\mathrm{MS}}$ & $\overline{M_{C}}$ & $M_{H}$ & $\overline{M S}$ \\
\hline 8 & 809.1 & 1257.6 & 30.6 & 578.4 & 1.55 & 0.04 & 0.72 \\
\hline 12 & 745.6 & 1793.5 & 563.8 & 1582.0 & 2.41 & 0.76 & 2.12 \\
\hline 14 & 2221.7 & 13102.9 & 5088.8 & 6145.8 & 5.90 & 2.29 & 2.77 \\
\hline 24 & 521.3 & 452.4 & 447.7 & 423.4 & 0.87 & 0.86 & 0.81 \\
\hline 31 & 329.1 & 2731.2 & 263.0 & 1082.5 & 8.30 & 0.80 & 3.29 \\
\hline
\end{tabular}

Explanation of Symbols:

$\mathrm{C}_{\mathrm{to}} \cdot(\max )=$ observed maximum of the total $\mathrm{SF}_{6}$ concentration $(\mathrm{ppt})$

$\mathrm{C}_{t \mathrm{p}}(\mathrm{max})=$ predicted maximum of the total $\mathrm{SF}_{6}$ concentration $(\mathrm{ppt})$

$\mathrm{M}_{\mathrm{C}}=\quad$ constant meteorological conditions based on SAM data

$\mathrm{M}_{\mathrm{H}}=\quad$ time-dependent meteorological conditions based on $\mathrm{H}$-area data

$\mathrm{M}_{\mathrm{S}}=\quad$ time-dependent meteorological conditions based on SAM data

asterisk $\left(^{*}\right)$ indicates values that may not be meaningful since the predicted plume did not pass directly through the sampler network

Table 4. Plume width of the total $\mathrm{SF}_{6}$ distribution that was observed along the sampler arc and predicted by PUFF/PLUME

\begin{tabular}{|c|c|c|c|c|c|c|c|}
\hline \multirow[t]{2}{*}{$\overline{\text { Exp. \# }}$} & \multirow[t]{2}{*}{ Sigma-y $y_{\text {to }}$} & \multicolumn{3}{|c|}{ Sigma-y $y_{t p}$} & \multicolumn{3}{|c|}{ Ratio: Sigma-y $y_{t p} / S i$ ma-y } \\
\hline & & $\mathrm{M}_{\mathrm{C}}$ & $\overline{M_{H}}$ & $\mathrm{MS}_{\mathrm{S}}$ & $\mathrm{M}_{\mathrm{C}}$ & $\mathrm{M}_{\mathrm{H}}$ & $\overline{M_{S}}$ \\
\hline $\begin{array}{r}8 \\
12 \\
14 \\
24 \\
31\end{array}$ & $\begin{array}{l}2342.7 \\
1381.2 \\
1691.2 \\
1907.2 \\
2119.2\end{array}$ & $\begin{array}{l}1781.4 \\
1284.7 \\
1112.7 \\
1486.5 \\
1855.4\end{array}$ & $\begin{array}{r}\text { * } 830.5 \\
1307.5 \\
1484.7 \\
1868.2 \\
* \quad 747.6\end{array}$ & $\begin{array}{l}1881.5 \\
1270.6 \\
1182.0 \\
1473.5 \\
1826.9\end{array}$ & $\begin{array}{l}0.76 \\
0.93 \\
0.66 \\
0.78 \\
0.88\end{array}$ & $\begin{array}{l}\text { * } \\
0.35 \\
0.95 \\
0.88 \\
0.98 \\
* \quad 0.35 \\
\end{array}$ & $\begin{array}{l}0.80 \\
0.92 \\
0.70 \\
0.77 \\
0.86 \\
\end{array}$ \\
\hline
\end{tabular}

Explanation of Symbols:

Sigma- $y_{t o}=$ observed plume width $(m)$ of the total $S_{6}$ distribution

Sigma- $y_{t p}=$ predicted plume width $(m)$ of the total $S_{6}$ distribution 
Table 5. Location of the maximum concentration of the total $S F_{6}$ that was observed and predicted by PUFF/PLUME

\begin{tabular}{|c|c|c|c|c|c|c|c|c|}
\hline \multirow[t]{2}{*}{ Exp. \# } & \multirow[t]{2}{*}{$\mathrm{S}_{\mathrm{o}}$} & \multicolumn{4}{|c|}{$S_{p}$} & \multicolumn{3}{|c|}{ Spatial Difference $(\mathrm{km}):\left|S_{p}-S_{o}\right|$} \\
\hline & & $\mathrm{M}_{\mathrm{C}}$ & & & $\mathrm{M}_{\mathrm{S}}$ & $\mathrm{M}_{\mathrm{C}}$ & $\mathrm{M}_{\mathrm{H}}$ & $\overline{M_{S}}$ \\
\hline 8 & $\# 11$ & $\# 5$ & * & $\# 8$ & $\# 2$ & 5.4 & 14.9 & 6.6 \\
\hline 12 & $\# 16$ & $\# 16$ & & $\$ 10$ & $\# 18$ & ().0 & 2.3 & 1.1 \\
\hline 14 & $\# 19$ & $\# 5$ & & $\# 3$ & $\# 3$ & 9.4 & 1.4 & 1.4 \\
\hline 24 & \#29 & \#32 & & \#33 & \#30 & 1.9 & 3.0 & 0.9 \\
\hline 31 & $\# 31$ & \#37 & * & $\# 49$ & $\# 44$ & 7.3 & 18.5 & 12.1 \\
\hline
\end{tabular}

Explanation of Symbols:

$S_{\mathrm{o}}=\quad$ observed sampler number location of the maximum concentration

$S_{\mathrm{p}}=\quad$ predicted sampler number location of the maximum concentration

Table 6. Maximum concentration of the total $\mathrm{SF}_{6}$ that was observed along the sampler arc and predicted by 2 DPUF

\begin{tabular}{|c|c|c|c|c|c|c|c|}
\hline \multirow[t]{2}{*}{ Exp. \# } & \multirow[t]{2}{*}{$\mathrm{C}_{\mathrm{to}}(\max )$} & \multicolumn{3}{|c|}{$C_{t p}(\max )$} & \multicolumn{3}{|c|}{ Ratio: $C_{\text {tp }}(\max ) / C_{10}(\max )$} \\
\hline & & $\overline{M_{C}}$ & $\overline{\mathrm{M}_{\mathrm{H}}}$ & $\overline{\mathrm{M}_{\mathrm{S}}}$ & $\overline{\mathrm{M}_{\mathrm{C}}}$ & $\mathrm{M}_{\mathrm{H}}$ & $\mathrm{M}_{\mathrm{S}}$ \\
\hline 8 & 809.1 & 795.5 & 5.6 & 293.0 & 0.98 & 0.01 & $0 . \overline{36}$ \\
\hline 12 & 745.6 & 886.0 & 438.9 & 500.7 & 1.19 & 0.59 & 0.67 \\
\hline 14 & 2221.7 & 13333.3 & 2593.1 & 3097.2 & 6.00 & 1.17 & 1.39 \\
\hline 24 & 521.3 & 571.0 & 482.8 & 535.1 & 1.10 & 0.93 & 1.03 \\
\hline 2 & 329.1 & 1523.1 & 13.1 & 851.8 & 4.63 & 0.04 & 2.59 \\
\hline
\end{tabular}

Explanation of Symbols:

$\mathrm{C}_{\mathrm{to}}(\max )=$ observed maximum of total $\mathrm{SF}_{6}$ concentration $(\mathrm{ppt})$

$\mathrm{C}_{\mathrm{tp}}(\max )=$ predicted maximum of total $\mathrm{SF}_{6}$ concentration $(\mathrm{ppt})$ 
Table 7. Plume width of the total $\mathrm{SF}_{6}$ distribution that was observed along the sampler arc and predicted by 2 DPUF

\begin{tabular}{|c|c|c|c|c|c|c|c|}
\hline \multirow[t]{2}{*}{ Exp. \# } & \multirow[t]{2}{*}{ Sigma- $y_{t o}$} & \multicolumn{3}{|c|}{ Sigma- $y_{t p}$} & \multicolumn{3}{|c|}{ Ratio: Sigma-y $y_{t p} /$ Sigma- $y_{t o}$} \\
\hline & & $M_{C}$ & $M_{H}$ & $\mathrm{MS}_{\mathrm{S}}$ & $M_{C}$ & $M_{H}$ & $\mathrm{MS}_{\mathrm{S}}$ \\
\hline 8 & 2342.7 & 2028.1 & 661.5 & 2281.1 & 0.87 & 0.28 & 0.97 \\
\hline 12 & 1381.2 & 1403.3 & 1566.2 & 1284.3 & 1.02 & 1.13 & 0.93 \\
\hline 14 & 1691.2 & 1239.8 & 1631.8 & 1338.5 & 0.73 & 0.96 & 0.79 \\
\hline 24 & 1907.2 & 1625.9 & 1967.8 & 1637.1 & 0.85 & 1.03 & 0.86 \\
\hline 31 & 2119.2 & 2465.9 & 668.5 & 2217.7 & 1.16 & 0.32 & 1.05 \\
\hline
\end{tabular}

Explanation of Symbols:

Sigma- $y_{10}=$ observed plume width $(m)$ of the total $\mathrm{SF}_{6}$ distribution

Sigma- $y_{t p}=$ predicted plume width $(m)$ of the total $S_{6}$ distribution

Table 8. Location of the maximum concentration of the total $\mathrm{SF}_{6}$ that was observed and predicted by 2 DPUF

\begin{tabular}{|c|c|c|c|c|c|c|c|}
\hline \multirow[t]{2}{*}{ Exp.\# } & \multirow[t]{2}{*}{$S_{0}$} & \multicolumn{3}{|c|}{$S_{p}$} & \multicolumn{3}{|c|}{ Spatial Difference $(\mathrm{km}):\left|S_{p}-S_{0}\right|$} \\
\hline & & $\mathrm{M}_{\mathrm{C}}$ & $\mathrm{M}_{\mathrm{H}}$ & $\mathrm{M}_{\mathrm{S}}$ & $\mathrm{M}_{\mathrm{C}}$ & $\overline{M_{H}}$ & $\overline{M_{S}}$ \\
\hline $\begin{array}{r}8 \\
12 \\
14 \\
24 \\
31\end{array}$ & $\begin{array}{l}\# 11 \\
\# 16 \\
\# 19 \\
\# 29 \\
\# 31\end{array}$ & $\begin{array}{r}\# 2 \\
\# 16 \\
\# 5 \\
\# 32 \\
\# 37\end{array}$ & $\begin{array}{rr}* & \# 8 \\
& \# 11 \\
& \# 16 \\
& \# 32 \\
* \quad \# 49\end{array}$ & $\begin{array}{r}\# 2 \\
\# 5 \\
\# 16 \\
\# 32 \\
\# 46\end{array}$ & $\begin{array}{l}6.6 \\
0.0 \\
9.4 \\
1.9 \\
7.3\end{array}$ & $\begin{array}{rr} & 14.9 \\
& 1.2 \\
& 1.1 \\
& 1.9 \\
* \quad 18.5\end{array}$ & $\begin{array}{r}6.6 \\
2.3 \\
1.1 \\
1.9 \\
14.6\end{array}$ \\
\hline
\end{tabular}

Explanation of Symbols:

$S_{0}=\quad$ observed sampler number location of the maximum concentration

$S_{p}=\quad$ predicted sampler number location of the maximum concentration 
Table 9. Maximum concentration of $\mathrm{SF}_{6}$ that was observed along the sampler arc and predicted by PUFF/PLUME

\begin{tabular}{|c|c|c|c|c|c|c|c|}
\hline \multirow[t]{2}{*}{ Exp. \# } & \multirow[t]{2}{*}{$\mathrm{C}_{0}(\max )$} & \multicolumn{3}{|c|}{$\mathrm{C}_{\mathrm{p}}(\max )$} & \multicolumn{3}{|c|}{ Ratio: $C_{p}(\max ) / C_{0}(\max )$} \\
\hline & & $\overline{M_{C}}$ & $\overline{M_{H}}$ & $\overline{M_{S}}$ & $\mathrm{M}_{\mathrm{C}}$ & $M_{H}$ & $\overline{M_{S}}$ \\
\hline$\overline{8}$ & 343.9 & 811.7 & 21.5 & 346.7 & 2.36 & 0.06 & 1.01 \\
\hline 12 & 468.3 & 1664.5 & 545.2 & 1531.8 & 3.55 & 1.16 & 3.27 \\
\hline 14 & 717.2 & 9929.7 & 2856.7 & 3247.3 & 13.85 & 3.98 & 4.53 \\
\hline 24 & 253.4 & 312.3 & 368.0 & 206.4 & 1.23 & 1.45 & 0.81 \\
\hline 31 & 193.3 & 1926.4 & 229.1 & 887.2 & 9.97 & 1.18 & 4.59 \\
\hline
\end{tabular}

Explanation of Symbols:

$\mathrm{C}_{6}(\max )=$ observed maximum concentration of $\mathrm{SF}_{6}(\mathrm{ppt})$

$\mathrm{C}_{\mathrm{p}}(\max )=$ predicted maximum concentration of $\mathrm{SF}_{6}(\mathrm{ppt})$

Table 10. Plume width of the $\mathrm{SF}_{6}$ distribution that was observed along the sampler arc and predicted by PUFF/PLUME at the time the maximum concentration of $\mathrm{SF}_{6}$ occurred

\begin{tabular}{|c|c|c|c|c|c|c|c|c|}
\hline \multirow[t]{2}{*}{ Exp. \# } & \multirow[t]{2}{*}{ Sigma-yo } & \multicolumn{3}{|c|}{ Sigma-y } & \multicolumn{4}{|c|}{ Ratio: Sigma- $y_{p} /$ Sigma-y } \\
\hline & & $\overline{M_{C}}$ & $\mathrm{M}_{\mathrm{H}}$ & $\overline{M_{S}}$ & $\bar{M}_{C}$ & & $\overline{T_{H}}$ & $\overline{M_{S}}$ \\
\hline 8 & 2102.2 & 1523.6 & 557.8 & 1548.2 & 0.72 & & 0.27 & 0.74 \\
\hline 12 & 1175.5 & 1284.0 & 1306.8 & 1270.6 & 1.09 & & 1.11 & 1.08 \\
\hline 14 & 1517.8 & 1116.6 & 1430.7 & 1061.8 & 0.74 & & 0.94 & 0.70 \\
\hline 24 & 1537.0 & 1399.4 & 1806.4 & 1487.5 & 0.91 & & 1.18 & 0.97 \\
\hline 31 & 1832.1 & 1580.1 & 747.6 & 18153 & 086 & * & 0.41 & 0.99 \\
\hline
\end{tabular}

Explanation of Symbols:

Sigma- $y_{0}=$ observed plume width $(\mathrm{m})$ of the $\mathrm{SF}_{6}$ distribution

Sigma- $\mathrm{y}_{\mathrm{p}}=$ predicted plume width $(\mathrm{m})$ of the $\mathrm{SF}_{6}$ distribution 
Table 11. Maximum concentration of $\mathrm{SF}_{6}$ that was observed along the sampler arc and predicted by 2 DPUF

\begin{tabular}{|c|c|c|c|c|c|c|c|}
\hline \multirow[t]{2}{*}{ Exp. \# } & \multirow[t]{2}{*}{$\mathrm{C}_{0}(\max )$} & \multicolumn{3}{|c|}{$C_{p}(\max )$} & \multicolumn{3}{|c|}{ Ratio: $C_{p}(\max ) / C_{o}(\max )$} \\
\hline & & $\mathrm{M}_{\mathrm{C}}$ & $M_{H}$ & $\overline{\mathrm{M}_{\mathrm{S}}}$ & $\mathrm{M}_{\mathrm{C}}$ & $M_{H}$ & $\overline{M_{S}}$ \\
\hline 8 & 343.9 & 472.7 & 3.4 & 148.2 & 1.37 & 0.01 & 0.43 \\
\hline 12 & 468.3 & 800.2 & 342.2 & 378.9 & 1.71 & 0.73 & $0.8 i$ \\
\hline 14 & 717.2 & 9570.9 & 1399.0 & 1766.8 & 13.34 & 1.95 & 2.46 \\
\hline 24 & 253.4 & 387.7 & 357.5 & 347.0 & 1.53 & 1.41 & 1.37 \\
\hline 31 & 193.3 & 855.6 & 7.4 & 604.6 & 4.43 & 0.04 & 3.13 \\
\hline
\end{tabular}

Explanation of Symbols:

$\mathrm{C}_{0}(\max )=\quad$ observed maximum concentration of $\mathrm{SF}_{6}(\mathrm{ppt})$

$\mathrm{C}_{\mathrm{p}}(\max )=$ predicted maximum concentration of $\mathrm{SF}_{6}(\mathrm{ppt})$

Table 12. Plume width of the $\mathrm{SF}_{6}$ distribution that was observed along the sampler arc and predicted by $2 D P U F$ at the time the maximum concentration of $\mathrm{SF}_{6}$ occurred

\begin{tabular}{|c|c|c|c|c|c|c|c|}
\hline \multirow[t]{2}{*}{ Exp. \# } & \multirow[t]{2}{*}{ Sigma-yo } & \multicolumn{3}{|c|}{ Sigma-y $y_{p}$} & \multicolumn{3}{|c|}{ Ratio: Sigma- $y_{p} /$ Sigma- $y_{o}$} \\
\hline & & $\mathrm{M}_{\mathrm{C}}$ & $\mathrm{M}_{\mathrm{H}}$ & $\overline{\mathrm{M}_{S}}$ & $\mathrm{M}_{\mathrm{C}}$ & $M_{H}$ & $M_{S}$ \\
\hline 8 & 2102.2 & 1707.2 & 481.5 & 1889.5 & 0.81 & 0.23 & 0.90 \\
\hline 12 & 1175.5 & 1397.6 & 1567.6 & 1288.9 & 1.19 & 1.33 & 1.10 \\
\hline 14 & 1517.8 & 1231.2 & 1576.3 & 1296.7 & 0.81 & 1.04 & 0.85 \\
\hline 24 & 1537.0 & 1484.8 & 1804.5 & 1491.0 & 0.97 & 117 & 0.97 \\
\hline 31 & 1832.1 & 2109.8 & 681.1 & 2104.1 & 1.15 & 0.37 & 1.15 \\
\hline
\end{tabular}

Explanation of Symbols:

Sigma- $y_{0}=$ observed plume width $(\mathrm{m})$ of the $\mathrm{SF}_{6}$ distribution

Sigma- $y_{p}=$ predicted plume width $(m)$ of the $S F_{6}$ distribution 
Table 13. Elapsed time at which the maximum concentration of $\mathrm{SF}_{6}$ occurred that was observed along the sampler arc and predicted by PUFF/PLUME

\begin{tabular}{|c|c|c|c|c|c|c|c|}
\hline \multirow[t]{2}{*}{ Exp. \# } & \multirow[t]{2}{*}{$T_{0}$} & \multicolumn{3}{|c|}{$T_{p}$} & \multicolumn{3}{|c|}{$T_{p}-T_{b}$} \\
\hline & & $\mathrm{M}_{\mathrm{C}}$ & $\mathrm{M}_{\mathrm{H}}$ & $\overline{M_{S}}$ & $\mathrm{M}_{\mathrm{C}}$ & $M_{H}$ & $\mathrm{MS}_{\mathrm{S}}$ \\
\hline 8 & 4800 & 8400 & $\begin{array}{ll}* & 93(00)\end{array}$ & 8400 & 3600 & $\begin{array}{ll}* & 4500\end{array}$ & 3600 \\
\hline 12 & 5400 & 5400 & 5400 & 5400 & () & 0 & 0 \\
\hline 14 & 9900 & 9900 & 11700 & 10800 & 0 & 1800 & $9(0)$ \\
\hline 24 & 4380 & 4380 & 4380 & 5100 & 0 & 0 & 720 \\
\hline 31 & 6840 & 9720 & 6840 & 7800 & 2880 & () & 960 \\
\hline
\end{tabular}

Explanation of Symbols:

$\mathrm{T}_{\mathrm{n}}=\quad$ observed time $(\mathrm{s})$ that the maximum concentration of $\mathrm{SF}_{6}$ occurred

$\mathrm{T}_{\mathrm{p}}=\quad$ predicted time $(\mathrm{s})$ that the maximum concentration of $\mathrm{SF}_{6}$ occurred

Table 14. Elapsed time at which the maximum concentration of $\mathrm{SF}_{6}$ occurred that was observed along the sampler arc and predicted by 2 DPUF

\begin{tabular}{|c|c|c|c|c|c|c|c|}
\hline \multirow{2}{*}{ Exp. \# } & \multirow[t]{2}{*}{$T_{0}$} & \multicolumn{3}{|c|}{$T_{p}$} & \multicolumn{3}{|c|}{$T_{p}-T_{o}$} \\
\hline & & $\overline{M_{C}}$ & $\overline{M_{H}}$ & $\overline{M_{S}}$ & $\overline{M_{C}}$ & $\overline{M_{H}}$ & $\overline{M_{S}}$ \\
\hline 8 & 4800 & 8400 & 9300 & 8400 & 3600 & 4500 & 3600 \\
\hline 12 & 5400 & 5400 & 5400 & 5400 & 0 & 0 & 0 \\
\hline 14 & 9900 & 9900 & 11700 & 9900 & 0 & 1800 & 0 \\
\hline 24 & 4380 & 4380 & 4380 & 4380 & 0 & 0 & 0 \\
\hline 31 & 6840 & 9720 & 6840 & 6840 & 2880 & * 0 & 0 \\
\hline
\end{tabular}

Explanation of Symbols:

$\mathrm{T}_{\mathrm{o}}=\quad$ observed time (s) that the maximum concentration of $\mathrm{SF}_{6}$ occurred

$\mathrm{T}_{\mathrm{p}}=\quad$ predicted time (s) that the maximum concentration of $\mathrm{SF}_{6}$ occurred 
Table 15. Integrated $\mathrm{SF}_{6}$ that was observed at all of the samplers and predicted by PUFF/PLUME, 2DPUF, and MATHEW/ADPIC

PUFF/PLUME

\begin{tabular}{|c|c|c|c|c|c|c|c|c|}
\hline \multirow[t]{2}{*}{ Exp. \# } & \multirow[t]{2}{*}{$\Sigma C_{10}$} & \multicolumn{3}{|c|}{$\Sigma C_{t p}$} & \multicolumn{4}{|c|}{ Ratio: $\Sigma C_{t p} / \Sigma C_{t o}$} \\
\hline & & $\mathrm{M}_{\mathrm{C}}$ & $\mathrm{M}_{H}$ & $\overline{M_{S}}$ & $\mathrm{M}_{\mathrm{C}}$ & & $I_{H}$ & $\mathrm{MS}_{\mathrm{S}}$ \\
\hline 8 & 3717.6 & 5580.9 & 45.5 & 3036.3 & 1.50 & & 0.01 & 0.82 \\
\hline 12 & 1976.2 & 5076.9 & 1710.0 & 4379.5 & 2.57 & & 0.87 & 2.22 \\
\hline 14 & 10211.4 & 32072.6 & 22946.7 & 21998.5 & 3.14 & & 2.24 & 2.15 \\
\hline 24 & 3360.1 & 2207.6 & 2510.3 & 2143.4 & 0.66 & & 0.75 & $0.6:$ \\
\hline 31 & 1740.6 & 12665.6 & 355.8 & 4037.7 & 7.28 & * & 0.20 & 2.3 \\
\hline
\end{tabular}

2DPUF

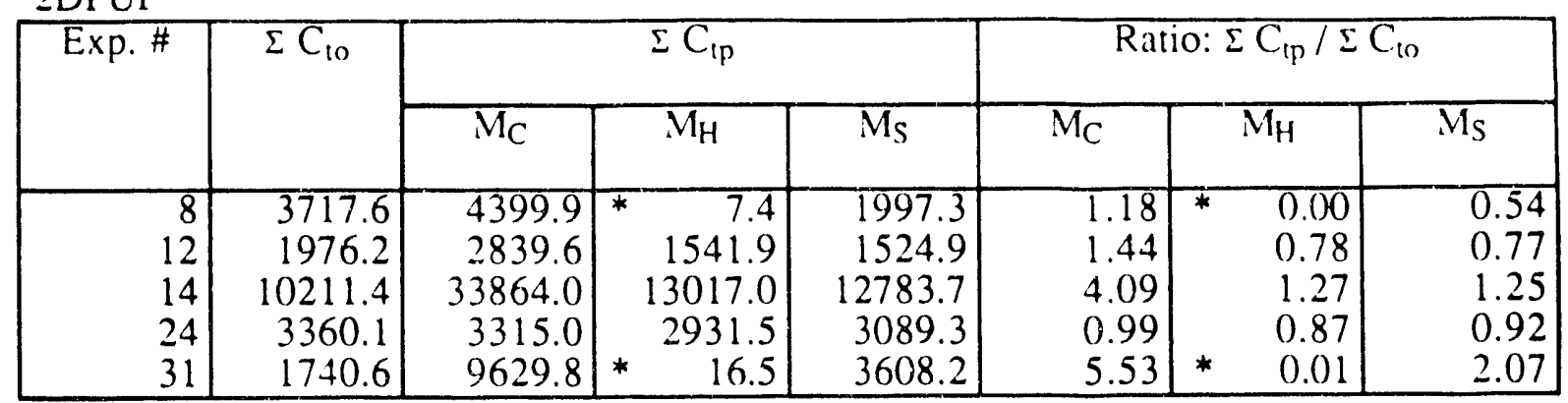

MATHEW/ADPIC

\begin{tabular}{|r|r|r|r|}
\hline Exp. $\#$ & $\Sigma C_{t o}$ & $\Sigma C_{t p}$ & Ratio: $\Sigma C_{t p} / \Sigma C_{t o}$ \\
\hline 8 & 3718.0 & 3518.0 & 0.91 \\
12 & 1976.0 & 286.0 & 0.14 \\
14 & 10210.0 & 10620.0 & 1.04 \\
\hline
\end{tabular}


Table 16. Concentration and plume width that was observed and predicted by PUFF/PLUME and 2DPUF for MATS experiment 27

Observations:

\begin{tabular}{|r|r|r|r|}
\hline Time (GMT) & Traverse & \multicolumn{1}{|c|}{$\begin{array}{c}\text { Maximum } \\
\text { Conconcentration. } \\
(\mathrm{ppt})\end{array}$} & Sigma-y $(\mathrm{km})$ \\
\hline $19: 11: 17$ & $\mathrm{AA}$ & 1432.0 & 1.770 \\
$19: 35: 53$ & $\mathrm{BB}$ & 632.1 & 1.654 \\
$20: 39: 00$ & $\mathrm{CC}$ & 189.5 & 1.364 \\
$20: 57: 58$ & $\mathrm{DD}$ & 317.7 & 0.702 \\
\hline
\end{tabular}

PUFF/PLUME:

\begin{tabular}{|r|r|r|}
\hline Time (GMT) & $\begin{array}{c}\text { Centerline } \\
\text { Concentration. }(\mathrm{ppt})\end{array}$ & \multicolumn{1}{|c|}{$\sigma_{\mathrm{y}}(\mathrm{km})$} \\
\hline $19: 11: 17$ & 1543.0 & 2.010 \\
$19: 35: 53$ & 1395.0 & 2.163 \\
$20: 39: 00$ & 1144.0 & 2.494 \\
$20: 57: 58$ & 1095.0 & 2.581 \\
\hline
\end{tabular}

2DPUF:

\begin{tabular}{|r|r|r|}
\hline Time (GMT) & $\begin{array}{c}\text { Centerline } \\
\text { Concentration. (ppt) }\end{array}$ & \multicolumn{1}{c|}{$\sigma_{\mathrm{y}}(\mathrm{km})$} \\
\hline $19: 11: 17$ & 603.1 & 2.242 \\
$19: 35: 53$ & 450.9 & 2.593 \\
$20: 39: 00$ & 248.3 & 3.493 \\
$20: 57: 58$ & 214.2 & 3.761 \\
\hline
\end{tabular}


Table 17. Same as Table 16, except for MATS experiment 32

Observations:

\begin{tabular}{|r|r|r|r|}
\hline Time (GMT) & Traverse & $\begin{array}{c}\text { Maximum } \\
\text { Conconcentration. } \\
\text { (ppt) }\end{array}$ & Sigma-y (km) \\
\hline $01: 46: 01$ & AA & 263.3 & 0.455 \\
$01: 58: 16$ & BB & 271.6 & 0.510 \\
$02: 07: 59$ & CC & 554.8 & 0.779 \\
$02: 19: 05$ & DD & 532.3 & 0.683 \\
\hline
\end{tabular}

PUFF/PLUME:

\begin{tabular}{|r|r|r|}
\hline Time (GMT) & $\begin{array}{c}\text { Centel line } \\
\text { Concentration. }(\mathrm{ppt})\end{array}$ & \multicolumn{1}{|c|}{$\sigma_{\mathrm{y}}(\mathrm{km})$} \\
\hline $01: 46: 01$ & 5066.0 & 0.805 \\
$01: 58: 16$ & 3794.0 & 0.907 \\
$02: 07: 59$ & 2671.0 & 1.000 \\
$02: 19: 05$ & 1962.0 & 1.102 \\
\hline
\end{tabular}

2DPUF:

\begin{tabular}{|r|r|r|}
\hline Time (GMT) & \multicolumn{1}{|c|}{$\begin{array}{c}\text { Centerline } \\
\text { Concentration. (ppt) }\end{array}$} & \multicolumn{1}{|c|}{$\sigma_{\mathrm{y}}(\mathrm{km})$} \\
\hline $01: 46: 01$ & 3336.0 & 0.843 \\
$01: 58: 16$ & 1932.0 & 1.107 \\
$02: 07: 59$ & 1348.0 & 1.322 \\
$02: 19: 05$ & 959.4 & 1.568 \\
\hline
\end{tabular}


Table 18. Same as Table 16, except for MATS experiment 37

Observations:

\begin{tabular}{|r|r|r|r|}
\hline Time (GMT) & Traverse & $\begin{array}{c}\text { Maximum } \\
\text { Conconcentration. } \\
\text { (ppt) }\end{array}$ & Sigma-y (km) \\
\hline $08: 23: 33$ & $\mathrm{DD}$ & 25.3 & 0.126 \\
$08: 26: 40$ & $\mathrm{EE}$ & 50.9 & 0.296 \\
$08: 46: 48$ & $\mathrm{FF}$ & 256.6 & 0.921 \\
$08: 53: 46$ & $\mathrm{GG}$ & 362.4 & 0.782 \\
$09: 01: 05$ & $\mathrm{HH}$ & 435.3 & 0.869 \\
$09: 07: 59$ & $\mathrm{II}$ & 398.4 & 0.821 \\
$09: 14: 59$ & $\mathrm{JJ}$ & 362.4 & 0.984 \\
$09: 31: 46$ & $\mathrm{KK}$ & 231.9 & 1.025 \\
\hline
\end{tabular}

PUFF/PLUME:

\begin{tabular}{|r|r|r|}
\hline Time (GMT) & \multicolumn{1}{|c|}{$\begin{array}{c}\text { Centerline } \\
\text { Concentration. (ppt) }\end{array}$} & \multicolumn{1}{|c|}{$\sigma_{\mathrm{y}}(\mathrm{km})$} \\
\hline $08: 23: 33$ & 2303.0 & 0.732 \\
$08: 26: 40$ & 2216.0 & 0.744 \\
$08: 46: 48$ & 1776.0 & 0.811 \\
$08: 53: 46$ & 1631.0 & 0.838 \\
$09: 01: 05$ & 1508.0 & 0.869 \\
$09: 07: 59$ & 1447.0 & 0.899 \\
$09: 14: 59$ & 1379.0 & 0.930 \\
$09: 31: 46$ & 1260.0 & 0.997 \\
\hline
\end{tabular}

2DPUF:

\begin{tabular}{|r|r|r|}
\hline Time (GMT) & \multicolumn{1}{|c|}{$\begin{array}{c}\text { Centerline } \\
\text { Concentration. }(\mathrm{ppt})\end{array}$} & \multicolumn{1}{|c|}{$\sigma_{\mathrm{y}}(\mathrm{km})$} \\
\hline $08: 23: 33$ & 7067.0 & 0.749 \\
$08: 26: 40$ & 6703.0 & 0.770 \\
$08: 46: 48$ & 5210.0 & 0.873 \\
$08: 53: 46$ & 4843.0 & 0.905 \\
$09: 01: 05$ & 3892.0 & 0.931 \\
$09: 07: 59$ & 3424.0 & 0.953 \\
$09: 14: 59$ & 3260.0 & 0.976 \\
$09: 31: 46$ & 2923.0 & 1.031 \\
\hline
\end{tabular}



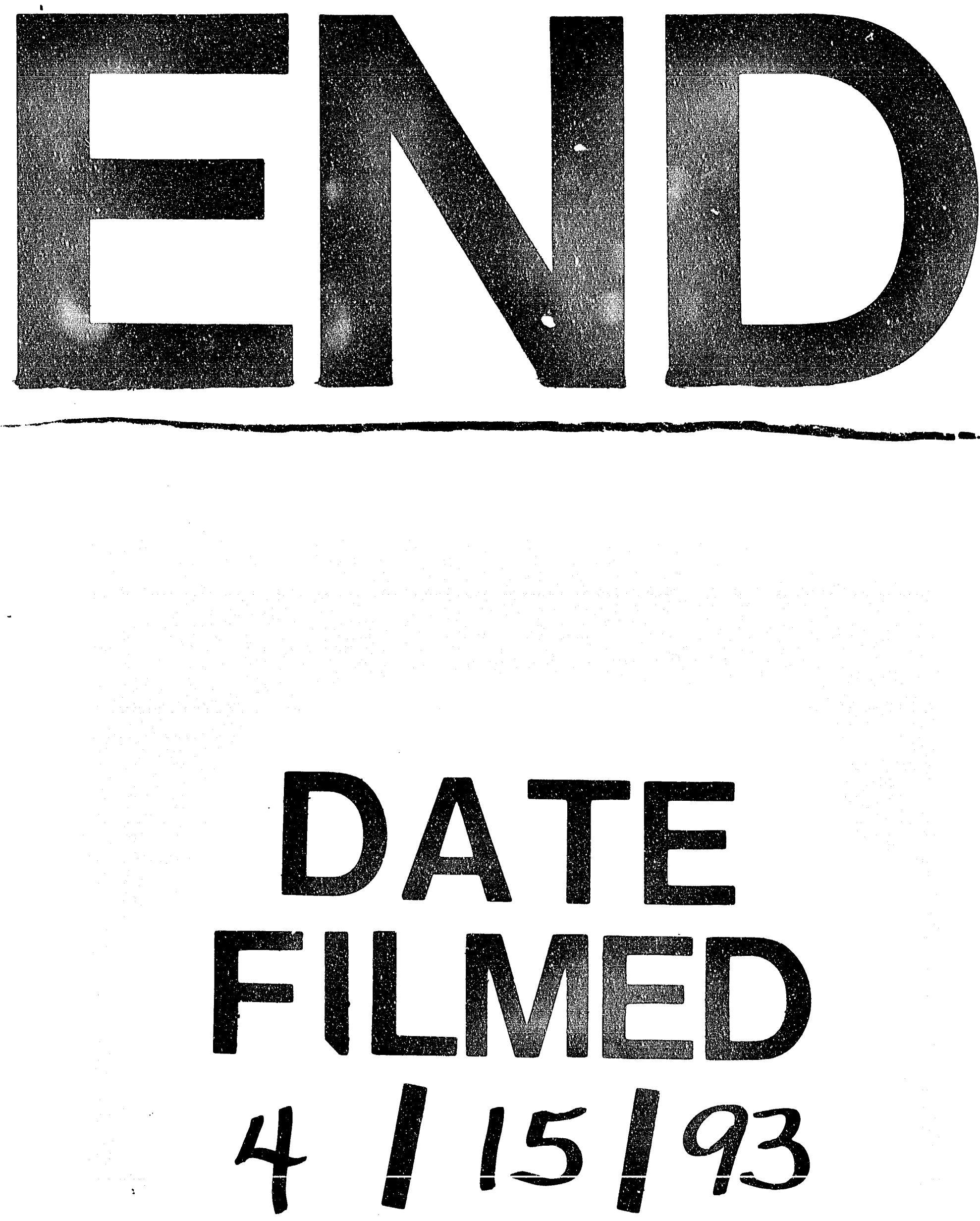
